\title{
INVESTIGACIONES SOBRE LAS \\ NECESIDADES DE INFORMACIÓN, EL COMPORTAMIENTO INFORMATIVO Y LA SATISFACCIÓN EN DIFERENTES COMUNIDADES: proyectos, avances y resultados
}

Juan José Calva González

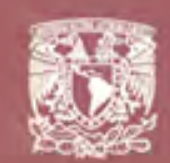


La presente obra está bajo una licencia de:

http://creativecommons.org/licenses/by-ncsa/3.0/deed.es MX

\section{(c) creative}

Eres libre de:

(15)

copiar, distribuir y comunicar públicamente la obra

(D)

hacer obras derivadas

Bajo las condiciones siguientes:

(1)

Atribución - Debes reconocer la autoria de la obra en los têrminos

especificados por el propio autor o licenciante.

No comercial - No puedes utilizar esta obra para fines comerciales.

Licenciamiento Reciproco - Si alteras, transformas o creas una obra a

partir de esta obra, solo podrás distribuir la obra resultante bajo una licencia igual a ésta.

Esto es un resumen fácilmente legible del: texto legal (de la licencia completa)

\section{En los casos que sea usada la presente obra, deben respetarse los términos especificados en esta licencia.}
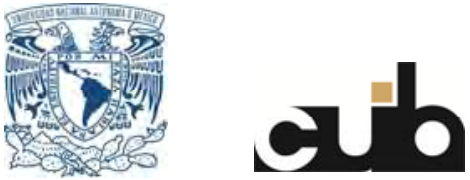
Investigaciones sobre las necesidades de información, el comportamiento informativo y la satisfacción en diferentes comunidades: proyectos, avances y resultados 

COLECCIÓN

Cuadernos de investigación, 15

Centro Universitario de Investigaciones Bibliotecológicas 

Investigaciones sobre las necesidades de información, el comportamiento informativo y la satisfacción en diferentes comunidades: proyectos, avances y resultados

Coordinador:

Juan José Calva González

Universidad Nacional Autónoma de México 2011 
Z678.88 Investigaciones sobre las necesidades de información,

I59 el comportamiento informativo y la satisfacción en diferentes comunidades : proyectos, avances y resultados / coordinador, Juan José Calva González.- México : UNAM, Centro Universitario de Investigaciones Bibliotecológicas, 2011

xi, 293 p. (Cuadernos de Investigación ; 15) ISBN: 978-607-02-1426-4

1. Necesidades de Información-Proyectos de Investigación 2. Comportamiento Informativo -- Comunidades Vitivinícolas 3. Comportamiento Informativo - Usuarios 4. Satisfacción del Usuario I. Calva González, Juan José, coordinador. II. ser.

Diseño de portada: Mario Ocampo Chávez

Primera Edición 2011

DR (C) UNIVERSIDAD NACIONAL AUTÓNOMA DE MÉXICO

Ciudad Universitaria, 04510 , México D.F.

Impreso y hecho en México

ISBN: 978-607-02-1426-4 


\section{Contenido}

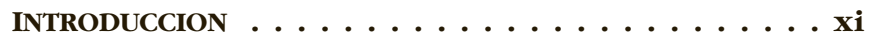

Juan José Calva González

Comportamiento informativo de estudiantes

de Biblioteconomía y Documentación . . . . . . . . . 1

Isabel Villaseñor Rodríguez

La satisfacción de las necesidades de información

como factor de cambio de la identidad indigena

en la comunidad amuzga. Nuevos avances . . . . . . 35

César Augusto Ramírez Velázquez

Comportamiento informativo de los tesistas

de licenciatura en bibliotecología de la ENBA, el Colegio de Bibliotecología de la UNAM y la UAEM.

Causas que lo originan. Avances . . . . . . . . . 47

Armando Sánchez Soto

La detección de las necesidades y comportamiento informativo de los matemáticos a través del análisis de referencias. Avances ............. . . 71 Angélica Guevara Villanueva

Comportamiento informativo de los usuarios de los sistemas de información geográfica: un piloteo . . 85 Antonia Santos Rosas

Los estudios de usuarios para evaluar la calidad de los servicios bibliotecarios en bibliotecas universitarias . . . . . . . . . 117 Fernando Xochiteotzin Peña 
La búsqueda de información de los investigadores de la UNAM que pertenecen al Sistema Nacional de Investigadores (SNI), del área 4 de Humanidades

y Ciencias de la conducta . . . . . . . . . . . 137

Silvia Castillo Barrera

Fuentes de información utilizadas por

los estudiantes de educación media superior

en el D.F. . . . . . . . . . . . . . . . . . . . . 159

Karen Méndez Ramón

Nuevas alternativas de servicios bibliotecarios

con base en las necesidades de información

de los estudiantes de preparatoria de ITESM.

Resultados de la investigación . . . . . . . . 181

Laura Miranda Munguía

Investigación del fenómeno de las necesidades

de información en comunidades de

vitivinicultores en México . . . . . . . . . . . . 187

Juan José Calva González

Los vitivinicultores de la región de Baja California:

necesidades de información y comportamiento

informativo. Avances de investigación . . . . . . . 191

Fermín López Franco

Aguascalientes, Zacatecas y Durango, empresas

vitivinícolas del siglo XX y XXI: las que ya no están,

sus huellas; las que están, quiénes son . . . . . . 217

José Tomás Palacios Medellín

El perfil de información de los

vitivinicultores de Vitis vinúfera en la región

de Coahuila. Avances . . . . . . . . . . . . . 239

Enedina Salazar Méndez 
Recursos de información para el uso de los productores de la vid en el estado de Guanajuato.

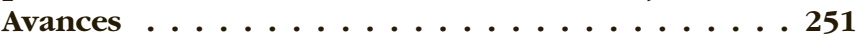

Ana Laura Peña Aguilar

El perfil informativo de los vitivinicultores

en el estado de Querétaro: el cultivo de la vid.

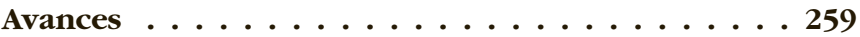

José Mejía Ruiz

Regulaciones nacionales e internacionales sobre la producción de Vitis vinífera. Información para

los vitivinicultores: resultados de la investigación . . 281

Miguel Ángel De La Rosa Hernández

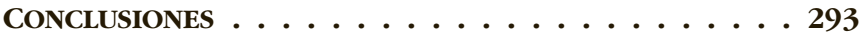

Juan José Calva González 



\section{Introducción}

Tos resultados de las investigaciones sobre usuaLrios de la información permiten el desarrollo de marcos teóricos de gran utilidad para delinear los perfiles informativos de diferentes comunidades; estos perfiles son un elemento clave para diseñar y desarrollar servicios bibliotecarios y de información que satisfagan adecuadamente las necesidades informativas de cada comunidad. Por lo que consideramos necesario desarrollar y discutir proyectos de investigación sobre los usuarios de la información en diferentes comunidades.

Por lo anterior, la discusión sobre las necesidades informativas, el comportamiento informativo y la satisfacción de dichas necesidades nos permite conformar el modelo teórico sobre dicho fenómeno en las actividades humanas.

Es por tal razón que el "Seminario de Usuarios de la Información: El fenómeno de las necesidades de información en diferentes comunidades", siendo uno de los seminarios permanentes de investigación 
Investigaciones sobre las necesidades de información,...

que tiene el Centro Universitario de Investigaciones Bibliotecológicas, es el lugar para la discusión y análisis académico de diversos resultados de proyectos de investigación que llevan a cabo: dos investigadores del CUIB, un profesor de la Universidad Complutense de Madrid, tres profesores del Colegio de Bibliotecología y seis alumnos de la maestría y el doctorado en Bibliotecología y Estudios de la Información, ya que todos reunidos han contribuido, desde su propia investigación, en la construcción del marco teórico del fenómeno de las necesidades de información. Ya que este seminario está formado por investigaciones de por lo menos tres años de duración, algunas de ellas, y otras con un tiempo de desarrollo más largo, todas han aportado una parte sustancial.

Por tal razón en este documento se presentan algunos avances de las investigaciones, el inicio de otras y los resultados obtenidos de algunas otras.

Por lo anterior, en este documento se tratan las investigaciones de diferentes comunidades como son los bibliotecólogos y documentalistas como usuarios de la información. Las comunidades indígenas y su identidad con respecto a la información que satisface sus necesidades de información; o bien cómo se presenta el fenómeno de las necesidades de información en comunidades de investigación como son: los matemáticos y los geógrafos, que a pesar de pertenecer a las "ciencias duras", ambos tienen 
características informativas totalmente diferentes, o bien como en el caso del comportamiento informativo de los investigadores nacionales en el área de humanidades y ciencias de la conducta.

Por otro lado, en este texto se aborda a comunidades como la de alumnos de bachillerato en instituciones públicas y privadas para contrastar las diferencias en cuanto a sus necesidades y comportamiento informativo. Asimismo, desde un enfoque administrativo, se investiga cómo los estudios de usuarios en diferentes comunidades pueden ayudar a la gestión de las unidades de información y por lo tanto del diseño de servicios bibliotecarios y de información.

Es notable que la bibliotecología inicia un abordaje a comunidades industriales como corresponde a la industria vitivinícola, donde varias de las investigaciones llevadas a cabo por un investigador del CUIB, dos profesores del Colegio de Bibliotecología y tres alumnos del posgrado en Bibliotecología y Estudios de la Información, dan muestra de ello y presentan los adelantos así como los obstáculos que implican el acercamiento a estas comunidades agroindustriales desde una disciplina humanista.

Es de esta forma que los objetivos particulares que se delinearon en el seminario permanente de investigación fueron: a) analizar y discutir diversos proyectos de investigación sobre el fenómeno de las 
Investigaciones sobre las necesidades de información,...

necesidades de información en distintas comunidades de usuarios; b) propiciar la generación de proyectos de investigación sobre diferentes comunidades de usuarios.

Hacia el final de este cuaderno de investigación se presentan los diversos documentos que se refieren a la industria vitivinícola mexicana. Asimismo están presentes algunas de las conclusiones y acuerdos obtenidos a través de los trabajos de investigación que fueron presentados en la sesión abierta del seminario ante un público académico de mayor amplitud, donde, además, se integraron no sólo los estudiantes de posgrado y licenciatura sino los especialistas en el área en pleno ejercicio de su profesión.

Juan José Calva González 


\title{
Comportamiento informativo de estudiantes de Biblioteconomía y Documentación
}

\author{
ISABEL VILLASEŃOR RODRÍGUEZ \\ Facultad de Ciencias de la Documentación \\ Universidad Complutense de Madrid
}

\section{Introducción}

$\mathbf{F}^{\mathrm{n}}$ un tiempo en el que la alfabetización infor-

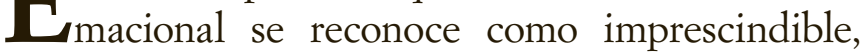
en tanto que recurso esencial, para adquirir competencias en información que permitan aprender de manera autónoma a lo largo de toda la vida, nos encontramos ante la experiencia personal de formar estudiantes que no sólo desconocen esa evidencia como responsabilidad en su futuro desempeño profesional, sino que además dan muestras de contar con escasos conocimientos respecto a sus necesidades de información (y las de sus usuarios), así como para saber localizar, evaluar, aplicar y crear información dentro de contextos personales y profesionales. Por tal motivo, proponemos como objeto de estudio el conocer y analizar el grado de alfabetización informacional con el que cuentan nuestros alumnos, teniendo como referencia su doble categoría de estudiantes universitarios y futuros profesionales de la información, responsables, en gran 
Investigaciones sobre las necesidades de información,...

medida, de alfabetizar. Para ello, tomaremos como muestra a los alumnos matriculados en la asignatura Bibliografía y fuentes generales de información, asignatura troncal del primer curso de la Diplomatura en Biblioteconomía y Documentación y que cuenta entre sus objetivos, con el dar a conocer y trabajar con recursos de información. La metodología empleada se basa en la técnica de la encuesta, formalizada a través de un cuestionario que mida sus experiencias y conocimientos personales y los conocimientos recibidos a través de su formación académica en relación con la información. Al final se presentan y comentan los resultados obtenidos para extraer conclusiones.

\section{Objetivos del estudio}

Con el presente estudio se ha pretendido conocer la experiencia que nuestros alumnos han tenido y tienen en relación con la información en su categoría de estudiantes. Queremos saber cuáles son sus hábitos en el uso de la información considerada como complemento a su formación y de sus rutinas de estudio. La finalidad no es otra que la de conocer las lagunas en su formación y la experiencia en la búsqueda y uso de la información y procurar completarlas con los contenidos de la asignatura de referencia, además de medir su nivel de alfabetización informacional. Todo ello contrastando la información obtenida de 
Comportamiento informativo de estudiantes...

los dos grupos de alumnos estudiados con el fin de detectar posibles diferencias teniendo en cuenta el momento en que han sido objeto de la investigación.

\section{Metodología empleada}

Para llevar a cabo este estudio se ha utilizado una metodología de investigación de campo que se propone la generalización de sus resultados utilizando técnicas para estudiar las percepciones, actitudes o comportamiento de los miembros de un grupo de usuarios de información. Se trata de un estudio de usuarios de información.

\section{Marco, población y muestra}

Se eligió para este estudio a los alumnos matriculados en la asignatura Bibliografía y fuentes generales de información de los cursos 2007/2008 y 2008/2009, en los turnos de mañana y tarde, tanto de la Diplomatura en Biblioteconomía y Documentación como del Curso de complementos de formación que da acceso a la Licenciatura en Documentación de la Universidad Complutense de Madrid. Se ha optado por esta asignatura por tres razones fundamentales:

- Momento en el que se imparte

- Carácter

- Contenidos 
Investigaciones sobre las necesidades de información,...

Es una asignatura que se imparte como obligatoria a los alumnos de primer curso de la Diplomatura en Biblioteconomía y Documentación así como a los alumnos de otras especialidades que acceden a la Licenciatura en Documentación. Cuenta con una tradición que se remonta a los orígenes de estos estudios (1991) y, entre sus objetivos, se destacan dos:

- Ofrecer una aproximación al conocimiento y manejo de las fuentes de información como instrumentos de trabajo

- Introducir al alumno en la metodología de la elaboración de repertorios bibliográficos

La duración es de un cuatrimestre, teniendo una carga docente de 6 créditos, equivalentes a 60 horas lectivas. Se imparte en dos turnos (mañana y tarde) con una metodología basada fundamentalmente en la lección magistral y en las prácticas de manejo de distintos tipos de fuentes de información tanto manuales como electrónicas.

La población la constituyen 149 alumnos matriculados en el curso 2007/2008 y 73 alumnos matriculados por primera vez en la asignatura para el curso 2008/2009, ${ }^{1}$ lo que significa un total de 222

1 Los alumnos matriculados son 107 pero hay 34 repetidores, luego los que cursan la asignatura por primera vez son 73 . 
Comportamiento informativo de estudiantes...

alumnos. La razón de haber elegido estos dos grupos es la de detectar posibles diferencias entre alumnos que ya han cursado la asignatura, alumnos iniciados, y los que empiezan a hacerlo, alumnos de iniciación.

En cuanto a la muestra, se contó con 100 alumnos del curso 2007/2008 (un 67,11\%) y con 43 (un $58,90 \%)$ del siguiente curso académico. Esto significa un total de 143 alumnos, esto es, el 64,41\% del total de la población.

Método, técnica e instrumento.

Descripción de su aplicación

Para llevar a cabo este estudio se ha optado por utilizar un método directo de recolección de datos. La razón fundamental de la elección de esta metodología es porque permite una interrelación con el usuario durante la investigación, al margen de cómo se analicen los resultados; permite obtener la información de lo que nos dicen los mismos usuarios. Se pretende que sea el propio usuario quien defina sus hábitos, necesidades o el uso que hace de la información que solicita, busca o consume.

La metodología se ha desarrollado con la aplicación de la técnica de la encuesta por ser una técnica que resulta familiar y que permite la obtención de resultados de una forma rápida. A través de esta técnica se investiga a una muestra representativa de 
Investigaciones sobre las necesidades de información,...

un grupo de sujetos, utilizando procedimientos estandarizados de interrogación, con el fin de obtener mediciones de una gran cantidad de características de la población.

Para aplicar esta técnica se ha utilizado un cuestionario ${ }^{2}$ entregado en mano en dos períodos diferentes: fin de la asignatura, en el caso de los alumnos del curso 2007/2008 y comienzo de la misma a los alumnos matriculados en el presente año.

El cuestionario consta de 20 preguntas, de las cuales 4 son de respuesta abierta por considerar que no se podía prever lo que contestarían los encuestados. El resto, son de respuesta cerrada (dos de ellas con posibilidad de explicación, del tipo ¿dónde?, ¿por qué?...) porque nos ha interesado fundamentalmente determinar la frecuencia de las opciones que se daban. Son de respuesta múltiple y se ha permitido al encuestado elegir cuantas respuestas considerase oportunas salvo en los casos de las excluyentes. Esto ha dificultado en algunos casos el análisis de los resultados pero ha permitido que el encuestado no se sintiese determinado por la elección de una sola opción. Las preguntas versan sobre el conocimiento y la práctica del alumno respecto a la información en relación con su experiencia como estudiante, antes y durante su formación actual.

2 Se incluye en anexo. 
Comportamiento informativo de estudiantes...

El objetivo perseguido con la aplicación del cuestionario se ha dado a conocer personalmente por parte de la autora del estudio y también se ha reflejado por escrito en el encabezado de la herramienta. La respuesta al cuestionario se ha hecho en presencia de su responsable con el fin de poder aclarar dudas en caso de que existieran.

\section{Datos obtenidos}

Analizando los resultados obtenidos por preguntas, obtenemos la siguiente información:

1. ¿Utilizas alguna biblioteca? ¿Cuál? ¿Para qué? ¿Por qué no la utilizas?

Se trata de una pregunta de respuesta excluyente del tipo Sí o NO. En el caso del SÍ se pueden marcar las opciones "la de mi barrio", "la de mi Facultad" y "otras" así como "para estudiar", "para préstamo" y "para buscar información". En el caso del NO, se pide explicar por qué con las opciones de "no lo necesito", "tengo libros en casa" y "uso Internet".

$137(95,80 \%)$ alumnos afirman utilizar alguna biblioteca mientras que $6(4,20 \%)$ alumnos confiesan no hacerlo.

En cuanto a las bibliotecas utilizadas, 63 alumnos $(44,05 \%)$ marcan una sola opción, 
Investigaciones sobre las necesidades de información,...

$71(49,65 \%)$ varias opciones (bien 2 bien 3 ) y $3(4,19 \%)$ no marcan ninguna. El tipo de biblioteca más utilizada, teniendo en cuenta todas las respuestas (una o varias opciones), se puede decir que es la biblioteca de la Facultad: 103 alumnos (73,57\%). La combinación más marcada resulta ser la compuesta por biblioteca de barrio y Facultad, con 45 alumnos (32,14\%).

Respecto a la actividad que se desarrolla en la biblioteca conviene señalar que 43 alumnos $(30,71 \%)$ marcan una sola de las propuestas y el resto (salvo 3, que no marcan ninguna opción) dos o tres. En los dos grupos estudiados, la actividad más señalada es la de "para préstamo" (103 alumnos, esto es, $73,57 \%$ alumnos) mientras que la segunda más señalada es la de "para estudiar" (69 de 100) en el grupo de los iniciados o la de "para buscar información” (25 de 43) en el de los de iniciación.

Por último, los alumnos que han respondido "No" (6) lo justifican afirmando que usan Internet (3), aunque otros afirman tener libros en casa (1) o que no necesitan utilizar alguna biblioteca (1). Un alumno marca las 3 opciones.

2. Los profesores que has tenido, ¿han motivado 
Comportamiento informativo de estudiantes...

el uso de la biblioteca?

La pregunta ofrece tres alternativas: "Sí, los que tuve antes de la Universidad", "Sí, los que he tenido en la Universidad" y "No, nunca". Las respuestas afirmativas pueden marcarse ambas.

134 alumnos (93,70\%) señalan las distintas opciones que se refieren a la motivación por parte de sus profesores para usar la biblioteca. Predomina el número de los que han marcado una sola opción del sí $(76,11 \%)$ frente a los que marcan las dos $(23,88 \%)$. Y de entre los primeros, el ámbito universitario $(89,21 \%)$ sobre el escolar $(10,79 \%)$. Del resto de alumnos $(6,30 \%)$ cabe decir que uno de ellos no contesta la pregunta.

3. ¿Han valorado que usaras bibliografía complementaria para tus trabajos y exámenes?

Las respuestas ofrecidas son las mismas que en la pregunta anterior.

La mayoría de los alumnos (115, esto es, $80,42 \%)$ señalan una opción. Ya sea el sí (87) o el NO (28). Se da el caso de 25 alumnos que marcan las dos opciones del sí. Tan sólo 3 alumnos no contestan.

Considerando la totalidad de las respuestas, vemos cómo la opción de "los que he tenido en la Universidad" es la más elegida $(67+25$ : 
Investigaciones sobre las necesidades de información,...

92) frente a la opción de "los que tuve antes de la Universidad" (20+25: 45).

4. ¿Te han enseñado a usar una biblioteca?

Se trata de una pregunta de respuesta cerra$\mathrm{da}$ con tres opciones afirmativas ("Sí, en la del barrio", "Sí, en la del Instituto", "Sí, en la Facultad") y una negativa ("No, nunca").

128 alumnos $(89,51 \%)$ han marcado una opción y 13 (9,09\%) varias opciones (sobre todo dos de las ofrecidas). A ellos hay que sumar el número de 2 alumnos que no contestan. De todos ellos, 31 alumnos (21,68\%) aseguran NO haber recibido formación en el uso de una biblioteca y el resto, sí (110, esto es, $76,92 \%$ ).

En cuanto a dónde, de las opciones ofrecidas (barrio, instituto, Facultad) ha sido la de la Facultad la más marcada, tanto en una opción (77) como en varias (10). Por otra parte, 11 alumnos dicen haber recibido formación únicamente en la biblioteca del barrio y 9 en la del Instituto.

5. ¿Has recibido formación en el uso de recursos de información? ¿Dónde?

La pregunta ofrece dos respuestas excluyentes del tipo Sí o NO y en el primer caso se ofrece la posibilidad de que el encuestado diga “¿dónde?” con respuesta abierta. 
Comportamiento informativo de estudiantes...

De los 143 alumnos, 77 (53,85\%) dicen haber recibido esta formación, $63(44,06 \%)$ señalan que NO y $3(2,09 \%)$ no contestan.

En cuanto a dónde han recibido esa formación, de los 77 alumnos hay 3 que no indican respuesta, 14 señalan diferentes lugares (instituto, trabajo, casa y, sobre todo, bibliotecas) y el resto (60), la Facultad (Universidad, Facultad, clase).

6. Cuando buscas un libro en una biblioteca, ¿preguntas al bibliotecario, buscas en el catálogo o en las estanterías?

La pregunta ofrece 3 respuestas que pueden marcarse según el interés del encuestado: "preguntas al bibliotecario", "buscas en el catálogo" y "buscas en las estanterías".

El $100 \%$ de los alumnos responden a esta pregunta. Eligen una opción la mayoría (84 de ellos, esto es, el 58,75\%) mientras que marcan dos 43 alumnos (30,06\%) y 16 $(11,19 \%)$ las tres que se ofrecen. De los 59 que utilizan distintas formas, la combinación más frecuente es la de buscar en catálogo y en estantería (26), lo que resultaría una secuencia lógica.

Considerando la totalidad de las respuestas (de una, dos o tres opciones), la forma más utilizada para buscar un libro en una biblioteca 
Investigaciones sobre las necesidades de información,...

es la de consultar el catálogo (97 alumnos, esto es, el 67,83\%) después la de buscar en las estanterías (79 alumnos o el 55,24\%) y, por último, la de preguntar al bibliotecario (42 alumnos, esto es el 29,37\%).

7. ¿Qué dato necesitas para poderlo encontrar en la estantería?

Se trata de una pregunta de respuesta abierta que permite al encuestado responder con sus propias palabras.

De la totalidad de los alumnos, $76(53,14 \%)$ responden erróneamente (una de las respuestas más señalada es la de "la materia") y $19(13,29 \%)$ no contestan. Tan sólo 48 $(33,57 \%)$ responden acertadamente (signatura, signatura topográfica o tejuelo).

8. Si usas el catálogo, ¿qué forma de acceso te resulta más difícil?

La pregunta ofrece 5 posibilidades de respuesta que pueden marcarse según los hábitos del encuestado: "por autor", "por materia", "por título" y "por palabra clave".

De los 134 alumnos (93,70\%) que han respondido la pregunta, $103(76,86 \%)$ han marcado una sola opción, $30(22,39 \%)$ dos opciones y $1(0,75 \%)$ elige tres. No se da el caso de que se marquen las 4 opciones dadas (autor, materia, título, palabra clave). La 
Comportamiento informativo de estudiantes...

opción más señalada, considerando la totalidad de las respuestas, es la de palabra clave $(37,31 \%)$ y la de materia $(35,07 \%)$.

9. Cuando te piden un trabajo en alguna asignatura, ¿te explican cómo bay que bacerlo?

Se trata de una pregunta de respuesta cerrada de tipo excluyente, esto es, Sí o NO.

111 alumnos $(77,63 \%)$ marcan el sí mientras que $30(20,97 \%)$ lo hacen con el NO y 2 $(1,40)$ no contestan.

10. ¿Y cómo citar la bibliografía que uses?

$\mathrm{Al}$ igual que la pregunta anterior, la presente ofrece una respuesta excluyente.

73 alumnos $(51,05 \%)$ marcan el NO, 59 $(41,25 \%)$ el sí, 7 (4,90\%) no contestan y 4 $(2,80 \%)$ no lo hacen de la forma en que se ha pedido (Sí/No).

11. ¿Te sientes capacitado para realizar una buisqueda de información?

Se trata de una pregunta de idénticas características que las anteriores.

123 alumnos $(86,01 \%)$ dicen que sí mientras que $19(13,29 \%)$ señalan el No. Hay 1 alumno $(0,70 \%)$ que no contesta.

12. ¿En qué te fijas cuando seleccionas información? señala 3 criterios en orden de importancia Como se trata de una pregunta de respuesta abierta, cada encuestado ha utilizado su propia 
Investigaciones sobre las necesidades de información,...

terminología, de forma que se han unificado los términos y se han elegido los criterios más señalados, ordenándolos según el número de respuestas marcadas.

Contestan 141 alumnos $(98,60 \%)$ y, teniendo en cuenta la totalidad de sus respuestas, los criterios más valorados han sido, y por este orden: pertinencia, autoría y actualidad.

13. ¿Qué recursos de información de los que se indican a continuación has usado alguna vez?

Se trata de una pregunta de respuesta múltiple donde se les ofrece la posibilidad de marcar las siguientes opciones: revistas especializadas, periódicos, libros, publicaciones oficiales, obras de consulta, catálogos de biblioteca, material audiovisual, Internet. 142 alumnos $(99,30 \%)$ marcan más de un recurso, aunque son sólo 7 (4,90\%) los que señalan todos los que se ofrecen.

Teniendo en cuenta la totalidad, se puede decir que los recursos más marcados han sido "libros" (139 alumnos) e "Internet" (141 alumnos).

14. ¿Qué datos necesitas para buscar un artículo de una revista especializada?

La presente pregunta es de respuesta abierta con el fin de conocer, también, la terminología empleada por los alumnos. 
Comportamiento informativo de estudiantes...

106 alumnos $(74,12 \%)$ responden de forma incorrecta o incompleta, 28 (19,59\%) no contestan y $9(6,29 \%)$ señalan los datos necesarios para localizar un artículo.

15. ¿Completas tus apuntes con la bibliografía recomendada por los profesores?

Las respuestas dadas son de dos tipos y excluyentes: afirmativas ("Sí, para rellenar lagunas", "Sí, porque me gusta saber más") y negativas ("No, no me recomiendan bibliografía", "No, no es necesario").

Salvo los alumnos que no contestan (3), el resto se decanta mayoritariamente por el Sí (113, esto es, el 79,02\%) frente a los que dicen NO (27, esto es, un 18,88\%). La razón de esto último es, sobre todo, la de no considerarlo necesario (26) y se da el caso de 1 alumno que marca la opción del NO porque no se lo recomiendan.

En cuanto a los alumnos que marcan el Sí, se da una mayor respuesta en la opción de "para rellenar lagunas" (95 alumnos, esto es, 89 que la marcan como única opción y 6 junto con la otra) mientras que la otra opción ("porque me gusta saber más") resulta ser la que despierta menor interés (24 alumnos, esto es, 18 que la marcan como única opción y 6 junto con otra). 
Investigaciones sobre las necesidades de información,...

16. ¿Utilizas Internet? ¿Dónde? ¿Para qué?

La presente pregunta ofrece la doble opción del sí y el NO. En el primer caso se pregunta el dónde y el para qué de forma abierta. En el caso del NO se pregunta al encuestado, de igual manera, sobre la razón (“¿Por qué?”).

141 alumnos $(98,60 \%)$ dicen utilizar Internet. En cuanto a dónde lo hacen, la mayoría (72 alumnos, esto es el 51,06\%) indica una sola opción mientras que el resto señala dos (52 alumnos o el 36,88\%), tres (13 alumnos o el $9,23 \%$ ) o ninguna (4 alumnos, esto es, el $2,83 \%$ ) opción. Considerando la totalidad de las respuestas, el tipo de espacio más utilizado, es el del domicilio particular (124 alumnos o el 87,94\%), seguido del de la Facultad ( 67 alumnos o un $47,51 \%$ ) y con diferencia respecto a las demás opciones señaladas (trabajo, biblioteca, clase, ciber o móvil). La combinación más marcada es precisamente la de domicilio y Facultad (40 alumnos, esto es, el 28,37\%).

Por lo que respecta a la razón del uso de Internet, esto es, para qué, la mayoría de los alumnos han marcado más de un motivo, por eso, teniendo en cuenta la totalidad, podemos decir que es "buscar información" (sin especificar para qué) la razón más marcada (91 
Comportamiento informativo de estudiantes...

alumnos, el 64,54\%) seguida de "como complemento al estudio" (para ampliar apuntes, consultar el campus virtual, hacer trabajos...) (47 alumnos o un 33,33\%), "ocio" (46, esto es, el 32,62\%), "comunicarse" (ver el correo, chat..), "razones laborales" (12), etc...

En cuanto a los 2 alumnos que dicen no usar Internet, las razones son carecer de conocimientos o tener suficiente con sus apuntes.

17. ¿Cómo preparas tus exámenes?

Con esta pregunta queremos saber si los alumnos amplían o contrastan sus apuntes con información adicional. Para ello, se les ha dado tres opciones, que pueden marcar en su totalidad: "con mis apuntes", "con apuntes de compañeros" y "con manuales".

56 alumnos (39,16\%) marcan dos opciones, $52(36,36 \%)$ una sola opción y 35 alumnos $(24,48 \%)$ han preferido señalar las 3 opciones ofrecidas.

Considerando la totalidad de respuestas en sus distintas modalidades vemos que 132 alumnos $(92,31 \%)$ han marcado, de una forma u otra, el uso de sus propios apuntes como recurso más empleado a la hora de preparar los exámenes; 81 alumnos $(56,65 \%)$ lo han hecho con la opción referida al uso de manuales y $45(31,47 \%)$ con la que tiene que 
Investigaciones sobre las necesidades de información,...

ver con los apuntes de los compañeros. La combinación más señalada es la de apuntes propios y manuales (41 alumnos de los 56 que marcan 2 opciones).

18. ¿Qué técnica utilizas para estudiar?

La pregunta ofrece tres opciones que pueden marcarse en su totalidad: "hago resúmenes", "hago fichas" y "subrayo los apuntes".

De los 143 alumnos, 3 no contestan. El resto o utiliza una de las técnicas propuestas (74 alumnos, el 52,85\%) o dos (64 alumnos, el $45,72 \%$ ) o las 3 (2 alumnos, el 1,43\%).

Las técnicas más utilizadas, considerando todas las opciones, son por igual la de hacer resúmenes y subrayar los apuntes (100 alumnos, esto es, el 71,43\%). En cuanto a la combinación más señalada, se trata de la de resumir junto con subrayar, con un total de 60 alumnos $(42,86 \%)$ que la han elegido.

19. ¿Te gusta trabajar en grupo para hacer trabajos de clase?

Se trata de una pregunta de respuesta excluyente.

La gran mayoría (95 alumnos, un 66,43\%) señala que sí gusta de trabajar en grupo para hacer trabajos de clase aunque son 47 $(32,87 \%)$ los alumnos que señalan que no. Se da el caso de un alumno indeciso que no 
Comportamiento informativo de estudiantes...

contesta $(0,70 \%)$.

20. ¿Por qué has elegido esta carrera?

Al tratarse de una pregunta de respuesta abierta, las respuestas utilizan un estilo propio. Por ello se han sistematizado de forma que puedan contabilizarse por grupos temáticos. Así podemos ver que la principal razón es la del gusto por los libros, la lectura y los centros de información (sobre todo bibliotecas) con un total de 52 alumnos (36,36\%). Le sigue el interés por las salidas profesionales que ofrece la carrera así como la vocación profesional con 40 alumnos $(27,98 \%)$. El resto de respuestas se reparten de la siguiente manera: por utilidad personal y laboral, 14 alumnos (9,80\%); por curiosidad, 8 (5,60\%); por formación continuada (como complemento a la formación recibida anteriormente) y adquisición de nuevos conocimientos, 8 (5,60\%); por nota de corte (acceso fácil a la Universidad), 8 (5,60\%) y por equivocación, 1 alumno. Se da el caso de 12 alumnos $(8,40 \%)$ que no contestan.

\section{Conclusiones}

A la hora de determinar conclusiones respecto a los datos obtenidos, podemos establecer una distinción atendiendo a dos asuntos: la metodología empleada 
Investigaciones sobre las necesidades de información,...

en la investigación y los objetivos marcados para su desarrollo.

\section{Respecto a la metodología}

Podemos decir que una vez concluida la presente investigación se advierte la necesidad de contrastar los datos obtenidos con los conseguidos mediante el uso de otros métodos (indirectos) y/u otras técnicas (la entrevista, por ejemplo) con el fin de poder aclarar algunos puntos que han quedado confusos.

\section{Respecto a los objetivos}

Presentamos a continuación algunas conclusiones asociándolas con distintos temas que pueden servir de referencia teniendo en cuenta los objetivos marcados para el presente trabajo.

- Uso y manejo de la información y de recursos y centros de información

Prácticamente la totalidad de los alumnos son usuarios de bibliotecas. Predomina el uso de varias, aunque es de destacar el hecho de que un elevado número señale sólo una. La biblioteca que más utilizan es la de la Facultad y, en cuanto a la combinación con otras, es con la de barrio la más frecuente. Podría señalarse el hecho de que, en el grupo de iniciación, el uso de "otras bibliotecas" es muy poco significativo 
Comportamiento informativo de estudiantes...

mientras que en el grupo de los ya iniciados son la cuarta parte de los alumnos los que, de una u otra manera, señalan el uso de otras bibliotecas distintas a la modalidad de biblioteca de barrio o de Facultad. Parece una respuesta evidente teniendo en cuenta que han cursado ya el primer año de la Diplomatura. En cuanto al uso que hacen de estos centros, en los dos grupos estudiados la actividad más señalada es la de "para préstamo" pero advertimos una diferencia con respecto a la segunda de las actividades marcadas porque en el grupo de los iniciados ésta es la de "para estudiar" mientras que en el de los de iniciación es la de "para buscar información".

Sobre la forma de buscar un libro en una biblioteca, cabe decir que todos los alumnos responden a la pregunta, incluso los que afirman no usar alguna biblioteca. El hecho de que hayan marcado una, dos o todas las opciones dadas nos aporta información sobre el grado de independencia que poseen en el manejo de una biblioteca. Así, cabe decir que son mayoría los alumnos que eligen una sola opción frente a los que eligen dos opciones o todas. Esto nos hace pensar que se trata de alumnos seguros de la única forma en que buscan un libro en una biblioteca. Incluso 
Investigaciones sobre las necesidades de información,...

en el caso de los alumnos que utilizan más de una opción, considerando que la combinación más frecuente es la de buscar en catálogo y en estantería, se puede decir que se trata de una secuencia lógica (en caso de que la utilicen así). Considerando la totalidad de las respuestas (de una, dos o tres opciones), la forma más utilizada para buscar un libro en una biblioteca es la de consultar el catálogo, después la de buscar en las estanterías y, por último, la de preguntar al bibliotecario, que resulta ser poco frecuente. Pero, una vez más, advertimos diferencias respecto a los dos grupos estudiados ya que la respuesta más marcada por parte de los alumnos de iniciación no es la de la consulta del catálogo sino la de buscar en las estanterías. El hecho de que se haya señalado esa opción hace pensar que la experiencia de la mayoría es la del uso de bibliotecas de libre acceso y colocadas por algún sistema de materias: los alumnos no consultan el catálogo bien porque conocen la ubicación del documento bien porque buscan otros de la misma materia. Aunque los datos obtenidos con la pregunta a la que nos referimos a continuación nos hacen pensar que se trata de lo primero. De cualquier forma, podemos decir que se trata de grupos de usuarios autosuficientes. 
Comportamiento informativo de estudiantes...

Por otro lado, sorprende el hecho de que la mayoría de los alumnos no sepa qué dato se necesita para buscar un libro en la estantería. $\mathrm{Al}$ no conocer esta información y afirmar que buscan en estanterías parece que lo hacen así para ver otros documentos relacionados o para encontrar el documento al azar.

En cuanto al uso del catálogo y la forma de acceso que consideran más dificultosa, la mayoría de los alumnos ha respondido la pregunta, incluso aquellos que no marcaron el uso del catálogo para buscar un libro. Se puede decir que el acceso al catálogo, en general, no les reporta excesiva dificultad ya que son mayoría los que han marcado una sola opción. Aunque la opción más señalada, considerando la totalidad de las respuestas, sea la de palabra clave o la de materia, si tenemos en cuenta cada grupo individualmente, el criterio es distinto ya que en el caso de los iniciados es el de la palabra clave y en el de los de iniciación, la materia, aunque con poca diferencia respecto al de palabra clave. Resulta inquietante el hecho de que haya alumnos que encuentren dificultad en buscar por autor o por título. Por otra parte, y en relación con los alumnos que no contestan, se puede interpretar esta circunstancia como que tales alumnos no encuentran dificultad a 
Investigaciones sobre las necesidades de información,...

la hora de buscar por cualquiera de las formas propuestas $\mathrm{o}$, también, que no entienden la pregunta.

Por otra parte, la inmensa mayoría de los alumnos encuestados se sienten capacitados para realizar una búsqueda de información; y de aquellos que no lo consideran así, son mayoría los alumnos de iniciación.

En relación con su hábito de "búsqueda de información", se les ha preguntado por los criterios en los que se fijan cuando tienen que seleccionar información que han encontrado en su búsqueda. Así, considerando las respuestas de los alumnos que han contestado, podemos decir que los criterios más valorados han sido, y por este orden: pertinencia, autoría y actualidad. Es cierto que este resultado se considera teniendo en cuenta la totalidad pero si analizamos los datos obtenidos según los grupos que constituyen la muestra, cabe señalar que en el caso de los alumnos de iniciación los criterios son otros y en distinto orden, de forma que valoran la autoría, la materia y la actualidad. No consideran la pertinencia, al igual que los iniciados la materia.

Los recursos de información más utilizados por los alumnos encuestados son los libros e Internet, con una diferencia poco significativa y en 
Comportamiento informativo de estudiantes...

distinto orden según los grupos: en el de los iniciados es el primero y en el de los de iniciación, el segundo. Se dan algunos casos anecdóticos tales como los alumnos que no señalan el recurso "libros" o los alumnos que marcan Internet en esta ocasión y no lo hacen cuando se les pregunta si usan Internet, o a la inversa. También el hecho de que de los alumnos que decían usar el catálogo para buscar un libro en la biblioteca, ahora son menos los que señalan este recurso. Resulta destacable el hecho de que, en tercer lugar, se encuentren casi por igual recursos tales como "periódicos" y "obras de consulta", por delante de "catálogos". Los recursos menos marcados han sido "publicaciones oficiales" y "revistas especializadas".

Los alumnos estudiados desconocen la forma de buscar un artículo en una revista especializada, hecho que resulta alarmante sobre todo en alumnos iniciados.

El uso de Internet es mayoritario, incluso entre aquellos alumnos que no lo han marcado como recurso informativo utilizado alguna vez. Se utiliza en distintos espacios y para distintas opciones, pero destaca el domicilio particular en combinación con la Facultad y para buscar información (sin especificar). Se da la 
Investigaciones sobre las necesidades de información,...

circunstancia de que si se analiza la respuesta dada considerando cada grupo por separado, la segunda opción varía y así, mientras que para el grupo de los iniciados resulta ser la de "ocio" por delante de "como complemento al estudio”, para el grupo de iniciación se antepone esta última a la primera.

- Influencia del profesorado respecto a sus hábitos y manejo de información

En general, se puede afirmar que la formación o motivación respecto al uso de la información y su manejo recibido por parte del profesorado anterior al universitario es escasa, lo que es de lamentar.

Son los profesores universitarios los que motivan el uso de la biblioteca, valoran el uso de bibliografía complementaria, les dicen cómo hacer un trabajo y cómo citar. Quizá por tratarse de la especialización que cursan. Por eso sorprende el hecho de que haya alumnos que no contesten las preguntas referidas a estos temas o que lo hagan negativamente, ya que se supone que todos han tenido la misma experiencia y práctica en la Universidad. Puede pensarse que no recuerdan o que no son conscientes de ello. Respecto a si la respuesta varía según los grupos estudiados, tan sólo en la referida a si los profesores explican cómo 
Comportamiento informativo de estudiantes...

citar la bibliografía utilizada en un trabajo advertimos una diferenciación según sea un grupo u otro, dándose el sorprendente caso de que son los alumnos iniciados los que niegan el hecho mientras que los de iniciación lo afirman. Parece evidente que no se refieren a la experiencia común de las asignaturas que cursan porque si fuera así coincidirían en su respuesta. Y más en la asignatura que sirve de marco al estudio, ya que en sus contenidos se incluye esta práctica.

- Formación en recursos de información, incluida la biblioteca

Una amplia mayoría de los alumnos estudiados dice haber recibido formación en el uso de una biblioteca, sobre todo en la Facultad. De cualquier forma, se puede considerar que, al no aparecer la expresión "en la de la Facultad" sino sólo "en la Facultad", la respuesta se refiere a formación recibida en las aulas (contenidos de las asignaturas) no en el espacio de la biblioteca de la Facultad. Si fuera así, se puede pensar que los alumnos que dicen no haber recibido ningún tipo de formación lo han considerado así. Sorprende la escasa experiencia habida anteriormente en este asunto y manifestada en las respuestas.

Algo distinto ocurre cuando se les pregunta 
Investigaciones sobre las necesidades de información,...

por su formación en recursos de información ya que, aunque la mayoría de los alumnos se muestre de acuerdo en que la han recibido y, sobre todo, en la Universidad, un alto porcentaje lo niega, no reconociendo como formación en el uso de recursos de información los contenidos de las asignaturas cursadas en la carrera, sobre todo los de la asignatura $B i$ bliografía y fuentes generales de información. También es cierto que en el grupo de los iniciados son más los alumnos que afirman haber recibido esta formación que los que lo niegan mientras que en el grupo de iniciación la respuesta se da a la inversa, esto es, son más los alumnos que dicen no haber recibido formación en el uso de recursos de información que los que afirman haberlo hecho. Por otra parte, si tenemos en cuenta que un elevado número de alumnos asegura haber recibido formación en el uso de una biblioteca, el que haya alumnos que nieguen haber recibido formación en el uso de recursos de información junto con los que no contestan la pregunta nos hace pensar que no consideran la biblioteca como uno de esos recursos.

La falta de conciencia respecto a la relación que existe entre lo que se pregunta y los contenidos de la asignatura mencionada la confirma, 
Comportamiento informativo de estudiantes...

también, el hecho de que no todos los alumnos que dicen haber recibido esta formación, la señalen como marco.

- Hábitos de estudio en relación con la información

Los alumnos estudiados utilizan la información en sus hábitos de estudio. Así lo vemos cuando afirman mayoritariamente que completan sus apuntes con la bibliografía recomendada por los profesores, sobre todo para "rellenar lagunas". Y, también, cuando aseguran preparar sus exámenes ampliando o contrastando sus apuntes con información adicional proveniente de manuales, aunque prefieren utilizar sus propios apuntes.

Se les ha preguntado asimismo por la técnica que más manejan para estudiar con el fin de conocer el método o métodos que emplean para sintetizar la información que aprenden a la hora de preparar sus exámenes. Y así, podemos decir que son dos las técnicas más utilizadas, bien independientemente o en combinación: la de hacer resúmenes y la de subrayar los apuntes, aunque el orden de preferencia sea diferente según se considere a un grupo u otro de la muestra. En el de los iniciados es la primera y en el de los que se inician, la segun$\mathrm{da}$, aunque la diferencia sea apenas apreciable. 
Investigaciones sobre las necesidades de información,...

Por último, la mayoría de los alumnos gustan de trabajar en grupo para hacer trabajos de clase. Teniendo en cuenta que esta pregunta se ha hecho para conocer el grado de disponibilidad por parte del alumnado en relación con una de las competencias más destacadas por la metodología afín al Espacio Europeo de Educación Superior (la del trabajo en equipo), se puede concluir que los alumnos objeto de estudio reúnen tal competencia.

- Razón de estudiar esta carrera

Se les ha preguntado por este asunto para determinar si, de alguna manera, sus hábitos o experiencia con el uso de la información habían determinado la elección de esta carrera. Teniendo en cuenta que las razones más señaladas han sido la del gusto por los libros, la lectura y los centros de información (sobre todo bibliotecas) o el interés por las salidas profesionales que ofrece la carrera, no parece que exista esa relación buscada ya que, de las respuestas dadas, tan sólo las que señalan que han elegido esta carrera por utilidad personal parece que tienen que ver con lo que pretendíamos, y éstas significan el 9,80\% de la totalidad. 
Comportamiento informativo de estudiantes...

\section{ANEXO}

Encuesta dirigida a los alumnos de la asignatura bibliografía y fuentes generales de información para conocer sus hábitos de información

${ }^{* * *}$ Marca con una $\mathrm{X}$ las respuestas que estimes oportunas (salvo las excluyentes)

1. ¿Utilizas alguna biblioteca?
$\square$ Sí,
$\square$ la de mi barrio
$\square$ la de mi Facultad
$\square$ otras
$\square$ para estudiar
$\square$ para préstamo
$\square$ para buscar información
$\square$ no lo necesito
$\square$ tengo libros en casa
$\square$ uso internet

¿Para qué?

$\square$ No

¿Por qué?

2. Los profesores que has tenido, ¿han motivado el uso de la biblioteca?
$\square$ Sí, los que tuve antes de la Universidad
$\square$ Sí, los que he tenido en la Universidad
$\square$ No, nunca

3. ¿Han valorado que usaras bibliografía complementaria para tus trabajos y exámenes?

$\square$ Sí, los que tuve antes de la Universidad

$\square$ Sí, los que he tenido en la Universidad

$\square$ No, nunca

4. ¿Te han enseñado a usar una biblioteca?

$\square$ Sí, en la del barrio 
Investigaciones sobre las necesidades de información,...

$\square$ Sí, en la del Instituto

$\square$ Sí, en la Facultad

$\square$ No, nunca

5. ¿Has recibido formación en el uso de recursos de información?

$\square$ Sí

¿Dónde?.

$\square \quad$ No

6. Cuando buscas un libro en una biblioteca

$\square$ preguntas al bibliotecario

$\square$ buscas en el catálogo

$\square$ buscas en las estanterías

7. ¿Qué dato necesitas para poderlo encontrar en la estantería?

8. Si usas el catálogo, ¿qué forma de acceso te resulta más difícil?
$\square$ por autor
$\square$ por materia
$\square$ portítulo
$\square$ por palabra clave

9. Cuando te piden un trabajo en alguna asignatura, ¿te explican cómo hay que hacerlo?

$\square$ Sí $\square$ No

10. ¿Y cómo citar la bibliografía que uses?
$\square$ Sí
No

11. ¿Te sientes capacitado para realizar una búsqueda de información?

$\square$ Sí $\quad \square \quad$ No

12. ¿En qué te fijas cuando seleccionas información? señala 3 criterios en orden de importancia 
Comportamiento informativo de estudiantes...

1.

2.

3.

13. ¿Qué recursos de información de los que se indican a continuación has usado alguna vez?

$\square$ revistas especializadas

$\square$ periódicos

$\square$ libros

$\square$ publicaciones oficiales

$\square$ obras de consulta

$\square$ catálogos de biblioteca

$\square$ material audiovisual

$\square$ Internet

14. ¿Qué datos necesitas para buscar un artículo de una revista especializada?

15. ¿Completas tus apuntes con la bibliografía recomendada por los profesores?

$\square \quad$ No, no me recomiendan bibliografía

$\square \quad$ No, no es necesario

$\square$ Sí, para rellenar lagunas

$\square$ Sí, porque me gusta saber más

16. ¿Utilizas Internet?

$\square$ Sí

¿Dónde?

¿Para qué?

$\square \quad$ No

¿Por qué?

17. ¿Cómo preparas tus exámenes?

$\square$ con mis apuntes 
Investigaciones sobre las necesidades de información,...

$\square$ con apuntes de compañeros

$\square$ con manuales

18. ¿Qué técnica utilizas para estudiar?

$\square$ hago resúmenes

$\square$ hago fichas

$\square$ subrayo los apuntes

19. ¿Te gusta trabajar en grupo para hacer trabajos de clase?

$\square$ Sí $\quad \square$ No

20. ¿Por qué has elegido esta carrera? 


\title{
La satisfacción de las necesidades de información como factor de cambio de la identidad indígena en la comunidad amuzga. Nuevos avances
}

\author{
CÉSAR Augusto Ramírez VeláZQuez \\ Centro Universitario de Investigaciones Bibliotecológicas \\ Universidad Nacional Autónoma de México
}

\section{Introducción}

$\mathbf{F}^{1}$ presente trabajo pretende conformar una viLión de la vinculación entre las necesidades de información de las comunidades indígenas y su satisfacción, con los factores y elementos que inciden en la identidad con el fin de tratar de establecer si este binomio es partícipe en el cambio o modificación de la misma en dichos grupos.

\section{Comunidades indígenas}

Las comunidades indígenas se encuentran inmersas en diversas zonas geográficas del mundo, y se mantienen unidas sin importar las divisiones políticas que a lo largo de los años han conformado los países y sus gobiernos; cuentan con una identidad propia que les da presencia en la sociedad que las envuelve. Un país viene siendo 
Investigaciones sobre las necesidades de información,...

la constitución de una nación, procura asociar de una manera política los intereses de un poder único, ya sea federal o central, con un orden jurídico y con una cultura única, aunque ésta pueda tener variantes sobre el mismo territorio, es decir, "una asociación de ciudadanos constituida como un territorio determinado ${ }^{1}$.

Cada país está compuesto a su vez por dos elementos esenciales que son las personas que los integran y el espacio geográfico en el cual tienen un pertenencia comunal que es la tierra, la cual trabajan para su subsistencia. Asimismo aunado a dichos elementos se tienen que considerar las tradiciones, su historia, su cultura, sus costumbres, sus hábitos de vida, su alimentación y sus expresiones orales y monumentales todo ello dándoles un sentido de identidad.

En el continente americano antes de la colonización, los territorios estaban definidos en cada región. Las comunidades indígenas como primeros pobladores tenían sus propias características en cuanto a cultura, historia, lengua, estructura social, religión, etcétera.

En los países con individuos indígenas, las diferencias son contrastantes entre indígenas y no

1 Frantz Fanon. Los condenados de la tierra. México: Fondo de Cultura Económica, 1961. p. 47. 
La satisfacción de las necesidades de información...

indígenas, los primeros tienen características muy particulares que los hacen únicos, conformando un mosaico cultural a partir de las diversas comunidades que integran. Su forma de vida, su cultura, idiosincrasia, su lengua, organización social y su ubicación geográfica, son particularidades que equilibran en gran medida la comparación que pudiera hacerse con otras sociedades de cualquier parte del mundo.

En este sentido, las características heterogéneas como las condiciones geográficas, la lengua y la identidad, y las características homogéneas: grupos vulnerables, religión, estructura social y cultura entre otras; se puede entender que es por demás decir que el individuo debe tener grandes necesidades de información, por lo que es preciso que se visualice el contexto sobre el cual aparecen dichas necesidades, esto implica investigar su situación de vida, temperamento, personalidad y la actitud del sujeto. ${ }^{2}$

\section{Identidad indígena}

Giménez (Sociología, 2002, p. 51), comenta que la identidad étnica se caracteriza por ser bastante tradicional; es decir, confiere al pasado una autoridad trascendente y tiene la convicción de que sumado a

2 N. M. Figueiredo de. Estudos de uso e usuarios da informacao. Brasilia, DF: IBICT, 1994. p. 31 
Investigaciones sobre las necesidades de información,...

la continuidad es capaz de incorporar incluso las innovaciones y reinterpretaciones que exige el presente.

Entre otros factores que se deben tomar en cuenta para considerarlos como parte de la identidad étnica, se tienen los siguientes:

- Territorialidad. El lugar de pertenencia por haber nacido, ser la tierra de los ancestros, herencia común, territorio modelado por muchas generaciones, vinculo material entre las generaciones del pasado y las del presente.

- Lengua nativa. No sólo como medio de comunicación, sino también como una forma de ver al mundo desde la perspectiva de la comunidad. Tiene una connotación ancestral que la enlaza con el mito de los orígenes, con la vida y con la muerte.

- Marcas distintivas de la identidad étnica, son el parentesco y la familia, que son signos de pertenencia, misma que se adquiere por nacimiento; En este sentido, Harold Issacs citado por Giménez (2002, p.54) comenta que "la familia es un grupo básico de identidad en cuyo seno el individuo interioriza una tradición cultural, un lenguaje, una religión y un sistema de valores y estatus".

- La religión sigue siendo un factor primordial de la identidad étnica. Se caracteriza por ser 
La satisfacción de las necesidades de información...

predominantemente ritual, centrada en la figura de los santos patrones y en las celebraciones festivas destinadas a honrarlos. Esencialmente la religión tiene un carácter identificador.

\section{Necesidades de Información}

El ser humano desde sus orígenes ha experimentado cotidianamente la necesidad de saber y conocer el por qué, el cómo, el cuándo, el para qué, de todo lo que existe a su alrededor; su afán, lo ha llevado desde siempre a estudiar, investigar, experimentar, analizar y discernir tanto los sucesos naturales (el ciclo del día y de la noche, las lluvias y tormentas, el fuego y los incendios, el viento, los huracanes, la sequía, los movimientos celestes, la vida de los animales y de las plantas, entre otros), como los acontecimientos que se desarrollan en su vivencia cotidiana (las diversas formas de comunicación entre los individuos, las relaciones sociales, las actividades individuales y grupales y aspectos relacionados con su existencia en sí).

Derivado de lo anterior, ha tenido la necesidad de obtener información que le dé la oportunidad de aprender y a partir de ello generar nuevos conocimientos; en este sentido, indica Morales ${ }^{3}$

3 E. Morales Campos, Infodiversidad, globalización y derecho a la información. Buenos Aires: Sociedad de Investigaciones Bibliotecológicas. 2003. p. 15. 
Investigaciones sobre las necesidades de información,...

para cualquier estudio o acción en la vida de todo ser humano se requiere de un acceso a la información diversa y plural, como insumo básico y fundamental... [porque entre los]...derechos naturales del hombre, ...[se encuentran] el de pensar, el de crear, el de escribir y el de comunicarnos [mismos que] son acciones inherentes a la información.

Por lo tanto se puede expresar que a través del desarrollo de la especie humana ésta ha presentado siempre necesidades de información y conocimiento, lo cual significa que la presencia de dichas necesidades en los sujetos ha estado presente en todo su proceso evolutivo.

\section{Satisfacción de necesidades de información de las comunidades indígenas}

La satisfacción de necesidades por parte de los grupos indígenas conlleva al desarrollo social de sus individuos ya que incide entre otros factores a:

- Mejorar la organización de su patrimonio cultural y documental.

- La preservación testimonial de su historia.

- La preservación de su cultura.

- La preservación de su cultura herbolaria y medicinal.

- La preservación de su organización social. 
La satisfacción de las necesidades de información...

- Desarrollar su agricultura y ganadería.

- Generar empresas y comercios familiares y a mediana escala.

- Activar servicios educativos.

- Generar y desarrollar servicios públicos.

- Organizar programas de capacitación y adiestramiento sanitarios y de salud.

- Proyectar mejores vías y medios de comunicación.

A partir de lo anterior, a continuación se presentan en cuadros algunos elementos a considerar en los cuatro factores ya señalados anteriormente: territorialidad, lengua nativa, marcas distintivas de la identidad étnica y la religión; que pueden inferir un cambio o modificación en la identidad indígena:

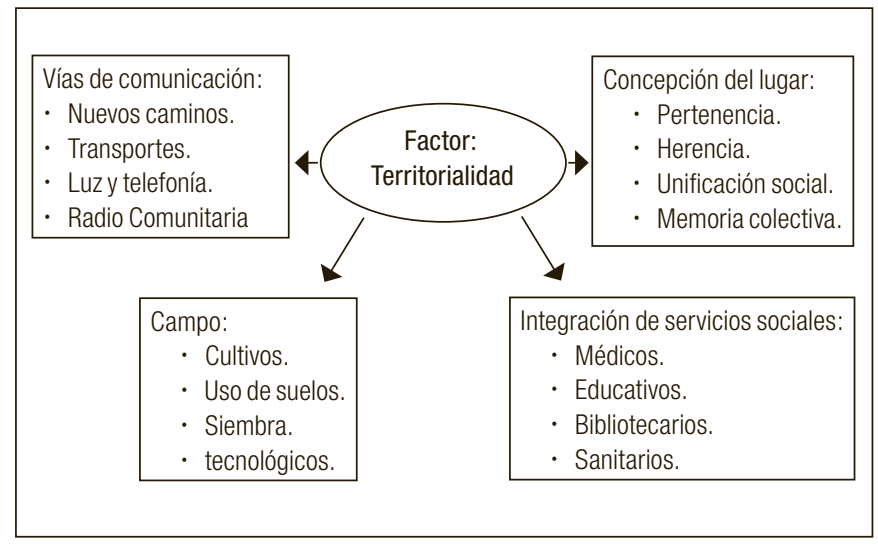


Investigaciones sobre las necesidades de información,...
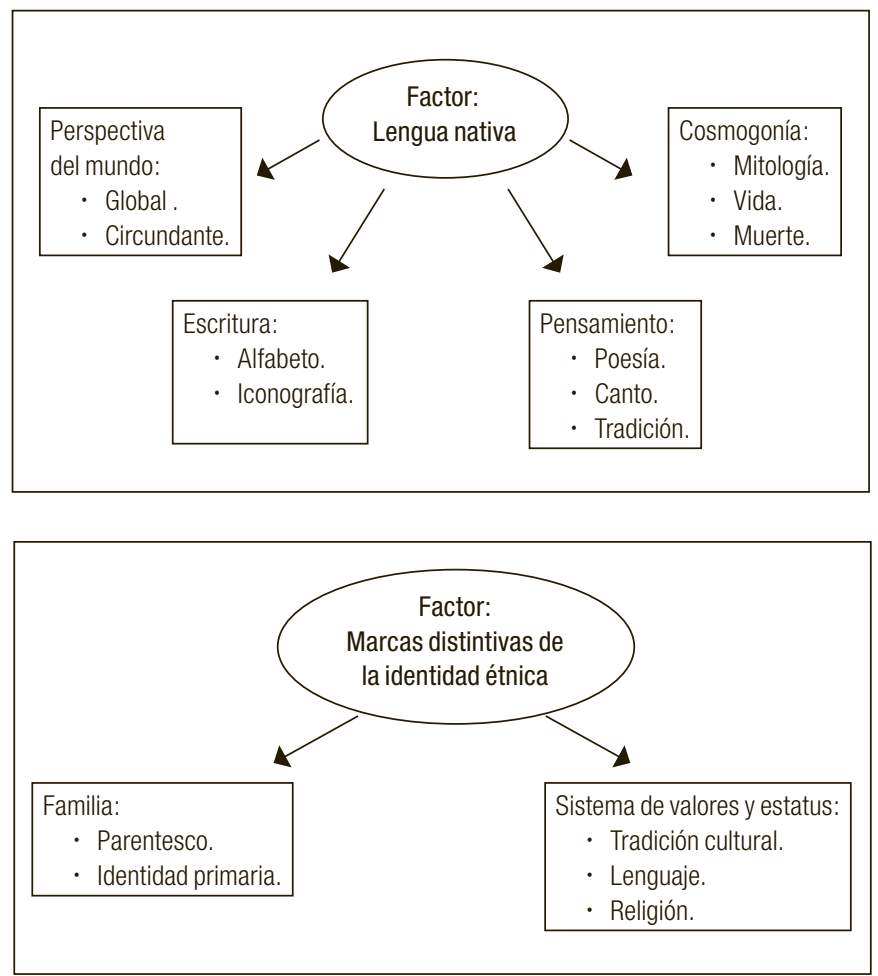
La satisfacción de las necesidades de información...

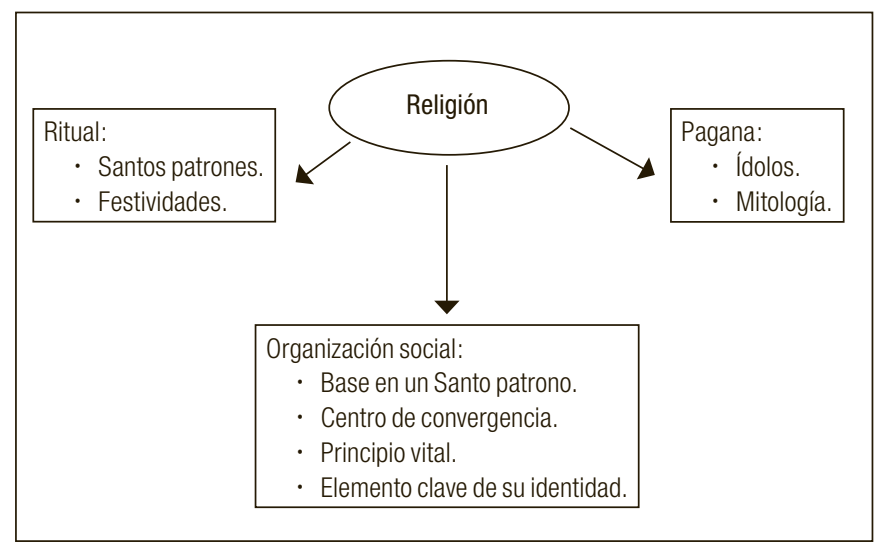

Como se puede observar en los cuadros presentados, los elementos a considerar crecen exponencialmente, ya que cada elemento general se encuentra integrado por varios específicos que surgen a partir de las necesidades propias de cada individuo.

\section{Conclusiones}

- El estudio de las necesidades de información a partir del desglose de la identidad étnica en factores y a su vez en los elementos que inciden en su desarrollo, permite al bibliotecólogo apoyar a las comunidades indígenas en:

- Su desarrollo social y cultural.

- La planeación e implantación de servicios comunitarios.

- El ejercicio de su derecho a la información. 
Investigaciones sobre las necesidades de información,...

- La ampliación de sus expectativas de vida.

- La integración de los propios individuos en diversos proyectos multidisciplinarios.

- Las comunidades indígenas se verán beneficiadas en cuanto a:

- La preservación de su cultura.

- Su desarrollo social.

- La salvaguarda de su identidad.

- La obtención de mayor información.

- El respeto a sus derechos tanto humanos como indígenas.

\section{Bibliografía}

Aguilar Cavallo, G. (2006). La aspiración indígena a la propia identidad. En: Revista Universum, 1, (21).

Fanon, F. Los condenados de la tierra. México: Fondo de Cultura Económica, 1961.

Figueiredo, N. M. de. Estudos de uso e usuarios da informacao. Brasilia, DF: IBICT, 1994.

Giménez Montiel, G. Paradigmas de identidad. En: Sociología de la identidad. Coord. Aquiles Chihu Amparán. México: Miguel Ángel Porrúa; UAM, Iztapalapa. 2002 
La satisfacción de las necesidades de información...

Morales Campos, E. Infodiversidad, globalización y derecho a la información. Buenos Aires: Sociedad de Investigaciones Bibliotecológicas. 2003

Ramírez Velázquez, C. A. Necesidades de información en comunidades indígenas: el caso de la comunidad tepebua. México: Centro Universitario de Investigaciones Sociología de la identidad. Coord. Aquiles Chihu Amparán. México: M. A. Porrúa; UAM, Iztapalapa. 2002 



\section{Comportamiento informativo de los tesistas de licenciatura en bibliotecología de la ENBA, el Colegio de Bibliotecología de la UNAM y la UAEM. Causas que lo originan. Avances}

ARMANDO SÁNCHEZ SoTO

Posgrado en Bibliotecología y Estudios de la Información Universidad Nacional Autónoma de México

\section{Introducción}

T a siguiente exposición es la continuación de dos upresentaciones previas, llevadas a cabo en el II y III Seminario de Usuarios de la Información, celebrados en los años 2006 y 2008 respectivamente.

En el segundo Seminario únicamente se presentó la propuesta de protocolo de tesis, mientras que en el tercero fueron mostrados el planteamiento del problema, la hipótesis, los objetivos y la metodología, así como los avances del Marco de Referencia (Capítulo 1) y del Marco Teórico (Capítulo 2).

En este IV Seminario finalmente se presentan los resultados obtenidos del análisis del comportamiento informativo de los tesistas de la licenciatura en Biblioteconomía de la ENBA, de la licenciatura en Bibliotecología del Colegio de Bibliotecología de la 
Investigaciones sobre las necesidades de información,...

UNAM y de la licenciatura en Ciencias de la Información Documental de la UAEM.

\section{Metodología}

- Se trata de una investigación documental en combinación con la de campo

- Se utilizó el método inductivo

- Como instrumento se utilizó un cuestionario.

\section{Población}

Se tomaron en cuenta todos aquellos estudiantes inscritos en alguno de los programas de titulación que actualmente existen dentro de las tres escuelas mencionadas (Seminario de titulación, Seminario de tesis, etc) o bien; a todos aquellos egresados de las mismas, que contarán con registro de trabajo de titulación (en cualquiera de sus modalidades). En los tres casos se estableció el período comprendido entre los meses de Junio y Diciembre del año 2008 (6 meses).

\section{Comentarios}

Una vez ubicado el número de tesistas en la población elegida, se entregó el cuestionario correspondiente a cada uno de los mismos; en algunos casos tal situación se hizo de manera personal, mientras que en otros fue vía correo electrónico o a través de su asesor. Dicho cuestionario constó de 17 preguntas abiertas y cerradas. 
Comportamiento informativo de los tesistas...

Una vez contestados los cuestionarios, se hizo un análisis de las respuestas obtenidas pregunta por pregunta; en el caso de las preguntas abiertas, estas se cerraron de acuerdo con los comentarios emitidos por parte de los tesistas.

Finalmente los resultados obtenidos fueron divididos en tres partes:

- En la primera los resultados se presentan de manera conjunta (resultados totales)

- En la segunda se hace un desglose de los mismos, escuela por escuela

- En la tercera se realiza un comparativo de los tres casos

Para efectos de esta presentación únicamente se muestran los resultados del primer caso, mismos que a continuación se presentan.

\section{Resultados totales}

Necesidades de información de los tesistas de la ENBA, el CB de la UNAM y la UAEM

Los tesistas de la ENBA manifestaron haber necesitado información de 59 temas diferentes, de los cuales 35 están relacionados directamente con la Bibliotecología y 24 de otros no relacionados con la misma (temas generales).

Los tesistas de la UNAM necesitaron información 
Investigaciones sobre las necesidades de información,...

de 83 temas diferentes, de los cuales 36 están relacionados con la Bibliotecología y 47 a temas generales. Finalmente los tesistas de la UAEM necesitaron información de 35 temas diferentes, de los cuales 11 están relacionados con la Bibliotecología y 24 a temas generales.

Temas de las tesis

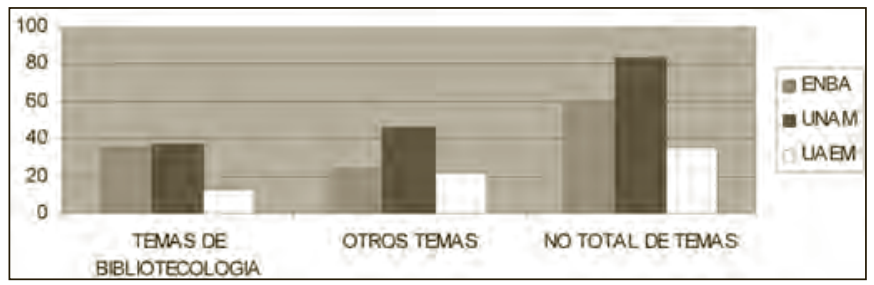

De lo anteriores algunos de los temas más recurrentes manifestados por los tesistas fueron:

Temas de Bibliotecología

\begin{tabular}{|l|l|}
\hline \multicolumn{1}{|c|}{$\begin{array}{c}\text { Temas relacionados con la } \\
\text { Bibliotecología }\end{array}$} & \multicolumn{1}{c|}{ Temas Generales } \\
\hline Bibliotecas especializadas & Análisis Foda \\
\hline Bibliotecas especializadas en arte & Calidad de Servicios \\
\hline Bibliotecas Públicas & Calidad Total \\
\hline Bibliotecas Universitarias & Conceptos de Outsorcing \\
\hline Desarrollo de Colecciones & Desempeño laboral \\
\hline Descarte & Evaluación \\
\hline Diseño de Servicios Bibliotecarios & FRBR \\
\hline Estudios de Usuarios & Gestión del conocimiento \\
\hline Evaluación de Bibliotecas & Historia de la ENAH \\
\hline Evaluación de Bibliotecas Públicas & Historia de México \\
\hline
\end{tabular}


Comportamiento informativo de los tesistas...

\begin{tabular}{|l|l|}
\hline Evaluación de Colecciones & Historia del INHA \\
\hline Fuentes de Información & Historia del Instituto Mora \\
\hline Historia de la ENBA & Métodos de Investigación \\
\hline Ley General de Bibliotecas Públicas & Modelos de Evaluación \\
\hline Mercado laboral del Bibliotecólogo & Normalización \\
\hline Necesidades de Información & Normas ISO en Servicios \\
\hline Normas para Bibliotecas Públicas & PIFIS \\
\hline Obras de Consulta & $\begin{array}{l}\text { Programas de Fortalecimiento } \\
\text { Institucional }\end{array}$ \\
\hline Organización de Bibliotecas & \\
\hline Parámetros en Bibliotecas & \\
\hline Perfil de egreso del Profesional Asociado & \\
\hline Préstamo a domicilio & \\
\hline Profesional Asociado & \\
\hline $\begin{array}{l}\text { Programas de fortalecimiento de la oferta } \\
\text { educativa }\end{array}$ & \\
\hline Programas de seguimiento de egresados & \\
\hline Publicaciones Periódicas & \\
\hline Red Nacional de Bibliotecas Públicas & \\
\hline Seguimiento de egresados & \\
\hline Servicios Bibliotecarios & \\
\hline Servicios de Información & \\
\hline Teoría de la Información & \\
\hline Teoría de los Servicios Bibliotecarios & \\
\hline Teoría de los Servicios de Referencia & \\
\hline Usuarios de la Información. & \\
\hline
\end{tabular}

\section{Fuentes con mayor número de consultas}

El libro resultó ser la fuente más consultada por los tesistas para obtener información con un total de 37 registros, las Publicaciones Periódicas con 11, la Internet con 10, la Literatura Gris con 8, las Bases de Datos y las Memorias con 4, las Bibliografías y las 
Investigaciones sobre las necesidades de información,...

Publicaciones Periódicas con 3, y los Materiales Audiovisuales, los Periódicos y los Informes con 1.

Fuentes mas consultadas

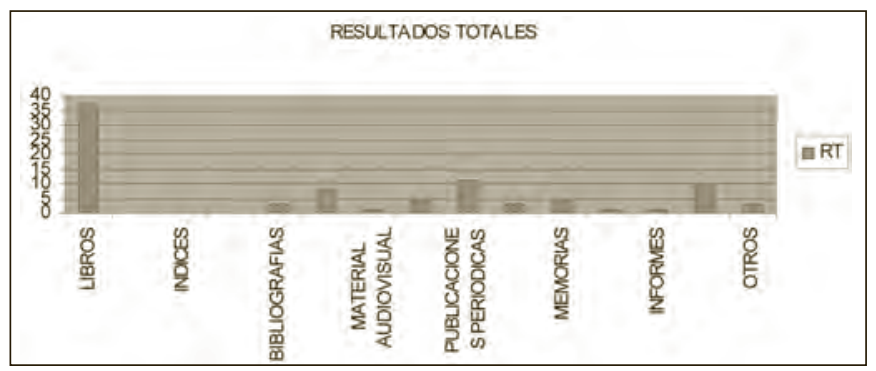

Características de las fuentes de información más consultadas

La opción "la información que contienen" fue elegida por los tesistas en 52 ocasiones, en 34 "la disponibilidad de acceso", en 33 "su vigencia", en 23 "el idioma en el que se encuentran", en 38 "su confiabilidad", en 17 "se encuentran en formato impreso", en 11 "se encuentran en formato digital", en 15 "se encuentran en la Biblioteca de su Facultad o Universidad", en 12 "se trata de documentos que circulan en la red", en 20 "se consultan en cualquier momento y en cualquier lugar" y en una "otras". 
Comportamiento informativo de los tesistas...

Características de las fuentes

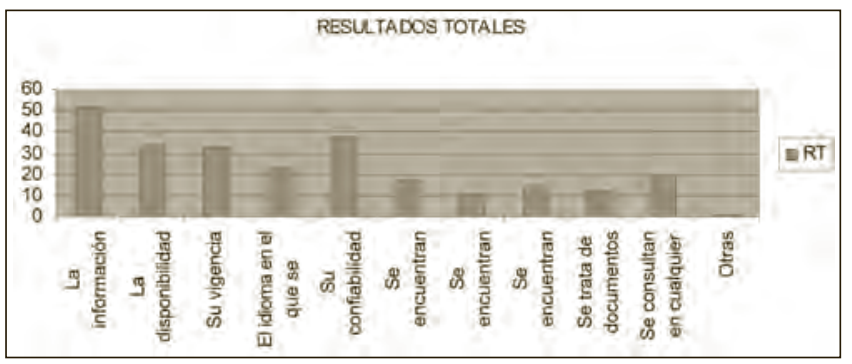

\section{Actualidad de las fuentes consultadas}

En cuanto a la actualidad de las fuentes consultadas, los tesistas señalaron a la opción "de 1 a 6 meses" en 8 ocasiones, de " 1 a 5 años" en 35, "de 6 a 10 años" en 24 , "de 10 años hacia atrás" en 3, "no importa la antigüedad" en 10 y en ninguna "otros".

Actualidad de las fuentes

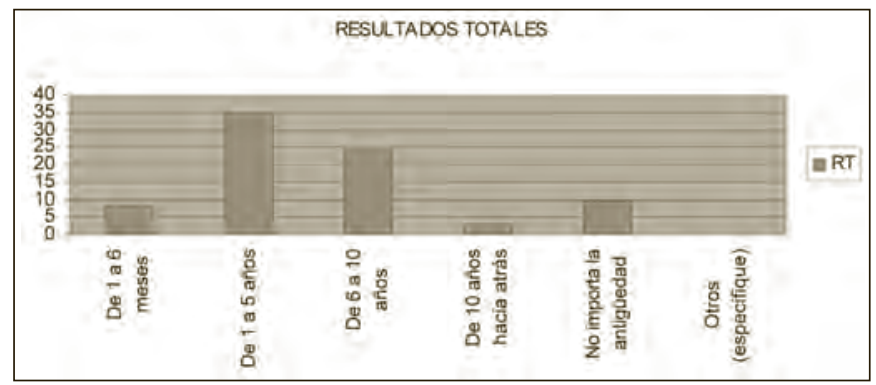


Investigaciones sobre las necesidades de información,...

\section{Idioma de las fuentes consultadas}

En cuanto al idioma de las fuentes consultadas, el español como opción principal fue señalado por los tesistas en 56 ocasiones, el inglés en 39, el francés en 9 y el portugués en 9; el idioma italiano y alemán no fueron señalados.

Idioma de las fuentes

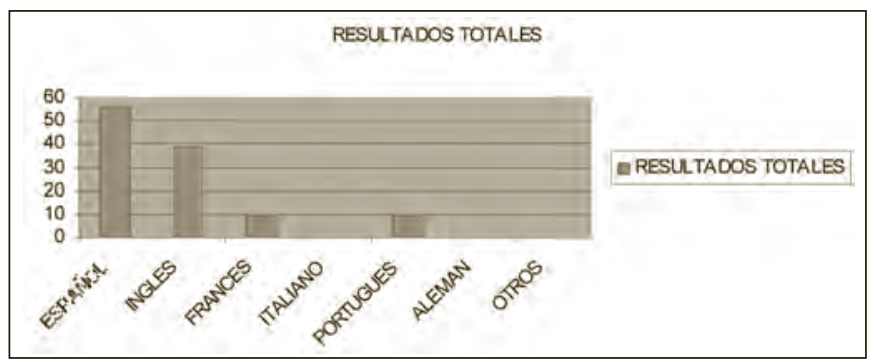

Recursos disponibles dentro de su Facultad, Escuela o Universidad

En cuanto a los recursos disponibles que existen dentro de las Facultades, Escuelas o Universidades de los tesistas, la opción "colegas" fue señalada en total en 25 ocasiones, "Bibliotecas" en 54, "Videotecas" en 20, "Hemerotecas" en 33, "Archivos" en 20, "Bases de Datos" en 37, "Internet" en 48, "Congresos" en 25, "Maestros" en 41, "Colecciones particulares" en 8, "Catálogos" en 40, "Colecciones" en 32 y en ninguna a la opción " otros". 
Comportamiento informativo de los tesistas...

Recursos disponibles en su institución

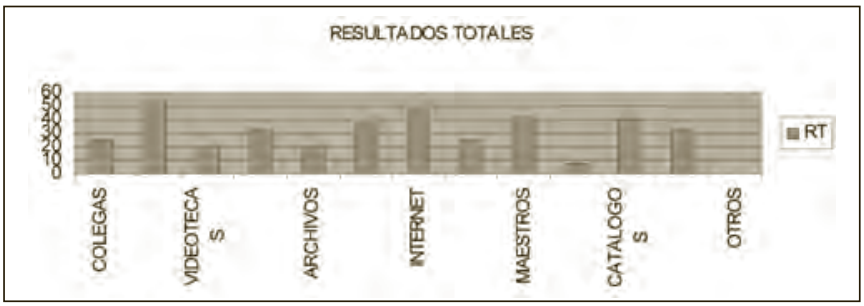

\section{Recursos más utilizados}

En cuanto a los recursos utilizados por los tesistas para realizar sus trabajos de titulación, la opción "Colegas" fue señalada en total en 24 ocasiones, en 53 "Bibliotecas", en 18 "Videotecas", en 31 "Hemerotecas", en 23 "Archivos", en 34 "Bases de Datos", en 48 "Internet", en 22 "Congresos", en 42 "Maestros", en 22 "Colecciones Particulares", en 35 "Catálogos", en 26 "Colecciones" y en uno "Otros".

Recursos utilizados

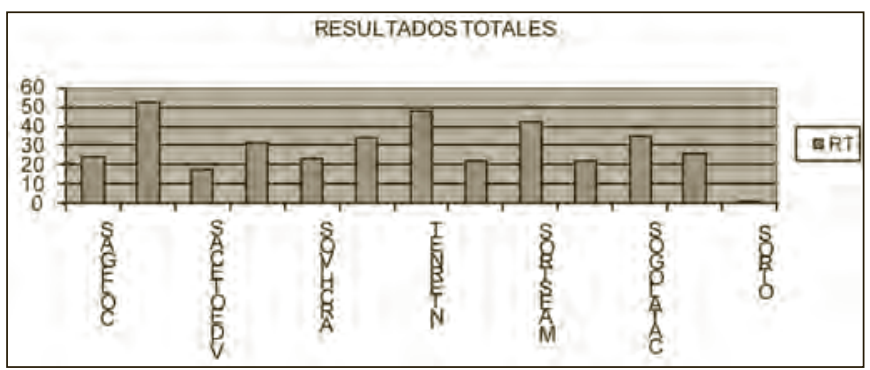


Investigaciones sobre las necesidades de información,...

\section{Frecuencia de consultas}

En cuanto a la frecuencia en la consulta de los recursos anteriores, la opción "diariamente" fue señalada en total en 10 ocasiones, "una vez a la semana" en 10 , "mas de una vez a la semana" en 29 , "una vez al mes" en 1, "mas de una vez al mes" en 3, "con poca frecuencia" en 6 y "nunca" en ninguna.

Frecuencia de Consultas

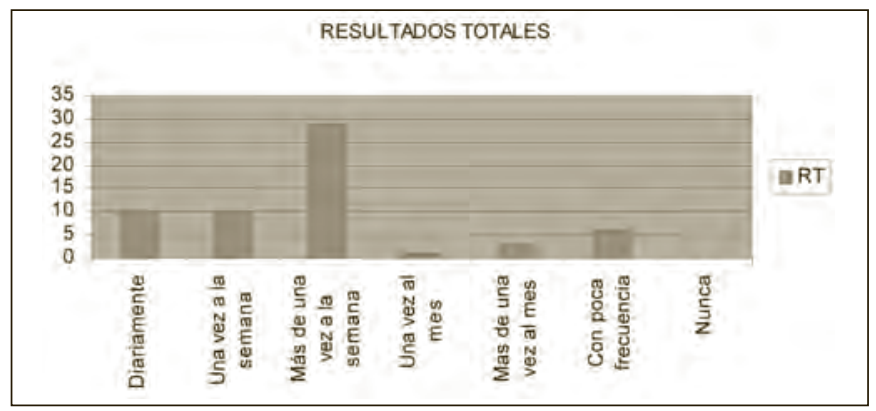

Uso de los recursos de otras bibliotecas aparte de los de su Facultad, Escuela o Universidad

En cuanto a los recursos de otras partes que utilizaron los tesistas, la opción "frecuentemente" fue señalada en total en 20 ocasiones, en 31 "esporádicamente" y en 5 "nunca o casi nunca". 
Comportamiento informativo de los tesistas...

Recursos de otras bibliotecas

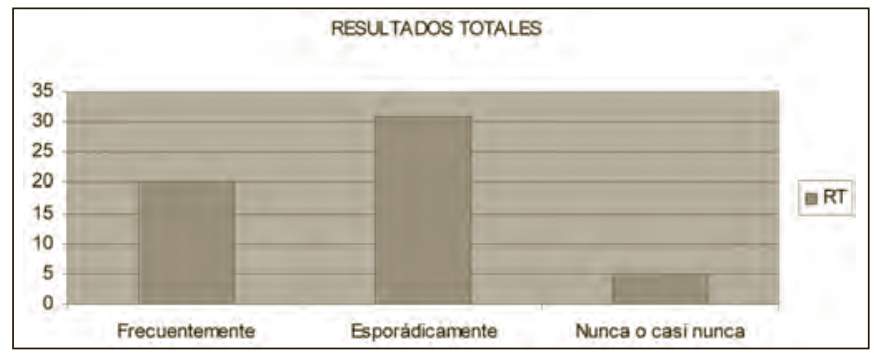

Como encuentran la información que han necesitado para realizar su trabajo de titulación

En cuanto a la forma en que los tesistas encontraron información para realizar sus tesis, la opción "hojeando libros y revistas" fue señalada en total en 30 ocasiones, "consultando referencias" en 42, "consultando reseñas" en 9, "consultando catálogos" en 42, "consultando bibliografías" en 30 y "otros" en 6

Como encuentran información

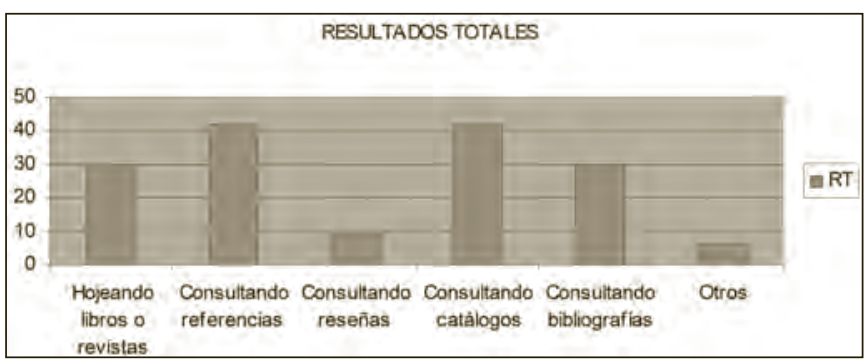


Investigaciones sobre las necesidades de información,...

Se han utilizado las TIC para obtener información para realizar su trabajo de titulación

En cuanto a si los tesistas utilizaron las TIC para realizar búsquedas de información, la opción "frecuentemente" fue señalada en total en 35 ocasiones, "esporádicamente" en 17 y 3 "nunca".

Nuevas tecnologías de información utilizadas

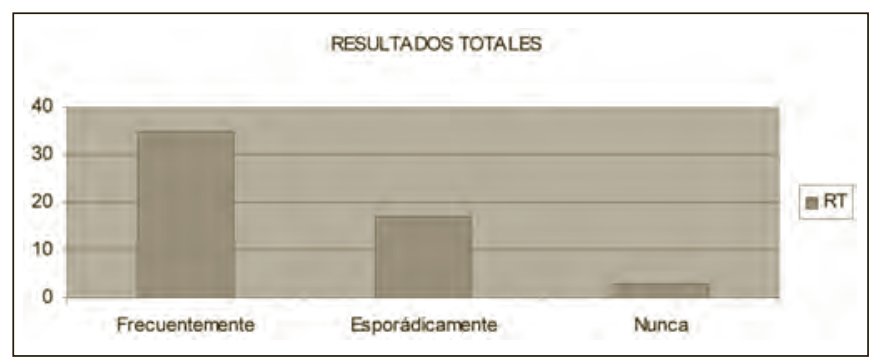

Se ha establecido algún tipo de intercambio con sus colegas o compañeros del área para obtener información

En cuanto a si se estableció algún tipo de intercambio con colegas y/o compañeros de la disciplina por parte de los tesistas, la opción "frecuentemente" fue señalada totalmente en 15 ocasiones, "esporádicamente" en 20 y "nunca" en 20. 
Comportamiento informativo de los tesistas...

Frecuencia de intercambio con colegas o compañeros

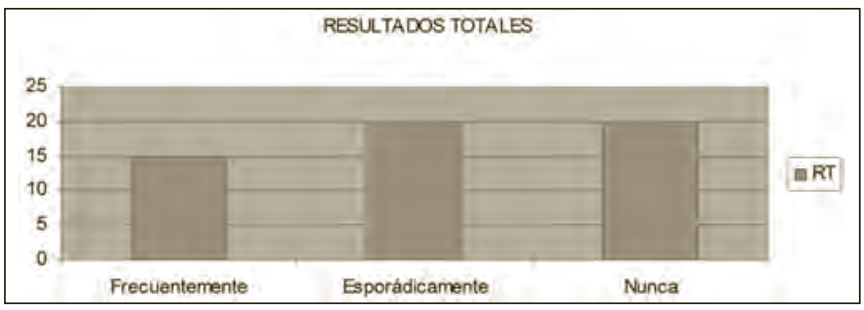

Se han consultado documentos originales (primarios)

En cuanto a si los tesistas consultaron documentos originales para obtener información la opción "frecuentemente" fue señalada en total en 32 ocasiones, en 14 "esporádicamente" y en 8 "nunca".

Documentos originales consultados

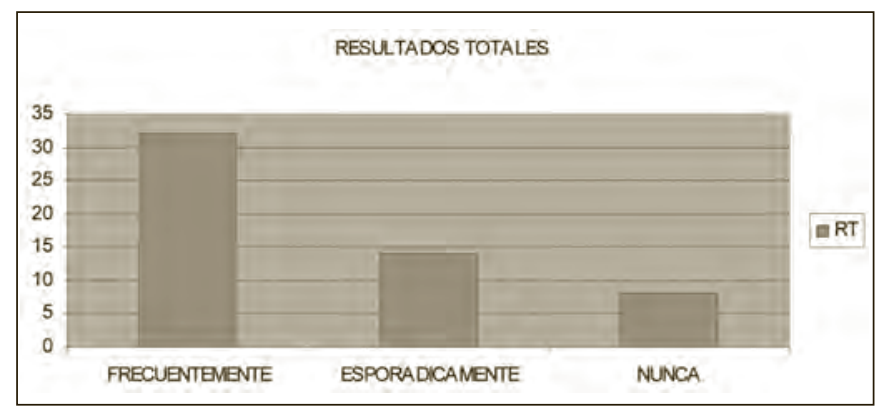

Se han consultado fuentes secundarias

En cuanto a si los tesistas consultaron fuentes secundarias para obtener información, la opción "frecuentemente" 
Investigaciones sobre las necesidades de información,...

fue señalada en total en 29 ocasiones, "esporádicamente" en 23 y "nunca" en 2.

Fuentes secundarias consultadas

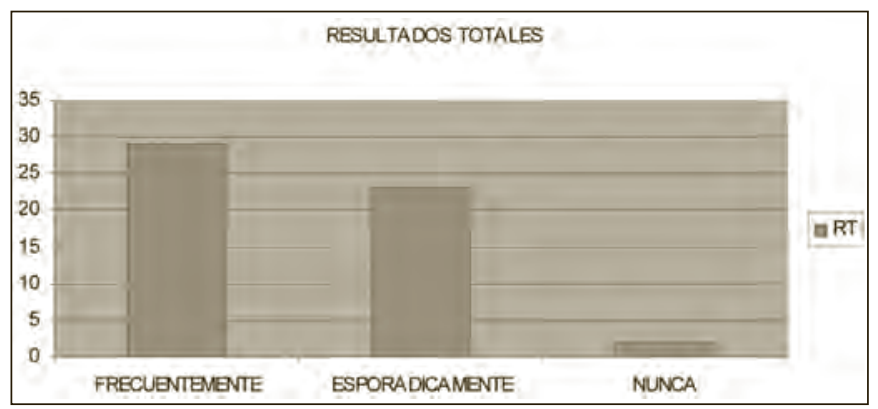

Se han consultado bases de datos

En cuanto a si los tesistas consultaron bases de datos para obtener información, la opción "frecuentemente" fue señalada en total en 21 ocasiones, "esporádicamente" también en 21 y "nunca" en 13.

Bases de datos consultadas

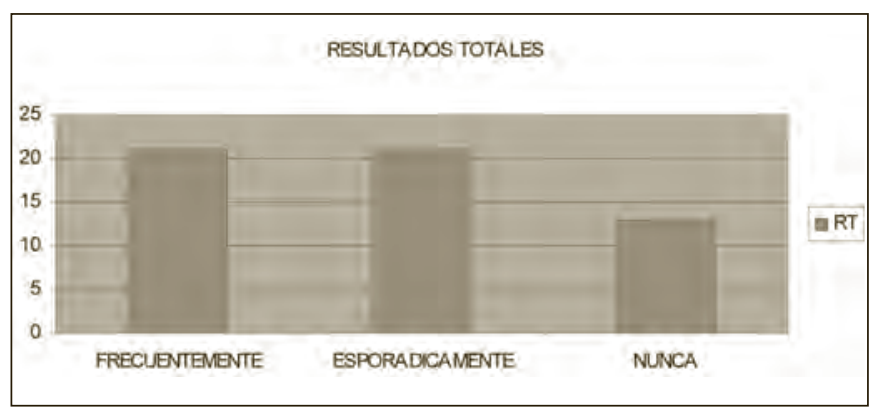


Comportamiento informativo de los tesistas...

Existe preferencia por consultar documentos en idiomas distintos al español

En relación a la preferencia a consultar fuentes en idiomas diferentes al que dominan los tesistas, la opción "frecuentemente" fue señalada en total en 7 ocasiones, "esporádicamente" en 33 y "nunca" en 15.

Documentos consultados en otro idioma

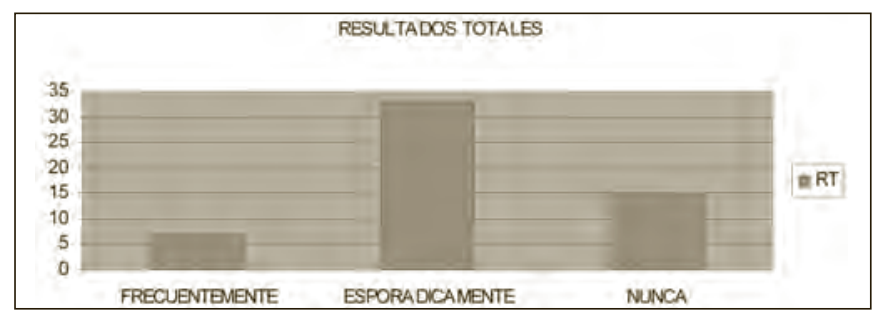

Idioma en el que prevalecen los documentos

Finalmente en cuanto al idioma de los documentos anteriores que consultaron los tesistas, la opción "inglés" fue señalada en total en 42 ocasiones, "francés" en 7, "portugués" en 2 e "italiano" y "alemán” en ninguna. 
Investigaciones sobre las necesidades de información,...

Idioma de los documentos mas consultados

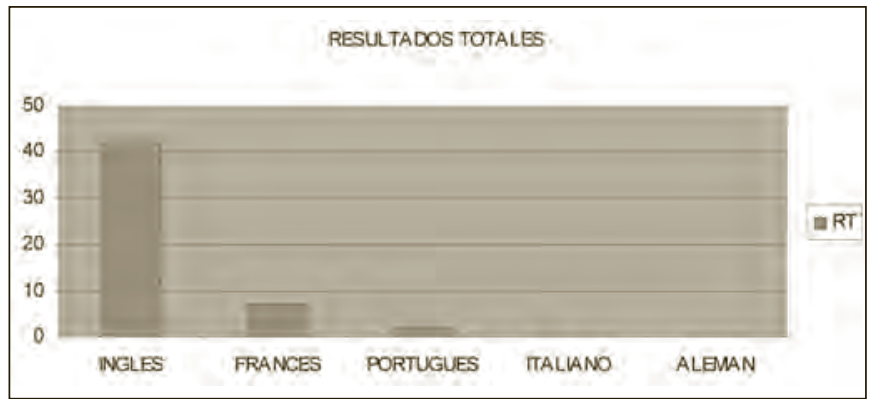

\section{Conclusiones}

Del total de los tesistas que integran la población elegida, la gran mayoría son mujeres, siendo la UNAM la que mayor número registra con un total de 21, seguido de la ENBA con 13 y la UAEM con 8; de hecho, en está última institución únicamente se aplicó un cuestionario a un solo varón.

De acuerdo a lo anterior se concluye que en las tres escuelas existe un interés mucho mayor de las mismas por titularse.

Por otra parte, se puede decir que del total de características que manifiestan los tesistas mencionados, en su comportamiento informativo; en su mayoría coinciden con las que presentan los humanistas como tales, de las cuales destacan las siguientes:

a) La tendencia a trabajar solos

b) La necesidad de hojear libros para encontrar 
Comportamiento informativo de los tesistas...

información

c) La preferencia a consultar monografías como fuente de información principal

d) La consulta de fuentes secundarias

e) Gran interés por utilizar las bibliotecas

Finalmente destacan las cuatro coincidencias en el comportamiento informativo entre los tesistas de las tres escuelas, a saber:

a) La preferencia en la consulta de libros como fuente principal para cubrir sus necesidades de información por encima de otras como las publicaciones periódicas o la Internet.

b) Las características que deben cumplir los anteriores para ser consultados tales como: antigüedad relativa (1 a 5 años), su confiabilidad y que haya disponibilidad de acceso a los mismos.

c) En el medio a través del cual consiguen información, en este caso: consultando referencias y/o bibliografías que aparecen en libros.

d) En los recursos que utilizan preferentemente, destacando: las bibliotecas, el Internet y los profesores (incluidos los respectivos asesores).

e) En la cantidad de veces que acuden a los 
Investigaciones sobre las necesidades de información,...

mismos: más de una vez a la semana por lo regular.

Lo anterior nos indica que a pesar de las diferencias en la formación de dichos tesistas, tomando en cuenta los programas de estudios de cada escuela, así como el contexto social, económico y cultural en el que se formaron los mismos; el comportamiento informativo de los tres casos es prácticamente salvo algunas diferencias es prácticamente el mismo.

\section{Comentarios finales}

Dentro de la exposición de los avances de la presente investigación, durante el III Seminario de Usuarios de la Información se destacó la escasa cantidad de investigaciones que se han realizado en torno a las necesidades de información y el comportamiento informativo de los profesionales de la información (bibliotecólogos, bibliotecónomos, archivólogos, documentalistas etc); señalando que hasta ese momento se había hecho un rastreo de otras investigaciones hechas en otras partes del mundo, de las cuales se habían encontrado una en el Reino Unido y otra en Rusia, dichas investigaciones son las siguientes: Bozic, M; Fabjan, U; Potocnick, V; Trtnik, Fuente Knjiznica. Razmisljanja in pricakovanja studentov bibliotekarstva in diplomiranih bibliotekarjev o bodoci profesionalni karieri. M. Considerations and 
Comportamiento informativo de los tesistas...

expectations of Librarianship student and working graduate librarians about their future careers. -43 (2/3) Oct 1999, p 145-58

Santos, M; Willet, P; Wood, F. E. "Research degrees in librarianship and information science: a survey of master's and doctoral students from the Department of Information Studies, University of Sheffield".- En Journal of Librarianship and Information Science; Vol. 30, no. 1, 1998, p 49-56

Recientemente se ubicó la investigación realizada por la doctora Isabel Villaseñor Rodríguez, profesora de la Facultad de Ciencias de la Documentación de la Universidad Complutense de Madrid; que lleva por título: Estudio de los hábitos de información de estudiantes de Biblioteconomía y Documentación y que fue aplicada a los alumnos matriculados en la asignatura Bibliografía y fuentes generales de información de los cursos 2007/2008 y 2008/2009 en los turnos de mañana y tarde, tanto de la Diplomatura en Biblioteconomía y Documentación como del Curso de complementos de formación, que da acceso a la Licenciatura en Documentación de la Universidad Complutense de Madrid.

De acuerdo con dicha investigación, se observó que existe una gran semejanza entre algunos de los resultados obtenidos de la misma y de los que surgieron de mi investigación; hecho con el cual se demuestra que las características que presentan los 
Investigaciones sobre las necesidades de información,...

profesionales de la información, en este caso los tesistas de Bibliotecología en México y los estudiantes de la Licenciatura en Biblioteconomía y Documentación en España; coinciden ampliamente con las que en general presentan los humanistas en su comportamiento informativo, y que fueron señaladas anteriormente. Las coincidencias encontradas entre una y otra investigación son las siguientes:

- Preferencia por utilizar a la biblioteca como recurso principal para obtener información.

- La Internet como segundo recurso más importante para obtener información.

- Preferencia por acudir a la biblioteca de su Universidad o Facultad

- Búsqueda de información a través de los catálogos

- En la actualidad de las fuentes que se consul$\tan$

- En la preferencia por consultar libros como fuente de información principal

- En el uso de las TIC como una fuente importante para obtener información.

Lo anterior desde mi punto de vista, nos permite establecer un parámetro en cuanto a la forma en como los futuros profesionales de la información de ambos países, hacen uso de los recursos y las fuentes de 
Comportamiento informativo de los tesistas...

información que actualmente existen; sobre todo cuando toman decisiones que repercuten en ellos mismos (en este caso como estudiantes o tesistas de la disciplina); así mismo, lo anterior cobra mayor importancia si consideramos que las habilidades informativas que hoy en día adquieran los mismos en su formación como tales, repercutirá en los servicios de información que en un futuro ofrezcan a su sociedad.

\section{Bibliografía}

Artellano Jiménez, Julissa. Estudio de las necesidades de información de la comunidad del Centro Mascarones pertenecientes al CELE-UNAM. México: Julissa Artellano Jiménez, 1999. 94 p

Calva González, Juan José. Las necesidades de Información: Fundamentos teóricos y Métodos. México: UNAM, CUIB, 2004. 284 p.

Calva González, Juan José. Las necesidades de información de los Investigadores del área de humanidades y Ciencias Sociales. En Revista General de Información y Documentación. Vol. 13, no 2 (2003) p. $155-180$ 
Investigaciones sobre las necesidades de información,...

Calva González, Juan José. "El comportamiento en la búsqueda de información de los investigadores del área de humanidades y Ciencias Sociales" Investigación bibliotecológica: archivonomía, bibliotecología e información. (México). 13 no. 27 julio-diciembre (1999): 3-29

Escuela Nacional de Biblioteconomía y Archivonomía (México) Modelo educativo de la Escuela $\mathrm{Na}$ cional de Biblioteconomía y Archivonomía. México: La Escuela, 1996. $1 \mathrm{v}$.

La educación bibliotecológica en México a través de sus instituciones educativas/ comp. Lina Escalona Ríos. México: UNAM: CUIB: Colegio Nacional de Bibliotecarios, 2005

Licenciatura en Ciencias de la Información Documental. Toluca, Estado de México: Universidad Autónoma del Estado de México, Facultad de Humanidades, 1992. 150 p.

López, Ana María del Pilar. Necesidades y Comportamiento Informativo en los investigadores del CCyDEL. México: Ana María López Jaramillo, 2000. $127 \mathrm{p}$ 
Comportamiento informativo de los tesistas...

Nazan Ozenc, Ucak; Serap Kurbanoglu. Necesidades de Información y Comportamiento para la búsqueda de información entre los estudiosos de una Universidad Turca. En.- 64th IFLA General Conference August 16-August 21, 1998. Amsterdam. Disponible en: (http://www.ifla.org/IV/ ifla64/041-112s.htm)

Sanz Casado. La realización de estudios de usuarios: una necesidad urgente. En Revista General de Información y Documentación. Vol. 3, no 1 (1993) 



\title{
La detección de las necesidades y comportamiento informativo de los matemáticos a través del análisis de referencias. Avances
}

\author{
ANGÉliCa GueVAra VillanUeVA \\ Colegio de Bibliotecología \\ Universidad Nacional Autónoma de México
}

\section{Introducción}

$\mathrm{F}^{1}$ presente trabajo, muestra los primeros pasos Cde una investigación más amplia y profunda que se pretende desarrollar a mediano plazo, y que ha surgido debido a la inquietud por corroborar los datos obtenidos de un estudio previo que se llevo a cabo en la comunidad de matemáticos, y cuyos resultados, han sido presentados en algunos trabajos publicados $^{1}$ que dan a conocer las necesidades de información y el comportamiento informativo que se encuentra latente dentro de sus actividades de investigación, docencia y difusión de la cultura que realizan los especialistas que integran a este sector.

1 Cfr. Angélica Guevara Villanueva. El fenómeno de las necesidades de información en el área de las matemáticas. Mesa redonda: el fenómeno de las necesidades de información en diversas comunidades. Proyectos y avances de investigación. Coord. Juan José Calva González. México: CUIB, 2007.- Cuadernos de Investigación; no. 3. pp. 27-57; "La comunidad de matemáticos en México: su comportamiento en la búsqueda de información." Anales de Documentación. Vol. 10, 2007. pp. 163-184. 
Investigaciones sobre las necesidades de información,...

Por lo anterior, sólo se menciona lo referente a las variables que se desean analizar, los objetivos, las hipótesis y la metodología que se dispone abordar.

Partiendo del concepto de reproducibilidad, pilar fundamental del método científico, y entendido, como la capacidad de repetir un determinado experimento en cualquier lugar y momento para construir un conocimiento, y de esta manera, exponer y confirmar fenómenos. Es así, como se persigue a través de este estudio, confirmar y/o descartar los resultados que se obtuvieron con anterioridad, y con ello, colaborar para cimentar un conocimiento más sólido y confiable sobre las características que se encuentran dentro de esta comunidad.

Para tal efecto, se recurrirá a la aplicación de un método indirecto, denominado, análisis de referencias, que consiste en

analizar la bibliografía referenciada en los trabajos de investigación que aparecen en las publicaciones periódicas, monografías, actas de congresos o cualquier otro documento ${ }^{2}$

que ha sido producto de los investigadores.

2 Elías Sánz Casado. Manual de estudios de usuarios. Madrid: Fundación Germán Sánchez Ruipérez; Pirámide, 1994. pp. 45-46 
La detección de las necesidades y comportamiento informativo...

De este modo, las variables que se retomarán para ser analizadas en relación a las necesidades de información serán:

a) el idioma en que se encuentran las fuentes o recursos que utilizan para la presentación de sus trabajos y, que se encuentran referenciados en ellos, y

b) la actualidad de las fuentes o recursos que han empleado en sus productos de investigación

En cuanto a comportamiento informativo se estudiarán:

c) Las fuentes de información o recursos que utilizan en el desarrollo y conclusión de sus documentos, $y$

d) El formato (impreso y/o electrónico) que emplean para realizar sus investigaciones

\section{Marco de teórico y de referencia}

La importancia de estudiar a esta comunidad se encuentra fundamentada por el papel esencial que desempeñan los investigadores que trabajan con las matemáticas en el desarrollo del conocimiento. Es una ciencia que permite comprender y estudiar la naturaleza, en la cual se fundamenta la base teórica 
Investigaciones sobre las necesidades de información,...

de la civilización técnica y el lenguaje común a muchas ramas de especialización. Su indiscutible repercusión en el proceso formativo desde temprana edad, constituye, junto con el lenguaje hablado, uno de los ejes principales de comunicación: las ideas y la palabra.

Por esta razón, es indispensable entender a las matemáticas no como una ciencia con aplicaciones inmediatas, sino como una ciencia básica, que por su estructura y formalismo riguroso, da lugar a procesos creativos que difieren con el trabajo de investigación en otras disciplinas científicas. ${ }^{3}$

De ahí que, por una parte, sustentada en el valor que representa para las diferentes disciplinas del conocimiento y, por otra, a la escasa literatura nacional e internacional que existe en torno al estudio de las necesidades y comportamiento informativo de los matemáticos, se ha decidido estudiar a estos especialistas, y de esta manera, obtener algunas características que se encuentran presentes dentro de estas comunidades en México, y con ello, proporcionar elementos que contribuyan a la toma de decisiones en aspectos de diseño y creación de bibliotecas, productos y servicios adecuados a los requerimientos que plantean los investigadores como usuarios de las unidades de información.

3 Sotero Prieto Rodríguez. Historia de las matemáticas. Toluca, Estado de México: Instituto Mexiquense de Cultura, 1991. p. XXXI 
La detección de las necesidades y comportamiento informativo...

En lo que corresponde a sus necesidades y comportamiento informativo dentro de este grupo, la literatura especializada ${ }^{4}$ que ha analizado alguna de las fases - necesidades, comportamiento, satisfacción- advierte que los investigadores de las ciencias exactas, tienden a utilizar información, oportuna y relevante, la cual obtienen generalmente en soportes documentales impresos y digitales, donde se revela que las publicaciones periódicas mantienen un lugar privilegiado.

Otro elemento característico, se refiere a que esta comunidad es la que utiliza documentos con menos años de antigüedad desde que han sido publicados, debido a que se considera que es una disciplina en constante evolución y desarrollo, implicando con

4 Cfr. Patricia Hernández Salazar. "La producción del conocimiento científico como base para determinar perfiles de usuarios." Investigación Bibliotecológica: Archivonomía, Bibliotecología e Información. Vol. 1, no. 30, enero-junio, 2001. p. 41; Juan José Calva González. Las necesidades de información de los investigadores del área de bumanidades y ciencias sociales, y del área cientifica. Informe de investigación. $2^{a}$ revisión. México: UNAM, CUIB, 1997. pp. 146, 147; Elías Sánz Casado. Manual de estudios de usuarios. Op. cit., p. 39; Cecelia Brown. "Information seeking behavior of scientists in the electronic information age: astronomers, chemists, mathematicians, and physicist." Journal of the American Society for Information Sciences. Vol. 59, no. 10, 1999. p. 932; Barbara Kirsch Schaefer. Using the mathematical literature: a practical guide. New York: Marcel Dekker, 1979. p. 29; Using the mathematics literature. Fowler, Kristine K. (ed). New York: Marcel Dekker, 2004. p. 381 
Investigaciones sobre las necesidades de información,...

ello que el investigador tenga que emplear documentos actuales para la elaboración de sus actividades. ${ }^{5}$ En cuanto a la búsqueda de información, la comunidad matemática se caracteriza, según la literatura, a ser proclives en delegar sus búsquedas a otras personas o profesionales de la información en comparación con otras comunidades como las humanísticas. ${ }^{6}$

Asimismo, en teoría, son otros colegas sus recursos de información principal; es decir, que dentro de esta comunidad la comunicación e intercambio de información entre pares es un medio importante. ${ }^{7}$ También la utilización de bibliotecas juega un papel sustancial en el desarrollo de sus actividades, en donde los investigadores acostumbran a revisar $\mathrm{u}$ hojear revistas, preguntar al bibliotecólogo directamente, o bien, caminar por los pasillos donde pueden ubicar la información sobre su respectiva línea de investigación. ${ }^{8}$

5 Elías Sánz Casado. Ibid., pp. 39,40

6 Elías Sánz Casado. Ibidem., p. 40

7 Barbara Kirsch Schaefer, Op. cit., pp. 33, 34; Kristine K. Flower, (ed.), Op. cit., p. 381; Elías Sánz Casado. Ibídem., p. 39

8 Nice Menezes de Figueiredo. Estudos de uso e usuarios da informacao. Brasilia, DF: IBICT, 1994. pp. 13, 14; Juan José Calva González. Las necesidades de información: fundamentos teóricos y métodos. México: UNAM, Centro Universitario de Investigaciones Bibliotecológicas, 2004. pp. 145, 146; Cecelia Brown, Op. cit., p. 936;, Odile Vigeannel-Larive. "La bibliotheque, laboratoire du mathématicien." Bulletin des Bibliotheques de France. Vol. 47, no. 6, 2002. pp. 50,51 
La detección de las necesidades y comportamiento informativo...

Con base en estos argumentos, es preciso subrayar que la presente investigación tiene como objetivo principal:

- Identificar las necesidades de información y comportamiento informativo que han tenido los investigadores matemáticos en México, para llevar a cabo sus trabajos de investigación, a través del análisis de sus referencias que son presentadas en éstos.

Así como objetivo específico:

- Confrontar los resultados de esta investigación, con los datos obtenidos anteriormente al estudiar a esta comunidad, con la intención de determinar las características distintivas que se encuentran comúnmente en sus necesidades de información y comportamiento informativo.

Tomando en consideración que los investigadores matemáticos utilizan la información para el desarrollo de sus investigaciones, y que de ésta depende el éxito o fracaso para la conclusión de sus proyectos, se formulan las siguientes hipótesis:

- Debido a la profundidad, temática o avances que se están desarrollando en su línea de 
Investigaciones sobre las necesidades de información,...

investigación, el matemático requiere para el desarrollo de sus proyectos, información en otros idiomas.

- Por ser una disciplina del conocimiento tan antigua, en donde se han desarrollado postulados que siguen vigentes, los matemáticos hacen uso de la información actual y retrospectiva.

- Las estrategias que emplean los investigadores en matemáticas se orientan por su biografía académica desarrollada (nivel de estudios, edad, antigüedad laboral, etcétera.) y encuentran en las publicaciones periódicas la fuente prioritaria.

- Debido a la aparición y desarrollo continuo de la publicación electrónica científica, el investigador matemático utiliza, cada vez más, el formato electrónico.

Para dar solución al objetivo general de la investigación y a la validación de las hipótesis establecidas, la presente investigación ha desarrollado una metodología que se a considerado adecuada al objeto de estudio que se pretende abordar, y en la cual, se precisan igualmente la población a analizar, la técnica y el instrumento correspondiente, para obtener así, las respuestas que contribuyan a la solución del problema planteado. 
La detección de las necesidades y comportamiento informativo...

\section{Población}

La población total que será objeto de estudio para la investigación comprende a 110 sujetos que se encuentran adscritos a las tres sedes (C.U., Morelia y Cuernavaca) del Instituto de Matemáticas de la UNAM; por el número no tan amplio de investigadores se ha decidido contemplarlos a todos dentro del estudio, y para esto, como se indicará en el apartado correspondiente a la metodología, se han ideado la técnica y el instrumento adecuado para recuperar la información sobre esta población. Ahora bien, dentro de las características esenciales que van a distinguir a nuestra población objeto de estudio se decidieron las siguientes:

1. Investigadores de tiempo completo

2. Poseer el grado académico de nivel maestría y/o doctorado

3. Que estén ejerciendo actualmente sus actividades profesionales

4. Con género indistinto

5. Con nacionalidad indistinta

\section{Muestra}

Como ya se indicó, no se tomará una muestra de la población de investigadores, sino que se ha decidido abordar a la población en su conjunto de acuerdo a las características que se han señalado, debido a que 
Investigaciones sobre las necesidades de información,...

se pretende obtener el mayor número de respuestas posibles, y con esto fortalecer la información que se desea recuperar para fines de la investigación.

\section{Metodología}

Para su realización, se decidió el siguiente procedimiento:

1. Tomando en consideración que nuestro objeto de estudio son los investigadores, se procederá a identificar el número total de ellos de acuerdo a las características establecidas.

2. A partir del reconocimiento de la población total, se solicitará a la unidad académica de las dependencias los expedientes de cada uno de los investigadores para conocer su producción literaria. Lo anterior se facilitará debido a que en este momento me encuentro laborando en la biblioteca ubicada en C.U. que depende del Instituto de Matemáticas.

3. Una vez identificada la producción literaria de cada investigador se tratará de recuperar a través de diversos medios una copia del documento que fue elaborado por él, recurriendo para ello, al propio investigador para solicitarle el documento o bien tratarlo de localizarlo en formato electrónico en alguna base de datos especializada (MathSciNet, 
La detección de las necesidades y comportamiento informativo...

Zentralblatt MATH o JSTOR) o en la propia WEB.

4. De las copias que se obtengan de cada uno de sus artículos se examinarán las referencias utilizando el método denominado análisis de referencias. Debido a que permite conocer de forma eficaz el comportamiento de comunidades científicas en el uso de la información, la tipología de documentos que utilizan, la actualidad de los documentos, entre otros, datos. ${ }^{9}$

5. Por consiguiente, la técnica a utilizar se desarrollará en función de la revisión de los datos de cada referencia que se analicen en los trabajos publicados por el investigador.

6. Finalmente, los datos obtenidos serán capturados en un hoja de registro (Instrumento) diseñada para tal fin, en la que se mencione las siguientes características: tipo de fuente que empleo (libro, revista, etcétera), idioma del documento, formato del documento (impreso o electrónico) y actualidad del documento.

Cabe aclarar que esta primera aproximación, estará sujeta a cambios o adaptaciones que irán surgiendo

9 Elías Sánz Casado. Ibídem., p. 105 
Investigaciones sobre las necesidades de información,...

y trabajándose con el desarrollo de la investigación, con la única intención de obtener datos más profundos que nos lleven al conocimiento de las necesidades y comportamiento informativo que se encuentra dentro de la comunidad científica de los matemáticos.

\section{Bibliografía}

Brown, Cecelia. "Information seeking behavior of scientists in the electronic information age: astronomers, chemists, mathematicians, and physicist." Journal of the American Society for Information Sciences. Vol. 59, no. 10, 1999. pp. 929-943

Calva González, Juan José. Las necesidades de información de los investigadores del área de bumanidades y ciencias sociales, y del área científica. Informe de investigación. $2^{a}$ revisión. México: UNAM, CUIB, 1997. p.

Calva González, Juan José. Las necesidades de información: fundamentos teóricos y métodos. México: UNAM, Centro Universitario de Investigaciones Bibliotecológicas, 2004. 272 p.

Figueiredo, Nice Menezes de. Estudos de uso e usuarios da informacao. Brasilia, DF: IBICT, 1994. 154 p. 
La detección de las necesidades y comportamiento informativo...

Gutiérrez Pantoja, Gabriel. Metodología de las ciencias sociales. México: Harla, 1984. 250 p.

Hernández Salazar, Patricia. "La producción del conocimiento científico como base para determinar perfiles de usuarios." Investigación Bibliotecológica: Archivonomía, Bibliotecología e Información. Vol. 1, no.30, enero-junio, 2001. pp. 29-64

Kirsch Schaefer, Barbara. Using the mathematical literature: a practical guide. New York: Marcel Dekker, 1979. p. 29

Prieto Rodríguez, Sotero. Historia de las matemáticas. Toluca, Estado de México: Instituto Mexiquense de Cultura, 1991. 145 p.

Sánz Casado, Elías. Manual de estudios de usuarios. Madrid: Fundación Germán Sánchez Ruipérez; Pirámide, 1994. 275 p.

Using the mathematics literature. Fowler, Kristine K. (ed). New York: Marcel Dekker, 2004. p. 381

Vigeannel-Larive, Odile. "La bibliotheque, laboratoire du mathématicien." Bulletin des Bibliotheques de France. Vol. 47, no. 6, 2002. pp. 50-54 



\title{
Comportamiento informativo de los usuarios de los sistemas de información geográfica: un piloteo
}

\author{
ANTONia SANTOS RoSAS \\ Colegio de Bibliotecología \\ Universidad Nacional Autónoma de México
}

\section{Introducción}

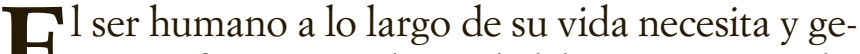

Enera información, la cual debe ser procesada, almacenada y difundida para que pueda ser usada por otras personas.

Esta actividad humana de conservar, organizar y acceder a la información generada, lo ha llevado a establecer diversas unidades de información que respondan a ella, así como generar sistemas de información utilizando las tecnologías de la información y la comunicación.

Los Sistemas de Información Geográfica o SIG, son utilizados además de los geógrafos por otros usuarios que

en los últimos años el número de usuarios, tanto en el sector público como en el privado, se han visto beneficiados con las facilidades y ventajas que proporciona el uso de un SIG. Tales organizaciones que han sido las receptoras de sus ventajas están relacionadas con 
Investigaciones sobre las necesidades de información,...

la prestación de servicios, trabajos de agricultura, minería, geología, arqueología, conservación de recursos naturales, impacto y protección ambiental, climatología, cartografía, procesamiento digital de imágenes, fotointerpretación y fotogrametría, ingeniería civil, catastro, planificación del uso de suelo, planeación urbana y regional, manejo de redes de energía eléctrica, estudios de mercado entre otros ${ }^{1}$

Los SIG persiguen la recuperación de información por parte de los usuarios que los utilizan ya que estos le permiten ver a detalle las características del terreno por lo que el diseño de los SIG permite la recopilación, organización, almacenamiento y consulta de información en diferente presentación como estadísticas, fotos, mapas, planos, texto, etcétera.

Por lo antes expuesto se puede observar que esta herramienta es ampliamente usada por profesionales de diferentes disciplinas, por lo que es importante analizar la recuperación de la información que alcanzan los usuarios de los SIG en términos de llevar a cabo el análisis espacial y de contenido de dichos Sistemas de Información Geográfica con la finalidad de aumentar su eficacia en el almacenamiento,

1 Dargermond citado por Laura Luna González. Los sistemas de información geográfica: una alternativa para el análisis socioespacial de los accidentes de transito en carretera. Propuesta metodológica. México: LLG, 1997. Tesis Maestría en Geografía, p. 40 
Comportamiento informativo de los usuarios...

organización y acceso a la información que contienen.

Lo anterior también permitirá la determinación de las variables que intervienen en dicha recuperación de la información desde un aspecto teórico y llevándolo a la prueba en comunidades de usuarios específicas que son las que precisamente utilizan los SIG. Asimismo, los resultados pueden servir de base a los profesionales que mantienen o desarrollan algún SIG.

Por lo anterior expuesto, el problema de esta investigación y de este piloteo plantea las siguientes interrogantes:

- ¿Cuáles son las variables que conforman el comportamiento informativo en los Sistemas de Información Geográfica?

- ¿Cuáles son las variables que intervienen en el comportamiento informativo de los usuarios de diferentes comunidades al utilizar los Sistemas de Información Geográfica?

- ¿Existe una relación en el comportamiento informativo de las diversas comunidades de usuarios que utilizan diferentes Sistemas de Información Geográfica?

Como objetivo de este piloteo se tienen los siguientes: 
Investigaciones sobre las necesidades de información,...

- Conocer el comportamiento informativo de los usuarios que utilizan los Sistemas de Información Geográfica.

- Identificar las diferentes comunidades que utilizan los Sistemas de Información Geográfica.

- Determinar el perfil de los usuarios que usan los diversos Sistemas de Información Geográfica.

Como supuesto para este piloteo se tiene que las variables que intervienen en el comportamiento informativo de los usuarios de diversos Sistemas de Información Geográfica permitirán explicar la recuperación de la información de los diferentes tipos de usuarios.

Si lo anterior se da, entonces, las variables que intervienen en el comportamiento informativo de los profesionales de las diferentes disciplinas, como usuarios de los SIG, permitirán analizar y establecer diferentes relaciones espaciales (geográficas) con los fenómenos de estudio de cada Sistema de Información Geográfica de manera pronta y oportuna y así poder predecir diferentes fenómenos físicos lo cual les permitirá tomar decisiones.

Las variables que se van investigar y que intervienen e influencian en algún grado o nivel en el comportamiento informativo del usuario de los SIG son: actitud del individuo en el uso del sistema, habilidad 
Comportamiento informativo de los usuarios...

para usarlo, experiencia en el uso de tecnologías, el idioma en el cual se encuentra la información contenida en el SIG, el lenguaje o jerga que usa el sistema.

\section{Metodología}

Para llevar a cabo este piloteo se determinó como:

1.- Unidad de análisis:

a) Variables que intervienen en el proceso de la recuperación de la información.

b) Sistemas de Información Geográfica en México.

c) Usuarios de los Sistemas de Información Geográfica en México.

La investigación es de carácter teórico en la parte concerniente a la discusión de las variables que intervienen en el proceso de la recuperación de la información y es una investigación de tipo exploratoria-descriptiva, en lo concerniente a verificar si dichas variables corresponden a explicar la recuperación de la información que tienen los diversos usuarios de los Sistemas de Información Geográfica.

\section{Método}

Para llevar a cabo esta investigación se realizó una investigación documental y una investigación de 
Investigaciones sobre las necesidades de información,...

campo con usuarios que utilizan los SIG para comprobar las variables propuestas que intervienen en dicho proceso.

\section{Técnica}

Se realizó el análisis y contratación de las variables teóricas que intervienen en el proceso de la recuperación de la información a partir de la literatura encontrada sobre este tópico.

\section{Instrumento}

Para la parte concerniente a la verificación de las variables, para explicar el proceso de la recuperación de la información de los usuarios de los SIG se utilizó como instrumento un cuestionario aplicado de forma personal.

\section{Comportamiento en la búsqueda de información}

Son varias las causas que influyen en el individuo para lograr la recuperación de información de manera satisfactoria tales como; el desconocimiento del manejo del sistema, el escaso uso de los SIG, la poca experiencia en el uso de los sistemas de información, el lenguaje de recuperación de la información que utilizan, el idioma en que se encuentra el sistema, entre otros aspectos que pueden generar algún comportamiento en el usuario al no obtener los resultados esperados del sistema. 
Comportamiento informativo de los usuarios...

Respecto al uso del lenguaje, Frank y $\mathrm{Mark}^{2}$ mencionan el uso de dos lenguajes, el lenguaje natural y el lenguaje formal que en un SIG puede traer varios problemas en la recuperación de la información de un usuario. Si se usa lenguaje natural o coloquial, el programa puede recuperar información en forma ambigua, por otro lado si el usuario usa lenguaje formal o técnico tiene que forzar la lectura al lenguaje que usa. Este potencial limita las habilidades de los usuarios para interactuar dentro del Sistema de Información Geográfica.

Asimismo, la recuperación de la información depende de los conocimientos previos que se tengan sobre el asunto en cuestión y del comportamiento que el individuo presente al enfrentarse a utilizar un SIG para satisfacer dicha necesidad de información.

Gluck menciona que,

es posible que un sistema proporcione perfecta precisión y recopilación, pero este no permita la recuperación de la información y que para entender el sistema hay que usarlo varias veces. Esto puede ocurrir por

2 A.U. Frank and Mark D.M. Languaje issues for GIS. (DE, 15 de agosto 2009: http://www.wiley.com/legacy/wileychi/gis/vol.1// BB1v1.ch//pdf) 
Investigaciones sobre las necesidades de información,...

varias razones: ${ }^{3}$

- El usuario no es claro con la necesidad de información que tiene.

- El usuario es incapaz de interpretar y analizar los documentos recuperados.

- El usuario desconoce la recuperación.

- El sistema no tiene toda la información que necesita.

- La información buscada no existe en el sistema.

- Los datos del sistema son organizados arbitrariamente y relativamente satisfacen las necesidades de los usuarios.

Estas variables que menciona Gluck, influyen en el comportamiento informativo, ya que la experiencia del usuario respecto al sistema, el que se desconozcan los términos empleados para la recuperación de la información, el que el usuario desconozca como interpretar y analizar la información, puede repercutir en el usuario regrese a la forma tradicional.

Otra variable del comportamiento informativo que influye en la recuperación de la información en

3 M. Gluck. Geospatial information needs of the general public: text, map and users tasks. (3 de agosto, 2009: http://www.ideal. illinois.edu/bitstream/handle/2142/408/Gluck.pdf? sequence=2) 
Comportamiento informativo de los usuarios...

los sistemas de información son estudiados por autores como Nilan et al. (1989), él indica

que la satisfacción de los usuarios frecuentemente depende de su habilidad para plantear preguntas al sistema que satisfagan su necesidad, usando un sistema orientado con un lenguaje apropiado o jerga. ${ }^{4}$

Sobre este mismo asunto Sheneiderman indica que,

los usuarios que emplean la jerga del sistema pueden ayudarse más a planear su pregunta a diferencia de los usuarios que no emplean la jerga del sistema. ${ }^{5}$

Por lo anterior, se puede considerar que, el lenguaje o jerga usado por los usuarios que utilizan el sistema es importante que lo conozcan quienes alimentan el sistema de información, ya que el usuario al buscar información, realiza su búsqueda con la terminología usada cotidianamente según su disciplina, asimismo, se debe considerar su normalización para evitar dispersión de conceptos y la obtención de la información sea lo más precisa posible.

4 Op cit.

5 Op.cit. 
Investigaciones sobre las necesidades de información,...

Del comportamiento informativo que presente el usuario ante el uso del sistema dependerá de que la obtención de la información sea satisfactoria, por lo que al respecto, Gluck indica que la satisfacción de la información puede ser descrita con tres diferentes perspectivas: evaluación global del sistema, satisfacción del usuario con la información requerida y si la información obtenida cubre las expectativas de los usuarios. ${ }^{6}$

Entonces, el investigar sobre las variables que interviene en el comportamiento informativo aporta fundamentos teóricos que pueden explicar el proceso de recuperación de la información de los usuarios de los SIG.

\section{Sistemas de Información Geográfica}

Los SIG, son un conjunto de herramientas de cómputo que facilitan el análisis espacial con la capacidad de establecer relaciones espaciales entre diferentes objetos o fenómenos, al ligar datos espaciales con información geográfica"

En cuanto al contenido:

El tipo de datos que pueden ser capturados y transformados para manejarse dentro de un SIG es muy amplio,

6 M. Gluck, Op. Cit., ref. 3

7 Understanding GIS. The ARC/INFO method. Environmental Systems Research Institute. United States of America. 1992. pp. 1-30 
Comportamiento informativo de los usuarios...

comprende mapas y cartas impresas, información digital existente, información de campo e información obtenida a partir de teledetección, sensores remotos tales como fotografías aéreas, imágenes de satélite, imágenes de radar, registro de coordenadas a partir de sistemas de posicionamiento. ${ }^{8}$

Chuvieco define a los SIG,

como bases informatizadas de datos en algún tipo de componente espacial. Esto significa que la información que almacenan esta referenciada geográficamente, ya sea que se trate de mapas, estadísticas o datos climáticos, sobre un territorio concreto, por lo que todas estas variables pueden relacionarse mutuamente de formas muy diversas. ${ }^{9}$

De acuerdo con diferentes autores como Aronoff $^{10}$, Burrough ${ }^{11}$, Maguire ${ }^{12}$, un SIG debe ser capaz

8 Laura Luna González. Op. Cit., ref. 1, p.34

9 Emilio Chuvieco. Fundamentos de teledetección espacial. Madrid. Ediciones Rialp, 1990. p. 397.

10 S. Aronoff. Geographic information systems. A management perspective. Otawa, WDL Publications, 1991. 294 p.

11 P. Burrough. Principles of geographical information systems form land resources assessment. Oxford University Press, 1990. 194 p.

12 D.L. Maguire. An overview and definition of GIS. Geographical information systems. Principles and application. V. 1. New York, John Willey \& Son, 1991 p.9-20. 
Investigaciones sobre las necesidades de información,...

de responder a ciertas preguntas referente al fenómeno estudiado, tales como:

- Localización. ¿Qué esta en...?, es decir que clase de objetos o hechos están, o suceden en el territorio que se analiza.

- Condición. ¿Dónde está...?, este principio permite determinar las porciones de territorio que cumplen con una condición específica.

- Tendencia. ¿Cuánto ha cambiado desde...? se se refiere al tipo de análisis que se puede hacer a partir de un seguimiento a través del tiempo.

- Definición de ruta. ¿Cuál es el mejor camino a...? este nivel corresponde a la aplicación de una serie de funciones que están relacionado con el análisis de redes dentro de un SIG.

- Patrones. ¿Qué patrones espaciales existen...? este nivel permite describir el patrón o arreglo espacial de objetos y hechos, es decir distribución espacial, a partir de esto entender cuales son los procesos que la condicionan.

- Escenarios. ¿Qué sucede si...?, es el nivel de análisis a partir de la integración de una serie de funciones, para llegar al objetivo de realizar la aplicación de un modelo.

Los SIG se desarrollaron en los años 60 como respuesta a las crecientes necesidades de información sobre 
Comportamiento informativo de los usuarios...

el territorio. Canadá resultó pionero en el nacimiento de estos programas, si bien se extendieron rápidamente a su vecino del sur y a otros países anglosajones. El creciente interés por la planificación medio ambiental permite que los SIG se consoliden en la década de los 70. En estos años aparecen los primeros planes de estudio universitarios sobre esta tecnología, así como algunas empresas dedicadas a su desarrollo y explotación, mientras crece el interés de agencias oficiales en sus distintas aplicaciones. ${ }^{13}$

Esta tecnología en México se está aplicando ampliamente en instituciones públicas y privadas como es el caso del Instituto Nacional de Estadística, Geografía e Informática. INEGI; Instituto Nacional Indigenista. INE; Secretaría de Comunicaciones y Transportes. SCT; Instituto Mexicano del Transporte. IMT; Comisión Nacional de Áreas Naturales Protegidas. CONANP; entre otros.

A continuación se mencionan algunos ejemplos de SIG que se han desarrollado en México:

- UNIGEO. Unidad de Información Geospacial desarrollado en el Instituto de Geografía dentro de la UNAM. Este sistema se desarrollo para dar acceso al acervo cartográfico de

13 Emilio Chuvieco. Op. Cit., ref. 9, p. 399 
Investigaciones sobre las necesidades de información,...

colecciones nacionales e internacionales, que albergan las diferentes dependencias de la UNAM. $^{14}$

- GEOINFORMACIÓN. Es una sección de consulta y disposición de cartografía temática e imágenes de satélite, de uso interno de la Comisión Nación Nacional de la Biodiversidad (CONABIO). ${ }^{15}$

- CONANP. Comisión Nacional de Áreas Naturales Protegidas. Contiene cartografía de las diferentes áreas protegidas de México. ${ }^{16}$

- OEGT. Insumos para el Ordenamiento Ecológico General. Este sistema reúne las bases de datos del Instituto Nacional de Ecología (INE), y se pone a disposición de los responsables e interesados en la planeación territorial para apoyar su tarea. La información está organizada en cinco temas: medio físico, medio biótico, medio social, medio económico y estudios regionales. ${ }^{17}$

Estos son sólo algunos ejemplos de SIG, ya que existe una gran variedad de estos sistemas enfocados a diferentes temas de estudio.

14 http://www.unigeo.igeograf.unam.mx.

15 http://www.conabio.gob.mx/información/geo_español/

$16 \mathrm{http}: / /$ www.conanp.gob.mx/sig

17 http://www.ine.gob.mx/index.html 
Comportamiento informativo de los usuarios...

\section{Comportamiento de los usuarios de los Siste- mas de Información Geográfica}

Para conocer el comportamiento informativo de los usuarios de los Sistemas de Información Geográfica se aplicó como instrumento un cuestionario a 16 alumnos de un total de 25 inscritos en el "v Diplomado de Geomática" impartido en el Instituto de Geografía de la Universidad Nacional Autónoma de México.

Los alumnos que no contestaron el cuestionario es porque no asistieron a clase el día en que aplicó, por lo que la muestra quedó integrada por el $64 \%$ de la población, lo cual la hace representativa.

Se tomó como muestra esta comunidad de usuarios debido a que pertenecen a diversas instituciones.

Asimismo, es importante mencionar que el conocimiento respecto al uso de los SIG es diferente en cada alumno debido al grado de experiencia en el uso del sistema.

El cuestionario constó de 7 preguntas, abiertas y cerradas. (Ver anexo 1)

\section{Análisis de resultados}

A continuación se presenta el análisis de los resultados. 
Investigaciones sobre las necesidades de información,...

Cuadro no. 1

\begin{tabular}{|l|c|}
\hline \multicolumn{1}{|c|}{ Institución a la que pertenece } & \\
\hline$\cdot$ Instituto de Geografía. UNAM & 6 \\
\hline$\cdot$ UNAM & 1 \\
\hline$\cdot$ Universidad Autónoma de Puebla & 1 \\
\hline$\cdot$ Universidad Autónoma de Chapingo & 1 \\
\hline$\cdot$ Comisión de Recursos Naturales del Distrito Federal & 1 \\
\hline$\cdot$ Instituto Nacional de Ecología & 1 \\
\hline$\cdot$ Instituto Nacional de Estadística y Geografía & 2 \\
\hline$\cdot$ Instituto Mexicano de Tecnología del Agua & 1 \\
\hline$\cdot$ Facultad de Ingeniería. UNAM & 1 \\
\hline$\cdot$ No Indicó & 1 \\
\hline \multicolumn{1}{|c|}{ Total } & 16 \\
\hline
\end{tabular}

En el cuadro no. 1 se observa que 6 individuos que dan un porcentaje de $37.5 \%$, pertenecen al Instituto de Geografía, 2 individuos que dan un porcentaje $12.5 \%$, pertenecen al Instituto Nacional de Geografía e Informática, y 8 individuos que pertenecen a instituciones diferentes dan un porcentaje de $50 \%$.

Por lo anterior, se puede decir que los usuarios de los SIG cubren diferentes temas, por lo que el espacio geográfico se puede estudiar desde diferentes enfoques.

Cuadro no. 2

Grado de estudios obtenidos

\begin{tabular}{|c|c|c|c|c|}
\hline Licenciatura & Maestría & Doctorado & 0tros & Total \\
\hline 10 & 6 & 0 & 0 & 16 \\
\hline
\end{tabular}


Comportamiento informativo de los usuarios...

El cuadro no. 2 muestra que 10 individuos que dan un porcentaje de $62.5 \%$ tienen el grado de licenciatura, 6 individuos que dan un porcentaje de $37.5 \%$ tienen el grado de maestría.

Este cuadro muestra que los usuarios de nivel licenciatura y maestría utilizan con mayor frecuencia los SIG, lo cual es de esperarse ya que en instituciones de investigación como en el caso de la UNAM, los Técnicos Académicos en su mayoría apoyan los proyectos de investigación de los investigadores titulares y por lo tanto son ellos quienes principalmente manipulan estos sistemas.

Cuadro no. 3

Tiene experiencia en Sistemas de Información Geográfica

\begin{tabular}{|c|c|c|}
\hline $\mathbf{S i}$ & No & Total \\
\hline 10 & 6 & 16 \\
\hline
\end{tabular}

En el cuadro no. 3 se observa que 10 individuos que dan un porcentaje de $62.5 \%$, si tiene experiencia, 6 individuos que dan un porcentaje de $37.5 \%$, no tiene experiencia.

Los individuos que contestaron que sí tienen experiencia, esta varía desde el que tiene 6 meses hasta el que tiene 12 años, como se observa en el cuadro no. 4. 
Investigaciones sobre las necesidades de información,...

Cuadro no. 4

Tiempo que llevan utilizando el SIG

\begin{tabular}{|l|c|}
\hline \multicolumn{1}{|c|}{ Tiempo } & Frecuencia \\
\hline$\cdot 6$ meses & 1 \\
\hline$\cdot 2$ años & 2 \\
\hline$\cdot 3$ años & 2 \\
\hline$\cdot 4$ años & 1 \\
\hline$\cdot$ Más de 5 años & 2 \\
\hline$\cdot 6$ años & 1 \\
\hline$\cdot 10$ años & 1 \\
\hline$\cdot 12$ años & 1 \\
\hline
\end{tabular}

Cuadro no. 5

\begin{tabular}{|l|}
\hline \multicolumn{1}{|c|}{ Dificultades le encuentra al sistema a simple vista } \\
\hline $\begin{array}{l}\text { - Como todo software, el no conocer bien el ambiente y por lo tanto no saber que } \\
\text { hacer en el momento exacto. }\end{array}$ \\
\hline - Dificultades con el uso de los diferentes programas de SIG (Arview, Ar-GIS, etc.) \\
\hline - Cuando no se conocen con anterioridad los conceptos básico es importante, ya que \\
es mucha información, por lo que si no se comprenden estos es más complicado \\
utilizarlos. \\
\hline$\cdot$ Introducción de datos, datum \\
\hline$\cdot$ Ninguna \\
\hline
\end{tabular}

El cuadro no. 5 muestra las dificultades que se encuentran en el sistema cuando no se tiene experiencia y como se puede observar son las comunes que se presentan en los programas de computo, como por ejemplo, desconocimiento del software y por lo mismo dificultades para manipular los programas y por lo tanto, en la inducción de datos.

Por lo anterior, para que el usuario perfeccione este tipo de herramientas se necesita de la práctica 
constante de quienes los utilizan, ya que los elementos en un sistema están presentes, lo importante es saber obtenerlos satisfactoriamente, lo cual se adquiere con la práctica constante del sistema.

\section{Cuadro no. 6}

Las bases conceptuales del SIG, repercute en al análisis e interpretación de datos

\begin{tabular}{|c|c|c|}
\hline Si & No & Total \\
\hline 16 & 0 & 16 \\
\hline
\end{tabular}

El cuadro no. 6 muestra que del total de la población encuestada, contestaron que las bases conceptuales del SIG, sí repercuten en el análisis e interpretación de resultados.

Algunas razones que se consideran en como repercute el desconocimiento de las bases conceptuales se muestran en el cuadro no. 7.

\section{Cuadro no 7}

Porque sí repercuten en el uso del SIG las bases conceptuales

\begin{tabular}{|l|}
\hline $\begin{array}{l}\text { - Porque debido a ellos permiten analizar de manera más satisfactoria el estado ac- } \\
\text { tual. }\end{array}$ \\
\hline - Porque es una herramienta que facilita el trabajo. \\
\hline - Son bases fundamentales para el usuario. \\
\hline - Porque nos ayuda a saber que es lo que debe representar adecuadamente el SIG en \\
todos sus atributos. \\
\hline - Porque se consideran las limitaciones o características de los procesos que influ- \\
yen en los resultados. \\
\hline - Si uno entiende los conceptos facilita la interpretación de los datos. \\
\hline - Para la toma de decisiones. \\
\hline
\end{tabular}


Investigaciones sobre las necesidades de información,...

\begin{tabular}{|l|}
\hline - Porque hay que tener en cuenta escala, proyección, etc. \\
\hline - Porque si no se tienen los conocimientos básicos es difícil obtener resultados. \\
\hline - Porque es necesario conocer los conceptos para hacer análisis espacial en un SIG. \\
\hline - Nos permite hacer un análisis mas detallado y optimo de la información. \\
\hline - Porque me ocurrió al principio que no sabía a que se referían cuando me solicitaban \\
cierto trabajo. \\
\hline - Al no conocer conceptos como referenciación, proyección, etc, los resultados pre- \\
sentan errores. \\
\hline - En la forma de estructural la información esta la forma de analizarla. \\
\hline - Porque se requiere de la base conceptual para poder explorar a lo máximo el siste- \\
ma sabiendo lo que se está haciendo, porque y para qué. \\
\hline - Sin elementos básicos no hay manera de entender. \\
\hline
\end{tabular}

Del cuadro no. 7 se puede concluir que es necesario que los usuarios conozcan los conceptos básicos del sistema tales como referenciación, proyección, escala, datum, atributos, entre otros, ya que estos facilita la interpretación de los datos de lo contrario, no se entiende el sistema ni como manipular los datos, y como consecuencia es difícil obtener resultados.

Entonces las bases conceptuales permiten al usuario explorar al máximo el sistema, sabiendo lo que se está haciendo al introducir adecuadamente los datos, obtener resultados esperados, analizarlos e interpretarlos para la adecuada toma de decisiones. 


\section{Comportamiento informativo de los usuarios...}

\section{Cuadro no. 8}

Repercusión de la amigabilidad del sistema, en el regreso a la forma tradicional, para analizar los datos

\begin{tabular}{|c|}
\hline $\begin{array}{l}\text { - No al contrario es más fácil de enriquecer el sistema y lo cual permite realizar las } \\
\text { consultas eficiente, construir puntos, líneas polígonos, y de utilizar más fácilmente } \\
\text { y rápida la información. }\end{array}$ \\
\hline$\cdot$ No \\
\hline$\cdot$ No \\
\hline$\cdot$ No \\
\hline \begin{tabular}{|l} 
- No, por que se debe dar un proceso continuo de autoaprendizaje, y regresar solo \\
sería en el caso de que no existieran opciones para algunos procesos o que el \\
tiempo para el autoaprendizaje fuera mucho más largo que el método tradicional.
\end{tabular} \\
\hline - No, en general nos facilita el manejo de datos \\
\hline$\cdot$ No \\
\hline $\begin{array}{l}\text { - Claro, además de saber como se hacen los procesos que uno ya conoce en las } \\
\text { extensiones de ArcView. }\end{array}$ \\
\hline$\cdot$ No \\
\hline$\cdot$ No \\
\hline - Un sistema amigable no da confianza y rapidez de la información que analizamos. \\
\hline $\begin{array}{l}\text { - Siempre es bueno conocer la forma tradicional, aunque siempre hay nuevas herra- } \\
\text { mientas que facilitan el trabajo. }\end{array}$ \\
\hline $\begin{array}{l}\text { - Si al volver después de un tiempo los archivos pueden estar revueltos e incluso otro } \\
\text { usuario puede no conocer la distribución y utilización. }\end{array}$ \\
\hline$\cdot \mathrm{Si}$ \\
\hline $\begin{array}{l}\text { - Que un sistema sea claro es importante, pero ya no se puede dar marcha atrás, hay } \\
\text { que emplear las nuevas tecnologías. }\end{array}$ \\
\hline$\cdot \mathrm{Si}$ \\
\hline
\end{tabular}

En el cuadro no. 8 se observa que 2 individuos que dan un porcentaje de $12.5 \%$ contestaron, que si el sistema no es amigable repercute en que regresen a la forma tradicional y 14 individuos que dan un porcentaje de $87.5 \%$ contestaron, que no regresarían a la forma tradicional, ya que esto implicaría 
Investigaciones sobre las necesidades de información,...

dar marcha atrás ante el reto de las nuevas tecnologías, lo que se debe hacer es enriquecer las tecnologías de acuerdo a las necesidades de los usuarios. Por otro lado los SIG permiten guardar la información en archivos y en un sistema tradicional se corre el riesgo de que la información se traspapele o se desordene.

Del cuadro no. 8 se puede concluir que siempre es bueno conocer la forma tradicional de elaborar mapas con todo y sus atributos, pero si ya existen las tecnologías que facilitan el trabajo se deben conocer, lo cual implica hacer estudios de usuarios de los SIG, para ir enriqueciendo el sistema, hacerlo más fácil, eficiente y sea rápida la obtención de la información.

Cuadro no. 9

El lenguaje o jerga que usa el sistema,

es un obstáculo para su aprendizaje

\begin{tabular}{|c|c|c|}
\hline Si & No & Total \\
\hline 4 & 12 & 16 \\
\hline
\end{tabular}

En el cuadro no. 9 se observa que 4 individuos que dan un porcentaje del $25 \%$ de la población, mencionan que el lenguaje o jerga que utiliza el SIG, si presenta un obstáculo para su aprendizaje. 
Comportamiento informativo de los usuarios...

Cuadro no. 10

Causas de por qué el lenguaje es obstáculo para su uso

\begin{tabular}{|l|}
\hline - El vocabulario o términos son difíciles o no se esta acostumbrado \\
\hline - Por que a veces no quedan claros algunos conceptos, lo que limita la comprensión \\
de los procesos \\
\hline - No todos los usuarios dominamos bases de datos, o todos los modelos del ArcView, \\
lo que limita conocer todo el lenguaje \\
\hline - No es fácil conceptuar las nuevas herramientas
\end{tabular}

Lo que se concluye con estos resultados es que el lenguaje o jerga no es el adecuado al usuario, por lo es importante conocer la jerga que usa el usuario y adaptarla al SIG, lo que también ayudaría a normalizar los términos usados en los SIG.

Asimismo en el cuadro no. 9 se observa que 12 individuos que dan un porcentaje del $75 \%$ de la población, mencionan que el lenguaje o jerga no es un obstáculo para su aprendizaje, las razones que se mencionan se observan en el cuadro no. 11.

\section{Cuadro no. 11}

Causas de por qué el lenguaje no es obstáculo para su uso

\begin{tabular}{|l|}
\hline$\cdot$ Por que solo es una base más para interpretar datos en este caso espaciales. \\
\hline - Con el uso para aplicación de teoría se va adquiriendo el manejo del sistema. \\
\hline - No, puesto que el lenguaje es enfocado a las necesidades técnico-científicas que \\
abordan el análisis espacial al que se hace referencia. \\
\hline - Con el uso del sistema se familiariza uno con los términos. \\
\hline - Es parte de lo que se tiene que aprender. \\
\hline - Por que los términos son muy usados en la geografía y sistemas de computadora. \\
\hline - Cuando la dominas no tienes mayor problema. \\
\hline - El lenguaje es sencillo en relación a los diversos tipos. \\
\hline
\end{tabular}


Investigaciones sobre las necesidades de información,...

\begin{tabular}{|l|}
\hline$\cdot$ Como toda rama del conocimiento requiere de su apropiación del lenguaje. \\
\hline - Por eso es importante la base conceptual. \\
\hline - Vocabulario, cultura general. \\
\hline
\end{tabular}

Del cuadro no. 11 se puede concluir que los SIG están enfocados para cubrir las necesidades técnicocientíficas para realizar análisis espaciales, por lo que para el uso del sistema no se requiere conocer el lenguaje o jerga, usado por quienes utilizan el sistema.

Cuadro no. 12

El idioma es un obstáculo para su aprendizaje

\begin{tabular}{|c|c|c|c|}
\hline Si & No & No contesto & Total \\
\hline 2 & 13 & 1 & 16 \\
\hline
\end{tabular}

Cuadro no. 13

Razones por las cuales el idioma es obstáculo

\begin{tabular}{|l|}
\hline - Por el idioma. \\
\hline - Siempre implica una actualización permanente del idioma. \\
\hline
\end{tabular}

Cuadro no. 14

Razones por las cuales el idioma no es obstáculo

\begin{tabular}{|l|}
\hline - La mayoría de estos sistemas se encuentran en el idioma universal \\
\hline $\begin{array}{l}\text { - Por que es la parte de la globalización tecnológica que conlleva al desarrollo del } \\
\text { planeta }\end{array}$ \\
\hline - Es un obstáculo saludable, al nivel de dominio del idioma inglés que manejo \\
\hline - Los usuarios en general traducimos inglés a lo "menso" \\
\hline - Por lo general en inglés técnico \\
\hline - Es obligado el inglés, conocer su significado \\
\hline
\end{tabular}


Comportamiento informativo de los usuarios...

- Por que es importante el significado conceptual, más que las palabras

- Por que la mayoría del software utilizado esta en inglés, si existieran programas en español sería confuso por la costumbre de usarlos en inglés

- Cuando tenemos realmente interés de aprender algo, no existen obstáculos

- El idioma que se maneja es muy sencillo

- No tengo problemas con el inglés

- Sabiendo el significado y explorando podemos aprender aunque requiera más esfuerzo

- El Lenguaje técnico y científico es el inglés

En el cuadro no. 12 se observa que 2 sujetos que dan un porcentaje de $12.5 \%$, encuentran en el idioma un obstáculo para su aprendizaje, 13 sujetos que dan un porcentaje de $81.25 \%$, no tienen problema con el idioma inglés que es el que usa el sistema y un sujeto que da un porcentaje de $6.25 \%$ no contestó.

De los cuadros 12,13 y 14 se puede concluir que el idioma en que se encuentran los SIG es el inglés del cual en su gran mayoría no es problema además de que el inglés es idioma universal, sin embargo para los sujetos que sí tienen problema con el idioma es necesario actualizarse ya que se debe tener presente que estos programas están diseñados para realizar actividades técnico-científico, lo cual demanda del usuario cierto nivel académico.

\section{Conclusiones}

Aunque los Sistemas de Información Geográfica son herramientas en donde siempre va estar inmerso el 
Investigaciones sobre las necesidades de información,...

espacio geográfico (mapa) relacionado con un tema en particular en relación al lugar, no es exclusiva de la disciplina geografía, existen otras disciplinas que utilizan los SIG, para la planeación de sus actividades.

Los tipos de usuario que utilizan los Sistemas de Información Geográfica son los usuarios de nivel licenciatura y maestría. En el caso de la UNAM, son los Técnicos Académicos que apoyan proyectos de investigación de los investigadores titulares y por lo tanto son ellos quienes principalmente manipulan estos sistemas.

El adecuado manejo y obtención de resultados del sistema se debe a la experiencia que el propio usuario va adquiriendo con la práctica constante del sistema.

Es necesario que los usuarios conozcan los conceptos básicos del sistema tales como referenciación, proyección, escala, datum, atributos, entre otros, lo cual les facilita la interpretación de los datos, de lo contrario no se entiende el sistema ni como manipular los datos.

Las bases conceptuales de los Sistemas de Información Geográfica permiten al usuario explorar al máximo el sistema, sabiendo lo que se está haciendo al introducir adecuadamente los datos, obtener los resultados esperados, analizarlos e interpretarlos para la adecuada toma de decisiones. 
Comportamiento informativo de los usuarios...

Siempre es bueno conocer la forma tradicional de elaborar mapas con sus atributos, pero si ya existen las tecnologías que facilitan el trabajo se deben conocer, lo cual implica hacer estudios de usuarios de los SIG, para ir enriqueciendo el sistema, para hacerlo más fácil, eficiente y rápida la obtención de la información.

Los SIG están enfocados a cubrir las necesidades técnico-científicas y realizar análisis espaciales, por lo que para el uso del sistema se requiere conocer el lenguaje o jerga que el ideal sería la jerga del usuario, no la del Ingeniero en Sistemas.

El idioma en que se encuentran los Sistemas de Información Geográfica es el inglés, el cual no presenta problemas de interpretación en la mayoría de los usuarios del sistema, por lo que considero que es ideal por ser un idioma universal y por el tipo de usuarios al que va dirigido.

\section{Bibliografía}

Aronoff, S. Geographic information systems. A management perspective. Ottawa, WDL Publications. $1991.294 \mathrm{p}$.

Burrough, P. Principles of geographical information systems form land resources assessment. Oxford, University Press. 1991.194 p. 
Investigaciones sobre las necesidades de información,...

Calva G., Juan José. Las necesidades de información: su naturaleza, manifestación y detección. México : J.J. Calva González, 1998, 247 p. Tesis (Maestría en Bibliotecología)--UNAM. Facultad de Filosofía y Letras, 1998.

Craig, William J., Harris, Trevor M. and Weiner, Daniel. Community participation and geographic information systems. London and New York, Taylor and Francis. c2002. p. 383.

Demers, Michael N. Fundamentals of geographic information systems. 3a. Ed. Estados Unidos de América, John Wiley and Sons. c2005. p. 468.

Eisenbers, K. "Special documents as sources for maps" En: Geography-and-Map-Division-Bulletin. (128) jun. 1982, 32-35. 12

Fallas, Jorge. "Sistemas de información geográfica: una visión integral". En: Revista geográfica de América Central". 1995 - 1996. No.32 - 33, jul. jun. pp.17-39.

Frank, A. U., and Mark, D. M. Languaje issues for GIS. (DE, 15 de agosto, 2009: http://www.wiley. com/legacy/wileychi/gis/vol.1//BB1v1_ch11. pdf). 
Comportamiento informativo de los usuarios...

Garrods, C. "Los sistemas de información geográfica en la geografía médica". En revista: El Colegio Mexiquense. 1998. V.1. No. 3, ene. - jun. pp. 597-618.

Gluck, M. Geospatial information needs of the general public: text, maps and users tasks. (DE, 3 de agosto, 2009: http://www.ideal.illinois. edu/bitstream/handle/2142/408/Gluck. pdf? sequence $=2$ ).

Korte, G. B. The gis book. Canada, Onword Press. c2001.387 p.

Lo, Ch. P. Concepts and techniques of geographic information systems. New Jersey, Prentice Hall, c2007.

Geographic information systems a science. Longley , Paul A. [et. al.]. New York, Jhohn Wiley and Sons. c2001. 454 p.

Lopez B., J. "Sistemas de información geográfica (SIG): Conceptos, definiciones y contexto metodológico". En: Quivera. 1998. V. 1. Jul. p.27 -38. 
Investigaciones sobre las necesidades de información,...

Luna G., L. Los sistemas de información geográfica: una alternativa para el análisis socioespacial de los accidentes de transito en carretera, Propuesta metodológica. México: La autora, 1997. Tesis de Maestría en Geografía, p.40

Maguire, D. J. An overview and definition of GIS. Geographical information systems. Principles and applications. V. 1. New York, John Wiley \& Sons. 1991.

Martinez B., J. O. "Desarrollo de la Tecnología SIG en Internet”. En: Revista Cartográfica. 2000. No. 71 jul - dic. p.29-34.

Mongomery, G. and Schuch, H. Gis data convertion handbook. USA, GIS World, Inc. 1993. 291 p.

Rivas, A. "Sistemas de información geográfica digitalizada. Control, eficiencia y servicio". En revista: Obras. 2003. V. 31 No. 363 mar. pp. 86-89.

Rodríguez B., Agustín. Expert systems and geographical information systems for impact assessment. London: Taylor \& Francis, 2004 
Comportamiento informativo de los usuarios...

Santos R., A. El comportamiento informativo de los investigadores del área de geografía en México. Tesis Maestría en Bibliotecología y Estudios de la Información. UNAM. FFyL, ASR. 2007. 159 p.

Semra, H. Documentary practices and needs of geographers specializing in the Maghreb En: INSPEL, Vol.20 no3 1986, pp. 168-73

Solano, M. A. "¿El estudio de sistemas de información geográfica (SIGs) es una disciplina?. El papel importante de los SIGs en la geografía”. En: Revista geográfica de América Central. 1995 - 1996. No. 32 - 33 jul. - jun. pp.13-23.

Summers, M.; Easdown, G. "Information technology in initial teacher education: preconceptions of history and geography interns, with reflections of mentors and tutors" En: Journal-of-Information-Technology-for-Teacher-Education. 5 (1 \& 2) 1996, p.155-172.

Tieleman, P. Some information of online databases for geographers. Amsterdam: University of Amsterdam, Laboratory of Physical Geography and Soil Science, 1979. 
Investigaciones sobre las necesidades de información,...

Understanding GIS. The Arc/Info method. Environmental Systems Research Institute. United States of America. 1992. pp.1-30

Verbyla, D. L. Practical GIS analysis. London and New York, Taylor and Francis. 2002. p. 294.

Wang, F. Quantitative methods and applications in gis. London and New York, Taylor and Francis. 2006. p. 263. 


\title{
Los estudios de usuarios para evaluar la calidad de los servicios bibliotecarios en bibliotecas universitarias
}

\author{
FERNANDO XOCHITEOTZIN PEŃA \\ Posgrado en Bibliotecología y Estudios de la Información \\ Universidad Nacional Autónoma de México
}

\section{Justificación del tema}

Tos estudios fundamentados en obtener infor- mación sobre los usuarios y no usuarios con respecto a sistemas de información se conocen genéricamente como estudios de usuarios. Se conforman por investigaciones de muy diversa índole si se considera: el objeto investigado, los objetivos que se plantean, los métodos para recopilar la información o la aplicabilidad de sus resultados.

Los estudios de usuarios comenzaron desde el momento de su nacimiento a diversificar sus objetos de estudio, sus campos o áreas de aplicación y los métodos de investigación, de modo que actualmente existe una multitud de modelos que atienden a fenómenos puntuales muy variopintos que sólo comparten entre sí el pertenecer al dominio del usuario (Izquierdo 1999 p. 113). 
Investigaciones sobre las necesidades de información,...

Existen diferentes concepciones sobre los estudios de usuarios que han impedido encontrar una definición exacta, aunque para Izquierdo (1999), las diversas definiciones parecen tener una base común: el estudio de la relación entre la información y el usuario. De ésta relación se desprenden diversos estudios enfocados a investigar a los usuarios individual o colectivamente y determinar cuándo es que buscan información, con qué propósito lo hacen, cómo la obtienen o para qué la utilizan. Por lo relevante de estos estudios particularmente para evaluar productos, servicios o sistemas de información, su utilización es imprescindible en el contexto de la gestión de calidad. La calidad total es un enfoque por el que toda organización persigue la mejora sistemática de productos y servicios con el propósito y filosofía de satisfacer las necesidades y expectativas de sus clientes/usuarios. Con el arribo de la calidad total como modelo de gestión en todo tipo de organizaciones, los usuarios se reafirman como figura principal de los sistemas de información, de ahí la importancia de los estudios fundamentados en obtener información respecto a las necesidades, comportamiento, opiniones, demanda, etc., que presentan los usuarios en el contexto de los productos, servicios y sistemas de información. 
Los estudios de usuarios para evaluar la calidad...

\section{Planteamiento del problema}

Uno de los ámbitos o dominios de aplicación de los estudios de usuarios es el de la Evaluación Institucional que mayoritariamente se centra en el diseño y evaluación de productos y sistemas de información. Ya sea desde la perspectiva de la rendición de cuentas, la autorregulación o la acreditación, la evaluación institucional gira en torno a la calidad.

La calidad ha sido considerada desde una moda hasta una filosofía,

y se ha convertido en una obsesión colectiva del mundo desarrollado, eminentemente complejo, plural y dinámico (Pinto, 1998 p.171).

Desde una perspectiva organizacional Antonio Barba (2004) comenta que la calidad ha evolucionado alrededor de tres aspectos: producción, administración y organización hasta llegar a su última expresión conocida como calidad total, la cual desarrolla su visión en el marco de la globalización y parte del principio de que la competencia en los mercados nacionales e internacionales desarrolla las exigencias del consumidor, por eso, su punto focal es el cliente y su relación con los productos y servicios de calidad. Los sistemas de información (en tanto unidades de servicios) no se han quedado al margen en esta búsqueda de calidad. 
Investigaciones sobre las necesidades de información,...

En el contexto de las unidades de información también se ha adoptado como modelo de gestión la calidad total, aunque con más retraso que en otro tipo de empresas de servicios (Abad, 2005 p. 172).

El objetivo de la calidad en un sistema de información se traduce en la optimización de los flujos de información y conocimiento, en tanto que sus servicios existen por y para los usuarios, bajo este argumento, los productos y servicios de información, deben contemplar los requerimientos de los usuarios/clientes en su concepción, funcionamiento y evaluación. En este sentido,

los estudios de usuarios constituyen la piedra angular de los programas de gestión de calidad, ya que suministran las bases sobre las que se proyecta y/o transforma un producto o un servicio de información e, incluso, un sistema entero. Con la aplicación de este tipo de estudios, la institución documental posee una valiosa información de primera mano sobre cómo están reaccionando los usuarios a las diferentes características de la calidad de los servicios y qué acciones concretas han de llevarse a cabo para mejorar y mantener la calidad (Izquierdo et al. 1998 p. 3).

Por su parte, para la Bibliotecología el objeto de estudio original era la biblioteca y su organización, 
Los estudios de usuarios para evaluar la calidad...

con el desarrollo de las tecnologías de la información este paradigma se cuestiona y cambia.

Este auge tecnológico nos ha hecho cuestionar el paradigma de organización y concebir otro que apunte hacia los usuarios, hacia el acceso a la información... (Hernández 2003 p. 25).

Ahora, el objeto de estudio para la disciplina bibliotecológica es la compleja relación entre el usuario y la información, a este respecto, cabe señalar la consideración de los "sujetos" (usuarios) como principio y fin del ciclo de la producción de información, ya que finalmente son estos quienes la generan, la recuperan y la usan para generar nuevo conocimiento.

Bajo este precepto de los usuarios como "sujetos de investigación", en lo general desde la disciplina bibliotecológica, y en lo particular desde la perspectiva de la gestión de calidad, se plantean los siguientes problemas de investigación:

a) Qué estudios de usuarios se han implementado para evaluar la calidad de los servicios bibliotecarios en bibliotecas universitarias.

b) Qué métodos, técnicas e instrumentos se han utilizado en estos estudios.

c) ¿Los estudios de usuarios recuperados para 
Investigaciones sobre las necesidades de información,...

fines de ésta investigación son realizados por bibliotecas universitarias en el marco de la Evaluación Institucional y/o como parte de un Sistema Gestión de Calidad?

\section{Objetivos}

- Determinar cuales son los estudios de usuarios que se utilizan para evaluar la calidad de los servicios bibliotecarios.

- Identificar los métodos, técnicas e instrumentos más utilizados en los estudios de usuarios para evaluar la calidad de los servicios bibliotecarios.

- Realizar un análisis de los estudios de usuarios desde la filosofía de la gestión de calidad.

- Realizar una aproximación a la utilización de los estudios de usuarios para evaluar los servicios bibliotecarios en bibliotecas universitarias como parte de un sistema de gestión de calidad o como efecto de la Evaluación Institucional.

\section{Hipótesis}

Si la calidad total fundamenta su filosofía en satisfacer las necesidades y expectativas de los clientes, y los estudios de usuarios se fundamentan en obtener información respecto a la relación usuario - información en el contexto de que los sistemas de información 
Los estudios de usuarios para evaluar la calidad...

deben satisfacer a sus usuarios / clientes, se puede inferir que:

a) La utilización de estudios de usuarios para evaluar la calidad de los servicios bibliotecarios puede estar fundamentada en la filosofía de la calidad total, y por eso son llevados a cabo en las bibliotecas universitarias.

b) La evaluación de los servicios bibliotecarios desde la filosofía de la gestión de calidad se puede realizar a través de determinados estudios de usuarios en tanto que:

- La calidad de los servicios bibliotecarios está directamente relacionada con los usuarios.

- Tanto los estudios de usuarios como la gestión de calidad conciben a los usuarios como parte de su eje principal de atención.

c) Los estudios de usuarios, como investigaciones formales sobre la figura principal de los sistemas de información, son utilizados en bibliotecas orientadas hacia la calidad.

La proximidad entre los estudios de usuarios y la gestión de calidad se puede comprender a través de los ocho principios que la norma ISO 9001:2000 establece para implementar un Sistema de Gestión 
Investigaciones sobre las necesidades de información,...

de Calidad en cualquier tipo de organización, estos son: enfoque al cliente, liderazgo, participación del personal, enfoque basado en procesos, enfoque de sistemas para la gestión, mejora continua, enfoque basado en hechos para la toma de decisiones y relaciones mutuamente benéficas con los proveedores.

A través de al menos tres de estos principios de calidad (enfoque al cliente, mejora continua y enfoque basado en hechos para la toma de decisiones), los estudios de usuarios se correlacionan con la gestión de calidad, por ejemplo:

El enfoque al cliente se refiere a que la gestión de los recursos (materiales, tecnológicos y de factor humano) debe estar dirigida hacia el usuario como la figura principal de la organización, en este sentido, los estudios de usuarios recopilan información sobre necesidades, hábitos, actitudes, comportamiento, satisfacción, demanda, etc., con la cual poder orientar la gestión hacia dicho fin. Respecto a la mejora continua, los estudios de usuarios permiten identificar los cambios respecto a las opiniones, expectativas, deseos, motivaciones, etc., que manifiesten los usuarios y que identifiquen la necesidad de algún tipo de cambio en la gestión. Finalmente, el enfoque basado en hechos para la toma de decisiones se refiere a que las decisiones que tomen las organizaciones deben estar fundamentadas en hechos, es decir en información fiable; en este sentido, 
Los estudios de usuarios para evaluar la calidad...

los estudios de usuarios proporcionan información recopilada metódicamente, con la cual se pueden tomar decisiones bajo este enfoque.

\section{Marco teórico}

El concepto de calidad es subjetivo y polisémico. Tenemos diferentes enfoques que utilizamos para referirnos a la calidad por ejemplo:

En el sentido de las exigencias que el mercado establece basadas en las necesidades de la gente, es decir, los atributos de los productos o servicios que generan las apreciaciones diferenciadas de los consumidores.

En el sentido de los procesos empleados por las organizaciones en torno al cumplimiento de estándares que sugieren que los productos o servicios son de calidad. En el sentido del valor económico, cuando el costo del servicio o producto determina su calidad. Siguiendo a Antonio Barba (2004), en términos generales la calidad como concepto organizacional ha evolucionado alrededor de tres aspectos, a) producción: que se expresó en la década de los veinte a través del control de la calidad mediante la inspección, es decir, la calidad de los productos se verifica una vez que el producto está terminado, aquí el concepto de calidad era producción sin defectos; b) administración: cuando la calidad se integró como objetivo propio de la administración a mediados de la 
Investigaciones sobre las necesidades de información,...

década de los cuarenta, para este momento, las organizaciones se proponen evitar producir productos defectuosos desde el momento de su elaboración, aquí, el concepto de calidad era cero defectos y capacitación y c) organización: que a partir de la década de los ochenta se expresa con la calidad total que implica la interpretación de la calidad como un problema estratégico para alcanzar la competitividad y como un símbolo organizacional, aquí el concepto de calidad es satisfacción del cliente.

Respecto a los estudios de usuarios, Sanz (1994) sitúa hacia 1920 su inicio, por su parte, Izquierdo (1999) indica que es hacia la mitad de los años 60 cuando comienza a tomarse en cuenta los resultados de estudios de hábitos, y necesidades de información para la gestión de las unidades de información, pero que va a ser a inicio de los años 80 cuando los resultados de estos estudios retoman mayor importancia para la gestión de unidades de información gracias a la generalización de los modelos de gestión de calidad total aplicados a los sistemas de información científica, e indica que el enfoque de estos estudios se centró en la evaluación de los servicios de información a través de la valoración de los usuarios.

Desde el punto de vista del usuario, la satisfacción de sus necesidades de información es la medida de la eficacia del sistema por excelencia (Abad, 2005 p. 174), 
Los estudios de usuarios para evaluar la calidad...

de tal forma que la satisfacción de los usuarios es un resultado buscado por los sistemas de información y constituye sin lugar a dudas información importante sobre su éxito o fracaso.

En el contexto de los sistemas de información, se entiende por satisfacción de usuarios la medida en la que estos creen que el sistema de información cumple con sus requisitos informativos (Rey, 2000 p. 141).

En lo que se refiere a la gestión de calidad, la ISO (Organización Internacional para la Normalización) es una organización no gubernamental con sede en Ginebra (Suiza), fundada en 1947 que agrupa voluntariamente a las organizaciones de normalización más importantes de cada país, tiene sus orígenes en la Federación Internacional de Asociaciones Nacionales de Normalización (1926 - 1939). En Octubre de 1946 representantes de veinticinco países acordaron el nombre de International Organization for Standarization. Su finalidad principal es promover el desarrollo de la normalización internacional para facilitar el intercambio de bienes y servicios en todo el mundo.

La ISO publica acuerdos internacionales bajo el nombre de "normas" mundialmente reconocidas,

Para llevar a cabo toda esta diversa y compleja actividad normalizadora, la ISO dispone de más de 200 comités 
Investigaciones sobre las necesidades de información,...

técnicos (CT) especializados cada uno en un tema o área específica. Cada CT tiene subcomités (SC) que, a su vez, se dividen en grupos de trabajo (WG) en los que están representados todos los países miembros. El Comité Técnico ISO 176 (ISO / TC176), fue formado en 1979 precisamente para armonizar el incremento de la actividad internacional en materia de gestión de la calidad y aseguramiento de estándares de calidad. El resultado de su trabajo es la serie de normas publicadas con la codificación ISO 9000, unas de las más conocidas internacionalmente, que describen la manera de construir el SGC y la Mejora Continua de una organización (Cidad, 2004 p. 660).

\section{Marco de referencia}

Para Luisa Orera (2005), la evolución de las bibliotecas universitarias se da en dos escenarios relacionados entre sí, el social y el universitario. En cuanto al escenario social hay que señalar el modelo social llamado sociedad de la información y del conocimiento, que entre otras cosas, se caracteriza por la importancia y valor económico que le da a la información, el peso que le da a las tecnologías de la información o al acceso mismo a la información, en este sentido, una de las características más visibles de ésta evolución de la biblioteca universitaria se da en lo que se ha denominado "colecciones híbridas", es decir, tanto impresas como electrónicas. 
Los estudios de usuarios para evaluar la calidad...

En el ámbito universitario, el principio cada vez más extendido de que las organizaciones, sobre todo del sector público deben rendir cuentas a la sociedad ha impulsado a las instituciones educativas a adoptar una cultura de calidad. Para las universidades, una de sus partes más importantes es sin duda la biblioteca, y esto lo podemos observar mediante los dos principales objetivos que este tipo de bibliotecas tienen: el apoyo a la docencia y la investigación.

\section{Las bibliotecas universitarias}

como generadores de actividad intelectual que reúnen, organizan, diseminan y administran un universo de información, previamente seleccionado y adquirido para satisfacer las necesidades de información científica de un determinado colectivo, participan activamente en la transformación evolutiva de la sociedad. También deben transformarse organizativamente, evaluando sus actividades, diagnosticando deficiencias y estableciendo Programas de Calidad (Pinto, 1998 p.180).

La búsqueda de la calidad en los servicios que proporciona, pero sobre todo la preocupación por hacer ésta búsqueda patente, hace necesaria su medición, es decir, la búsqueda de la calidad lleva implícita un proceso de evaluación. 
Investigaciones sobre las necesidades de información,...

Calidad y evaluación son así dos conceptos que implican una gestión orientada al cliente, donde la clave del éxito consiste en obtener su satisfacción. Si la calidad del servicio depende únicamente de hasta dónde este servicio es capaz de satisfacer las necesidades del cliente, es evidente que cualquier gestión de calidad implica conocer esas necesidades y ser capaz de medir el grado de satisfacción que obtiene el cliente (Malo y Montalvo, 2005 p. 187).

\section{Metodología}

Como unidad de análisis se tienen a los documentos publicados (artículos, reportes, informes, libros y ponencias) que sean estudios de usuarios que se utilizaron para evaluar la calidad de los servicios bibliotecarios en bibliotecas universitarias.

\section{Métodos:}

1) Investigación documental. Localización de los documentos ya mencionados.

2) Análisis crítico de los documentos recuperados con base en los parámetros relacionados con la evaluación de los servicios bibliotecarios y gestión de calidad de bibliotecas universitarias. 
Los estudios de usuarios para evaluar la calidad...

\section{Bibliografía inicial}

Abad García, María Francisca. Evaluación de la calidad de los sistemas de información. Madrid: Síntesis, 2005.

Abad García, María Francisca. Investigación evaluativa en documentación: aplicación a la documentación médica. Valencia: Universidad de Valencia, 1997.

Arriola Navarrete, Oscar. Evaluación de bibliotecas: un modelo desde la óptica de los sistemas de gestión de calidad. México: Colegio Nacional de Bibliotecarios, 2006.

Barba Álvarez, Antonio. Calidad total en las organizaciones: poder, ambigüedad y aspectos simbólicos. En Los estudios organizacionales en México: cambio, poder, conocimiento e identidad. México: Universidad Autónoma Metropolitana, 2004.

Calva González, Juan José. Las necesidades de información: fundamentos, teoría y práctica. México: UNAM, Centro Universitario de Investigaciones Bibliotecológicas, 2004. 
Investigaciones sobre las necesidades de información,...

Cidad Maestro, Emilio. La gestión de la calidad en las organizaciones de educación superior. Aportación del enfoque de la Organización Internacional de Normalización (ISO). Revista Complutense de Educación Vol. 15 No. 2. 2004

Cañón Vega, Nora. Sociología de la información. Colombia: Universidad de la Salle, 2002.

Cidad Maestro, Emilio. La gestión de calidad en las organizaciones de educación superior. Revista complutense de educación Vol.15 No. 2004.

Cruz Paz, Víctor E. Evaluación de instituciones de información y bibliotecas: el benchmarking. Ciencias de la información Vol. 26 No.3 1995.

Duarte Barrionuevo, Miguel. La biblioteca universitaria eficaz: directrices para la evaluación del rendimiento en bibliotecas universitarias. Cádiz: Universidad, 1999.

Fuentes, Juan José. Evaluación de bibliotecas y centros de documentación e información. España: Trea, 1999. 
Los estudios de usuarios para evaluar la calidad...

Hernández Salazar, Patricia. Análisis metodológico para abordar el fenómeno usuarios de la información en América Latina. Investigación bibliotecológica Vol. 17 No. 352003.

Izquierdo Alonso, Mónica. Una aproximación interdisciplinar al estudio del usuario de información: bases conceptuales y metodológicas. Investigación bibliotecológica Vol. 13 No. 261999.

Izquierdo Alonso, Mónica et al. Los estudios de usuarios en los programas de gestión de calidad: propuesta de un marco teórico integrador para el estudio del usuario de información. En: VI Jornadas Españolas de Documentación FESABID 98. Valencia: Federación Española de Sociedades de Archivística, Biblioteconomía y Documentación, 1998.

Jaramillo, Orlanda. La biblioteca universitaria: autoevaluación y acreditación. Revista Interamericana de Bibliotecología. Vol. 21 No.2 1998.

Lafuente López, Ramiro; Morales Campos, Estela. Reflexiones en torno a la enseñanza de la bibliotecología. Investigación bibliotecológica Vol.1 No.1 1992. 
Investigaciones sobre las necesidades de información,...

Lancaster, Frederic Wildrid. Evaluación de la biblioteca. Madrid: Anabad, 1996.

López Leyva, Santos. et al. Modelos y mecanismos de evaluación institucional: una visión desde la educación superior de México. México: Universidad Autónoma de Sinaloa, Universidad de Arizona, 2006.

Madrid, Isabel. Evaluación de bibliotecas: su necesidad e importancia. Información, cultura y sociedad. No. 62002.

Malo De Molina Y Montalvo-Martín. La evaluación: una herramienta imprescindible para la gestión de la calidad en las bibliotecas universitarias. En Biblioteca universitaria: análisis en su entorno bíbrido. Madrid: Síntesis, 2005.

Montaudon Tomas, Cynthia. Historia de la calidad mundial: la evolución de las ideas en la gestión de calidad. México: Universidad Iberoamericana, Instituto Tecnológico y de Estudios Superiores de Occidente, 2004. 
Los estudios de usuarios para evaluar la calidad...

Moreno Jiménez, Daniel. Interpretación de la norma ISO 9001: 2000 para obtener el certificado de calidad en bibliotecas. México: Colegio Nacional de Bibliotecarios: Universidad del Valle de México: Library Outsourcing Service, 2005.

Orera Orera, Luisa. La biblioteca universitaria: concepto, funciones y retos futuros. En Biblioteca universitaria: análisis en su entorno bibrido. Madrid: Síntesis, 2005.

Pinto Molina, María. Gestión de calidad en documentación. Anales de Documentación No.1 1998.

Rey Martín, Carina. La satisfacción del usuario: un concepto a la alza. Anales de documentación. No. 32000.

Romanos De Tiratel, Susana. Necesidades, búsqueda y uso de la información: revisión de la teoría. Información, cultura y sociedad. No 22000.

Sánchez Rodríguez Iván y Aurelio Navarro, Marco. Evaluación institucional: perspectiva histórica y modelos clásicos. México: Universidad Autónoma de Tamaulipas, 2005. 
Investigaciones sobre las necesidades de información,...

Sanz Casado Elías. La realización de estudios de usuarios: una necesidad urgente. Revista general de información y documentación. Vol. 3 No. 11993.

Sanz Casado Elías. Manual de estudios de usuarios. Madrid: Fundación Germán Sánchez Ruipérez, 1994.

Sistemas de gestión de calidad - Requisitos NMXCC-9001-IMNC-2000 México: Instituto Mexicano de Normalización y Certificación, 2001. 


\title{
La búsqueda de información de los investigadores de la UNAM que pertenecen al Sistema Nacional de Investigadores (SNI), del área 4 de Humanidades y Ciencias de la conducta
}

\author{
Silvia Castillo Barrera \\ Posgrado en Bibliotecología y Estudios de la Información \\ Universidad Nacional Autónoma de México
}

\section{Introducción}

Toda biblioteca, unidad de información, centro 1 de documentación, etc., ya sea de tipo escolar, pública, universitaria o especializada, tiene como función primordial el atender y satisfacer las necesidades de información de los usuarios a los que atiende. Es por ello importante, el que se investiguen, conozcan, y analicen las necesidades y el comportamiento informativo de su comunidad a la que sirve, ya que con ello podrá apoyar de manera relevante en el quehacer documental de los usuarios satisfaciendo sus necesidades de información.

Los estudios de usuarios se llevan a cabo para identificar las necesidades de información para la toma de decisiones; para brindarnos información sobre el estado en el que se encuentra determinado sistema o servicio de información; para analizar la interacción del usuario con el sistema; además de 
Investigaciones sobre las necesidades de información,...

manera generalizada identificar las características de los usuarios y finalmente para apoyar los estudios científicos y comparativos.

Las necesidades de información que presentan los individuos versan sobre el conocimiento que ellos consideran que les hace falta obtener, de ahí que presenten varios aspectos de comportamiento, que es necesario que el profesional de la información observe y estudie para brindarle de manera óptima la información que necesita, y así el individuo logre transformarla en conocimiento.

Las bibliotecas cuentan con comunidades de usuarios a las que sirven, es por ello relevante el que dichas comunidades sean estudiadas para diagnosticar el estado, ya sea de los servicios o de algún aspecto de la biblioteca que aporte información que sea analizada, y con ello se gestionen y tomen decisiones para la mejora de determinado servicio o sistema, todo ello con el fin de brindar el mejor servicio a la comunidad usuaria de la que se trate, ya que la existencia misma de la biblioteca, su acervo, servicios, personal, equipo y mobiliario son para y por los usuarios.

En nuestra universidad existen una gama de bibliotecas, las cuales cuentan con su propia comunidad de usuarios, a la que debe satisfacer y para ello es pertinente y relevante el realizar estudios de usuarios. 
La búsqueda de información de los investigadores...

La UNAM, en el ámbito de la investigación, cuenta con recintos donde se llevan a cabo una variedad de investigaciones en las diferentes áreas del conocimiento como son los institutos y centros de investigación, donde cada uno tiene su biblioteca especializada y se atienden principalmente a los investigadores.

En el presente estudio se pretende realizar una investigación sobre la búsqueda de información que realizan los investigadores de la UNAM que pertenecen al Sistema Nacional de Investigadores (SNI), del área 4 perteneciente a las humanidades y ciencias de la conducta.

\section{Justificación}

La justificación que se argumenta para la realización del presente trabajo, se fundamenta en lo siguiente:

Dentro de las actividades primordiales que se realizan en la Universidad Nacional Autónoma de México (UNAM), está la investigación, actividad que toma gran relevancia para el desarrollo de nuestro país, ya que en esta casa de estudios se genera el 50 por ciento de las investigaciones a nivel nacional, de ahí su gran importancia.

Considero relevante el conocer e investigar el tema: "Las necesidades y comportamiento informativo de los investigadores de la UNAM que pertenecen 
Investigaciones sobre las necesidades de información,...

al Sistema Nacional de Investigadores (SNI) en el área 4 de Humanidades y Ciencias de la conducta, ya que son considerados investigadores nacionales, que por haber sido evaluados bajo ciertos criterios como: la calidad de los trabajos, productividad reciente, trabajos citados, factor de impacto, aportes al desarrollo científico, tecnológico, social y cultural de México, etc., y recibiendo una resolución favorable a dicha evaluación forman parte del SNI, que los apoya otorgándoles incentivos económicos por ser investigadores destacados por sus aportaciones a la investigación en México, lo cual hace de mi interés el conocer sus necesidades y comportamiento informativo de este grupo de investigadores, para contar así con el conocimiento o bases que nos den la pauta para satisfacer de la mejor manera sus necesidades de información haciéndoles el camino a recorrer más fácil, y de esa manera apoyar en el desarrollo y generación del conocimiento que dé como resultado o impacte en un incremento de la investigación en México.

\section{Planteamiento del problema}

Para dicho estudio las cuestiones a resolver son:

- ¿Cuáles son los factores que influyen en la aparición de las necesidades de información de los investigadores de la UNAM que pertenecen al 
La búsqueda de información de los investigadores...

SNI del área 4 de Humanidades y Ciencias de la conducta?

- ¿Cuáles son sus necesidades de información de dichos investigadores?

- ¿Cuál es el comportamiento en la búsqueda de información de los investigadores?

- ¿Este grupo de investigadores considera que por pertenecer al SNI, tienen mayores necesidades de información por la calidad de las investigaciones?

\section{Objetivos}

Dentro de los objetivos que pretendo alcanzar son los siguientes:

- Determinar los factores que influyen en la aparición de las necesidades de información de los investigadores de la UNAM que pertenecen al SNI del área 4 de Humanidades y Ciencias de la conducta.

- Establecer las necesidades de información de los investigadores de la UNAM que pertenecen al SNI del área 4 de Humanidades y Ciencias de la conducta.

- Analizar el comportamiento en la búsqueda de información de los investigadores de la UNAM que pertenecen al SNI del área 4.

- Determinar si este grupo de investigadores 
Investigaciones sobre las necesidades de información,...

por pertenecer al SNI, considera que tiene mayores necesidades de información por la calidad de sus investigaciones.

\section{Hipótesis}

Hay factores que influyen en la aparición de las necesidades de información de este grupo de investigadores como son los relacionados al medio ambiente donde laboran, así como las condiciones bajo las cuales realizan la investigación como son: Horas laborables, el pertenecer al SNI de cierta manera puede presionar al investigador a que presente una mayor necesidad de variedad de información, los años de experiencia en la investigación, la edad del investigador, recursos de información tanto impresos como electrónicos a su alcance, tiempo disponible para realizar búsqueda de información, área del conocimiento a la que pertenecen sus investigaciones, tiempo determinado para llevar a cabo sus investigaciones.

Las necesidades de información que presentan son de todas las áreas del conocimiento, pero principalmente de la humanística a diferencia de la científica.

Referente al comportamiento que presentan los investigadores al realizar una búsqueda de información tienen mayor habilidad para manejar los recursos de información impresos contando ya con 
La búsqueda de información de los investigadores...

un modo o forma de búsqueda habitual, no siendo así de igual forma para la consulta de los recursos de información electrónicos, ya que éstos presentan características de manejo diferentes que quizás algunos de los investigadores no tengan el tiempo y la dedicación para su consulta, ya que se van adquiriendo nuevos recursos de información electrónica, para esto el investigador acude al bibliotecólogo para solucionar su necesidad de información.

Los investigadores de la UNAM que pertenecen al SNI, sí consideran que por pertenecer al SNI tienen mayores necesidades de información por la calidad de sus investigaciones.

\section{Marco teórico}

Antes de indicar los modelos fundamentales que existen en la literatura, además de autores relevantes para dicha temática, es pertinente el definir los siguientes conceptos:

- Necesidades de información

- Comportamiento informativo

- Satisfacción de necesidades de información

Lo anterior porque puede causar cierta ambigüedad ya que los términos están ligados unos con otros.

Así las necesidades de información se definen como: 
Investigaciones sobre las necesidades de información,...

la carencia de conocimientos e información sobre un fenómeno, objeto, acontecimiento, acción o hecho que tiene una persona, producidos por factores externos e internos, que provocan un estado de insatisfacción, misma que el sujeto se ve motivado a satisfacer a través de presentar un comportamiento para buscar la satisfacción (Calva González : 68, 2004).

En cuanto al concepto de comportamiento informativo se entiende como:

la manifestación de las necesidades de información del sujeto, originadas a partir de la insuficiencia de conocimiento e información sobre algún fenómeno, hecho u objeto (Calva González : 102, 2004).

Por lo que respecta a la satisfacción de información es entendida como:

el restablecimiento del equilibrio del sujeto con su medio circundante, a partir de la desaparición de las carencias de conocimiento e información que tenía sobre un hecho, objeto o fenómeno y que fue lo que provocó una necesidad de información (Calva González : 137, 2004).

De los tres conceptos anteriores podemos observar que el comportamiento informativo que presenta un individuo surge de la falta de información 
La búsqueda de información de los investigadores...

(necesidad de información) que se genera en el individuo, presentando un estado de molestia o incomodidad, lo cual expresa con lenguaje oral, corporal o manifestando ciertas actitudes de comportamiento, y que una vez que obtiene lo que desea, cambiará su estado de desequilibrio a una satisfacción emocional.

Si el sujeto logra sentirse satisfecho tenderá a presentar un comportamiento futuro diferente al que no obtuvo la satisfacción informativa, ya que el primero tendrá mayor confianza en asistir y/o en utilizar las fuentes y recursos informativos de la biblioteca o centro de información del que se trate.

Una vez que se abordaron los tres conceptos anteriores, podemos tratar algunos de los modelos que existen para el estudio de usuarios.

Dentro de la literatura sobre necesidades informativas es relevante mencionar el Modelo NEIN, el cual aborda dicha temática tratándola desde la constitución del fenómeno, surgimiento, manifestación, detección, satisfacción y poder llegar a predecirlo. Todo con la finalidad de conocer más a fondo las necesidades de información de la comunidad a la que sirve una biblioteca o unidad de información.

Dentro de las necesidades de información como del comportamiento informativo que presenta un individuo, influyen tanto factores internos (características particulares del individuo) como externos 
Investigaciones sobre las necesidades de información,...

(el ambiente que rodea al sujeto), de los cuales se mencionarán algunos a continuación:

Factores internos:

- La experiencia.

- Conocimiento sobre algún campo, actividad.

- Temática

- Habilidades para el desarrollo de una actividad

- Capacidades de aprendizaje

- Preferencias

- Disgustos

- Personalidad del individuo (Calva González : 34, 2004)

Factores externos:

- Sociales

- Económicos

- Políticos

- Educativos

- Culturales: costumbres, tradicionales, creencias.

- Geográficos

- Físicos: espacioso, pequeño, frío, caluroso, accesible, inhóspito (Calva González : 34, 2004)

Es de vital importancia que al realizar un estudio de usuarios se consideren los factores internos y externos que influyen, ya que sus necesidades y comportamiento informativo serán diferentes a los de otra comunidad de usuarios. 
La búsqueda de información de los investigadores...

Dentro de la diversidad de modelos que tratan sobre el comportamiento informativo se enuncian de manera general los siguientes:

- Comportamiento en la búsqueda de información (James Krikelas)

La propuesta del autor es teórica.

Según Krikelas, el comportamiento en la búsqueda de información puede presentarse de diversas maneras de acuerdo con la naturaleza del problema. Las características del problema pueden ser un indicador más crítico del comportamiento potencial que variará según la persona y el trabajo que desempeña. Menciona que una persona puede llegar a estar consciente del estado de incertidumbre acerca de un problema e intentar reducir ese estado de incertidumbre a un nivel aceptable. Pero la causa de esa incertidumbre puede ser un evento específico o un simple proceso continuo asociado con el trabajo, la vida o ambos (Análisis de modelos de comportamiento en la búsqueda de información, 2007).

- Proceso de búsqueda de información (Carol C. Kuhlthau)

El modelo consta de las siguientes etapas: iniciación; selección; exploración; formulación; recopilación; y presentación. 
Investigaciones sobre las necesidades de información,...

El principio racional en el que se basa el modelo es la tendencia psicológica denominada cognoscitivismo, la cual considera que un sujeto genera nuevos conocimientos a partir de los que ya posee. El requerimiento de una nueva información se producirá a partir de que tenga una ruptura en su cadena cognoscitiva, esta ruptura lo lleva a tratar de encontrar el eslabón para completar la cadena, lo encuentra, acomoda y asimila, lo cual hace que su estructura sea reestructurada. De acuerdo con este principio, Kuhlthau establece los conceptos de necesidad de información y de proceso de búsqueda; determina las características a estudiar y las tareas apropiadas para cada etapa.

Las características que estudia son de tres tipos: afectivas, cognitivas y físicas (Análisis de modelos de comportamiento en la búsqueda de información, 2007).

- Comportamiento informativo (Tom D. Wilson)

Wilson establece los conceptos de necesidad; comportamiento informativo; comportamiento en la búsqueda; procesamiento y uso de la información; determina los mecanismos de activación y las variables que intervienen en el proceso, así como los tipos de búsqueda (Análisis de modelos de comportamiento en la búsqueda de información, 2007). 
La búsqueda de información de los investigadores...

Cada uno de los tres autores señalados anteriormente apuntan algunos elementos y conceptos que comparten dentro de cada uno de sus modelos, así como manejan y estructuran de diferente forma las etapas en base a su enfoque o tendencia.

Dentro de la literatura que existe sobre estudios del comportamiento en la búsqueda de información en investigadores de las ciencias sociales y las humanidades, podemos mencionar a la autora Patricia Hernández Salazar, ya que nos brinda las características del comportamiento informativo, que presentan dichos investigadores.

Lo anterior nos puede mostrar un panorama o referencia del comportamiento que presenta éste tipo de usuarios en el área de humanidades, ya que coincidirán en algunos factores internos y externos con los investigadores a estudiar en el presente proyecto de investigación.

\section{Marco de referencia}

Aproximadamente México contaba en 2009 con 16,000 investigadores que pertenecen al Sistema Nacional de Investigadores (SNI) de diferentes dependencias educativas tanto públicas como privadas y dentro de ellas están universidades, institutos, centros, direcciones, secretarías, etc.

De acuerdo al marco jurídico, la estructura y organización de la UNAM, la investigación se realiza 
Investigaciones sobre las necesidades de información,...

principalmente en los institutos y en los centros, sin olvidar que también se desarrollan investigaciones en sus escuelas y facultades.

El subsistema de la investigación está dividido en dos áreas:

- La científica: Con 18 institutos, 10 centros y 5 programas.

- La humanística: Con 9 institutos, 7 centros y 3 programas.

Los institutos y centros de investigación se encuentran ubicados en el Campus de Ciudad Universitaria, en otras sedes del área metropolitana, y en otros estados de la República.

Las áreas del conocimiento consideradas por el SNI son:

- Área I: Físico matemáticas y Ciencias de la tierra.

- Área II: Biología y Química

- Área III: Medicina y Ciencias de la salud.

- Área IV: Humanidades y Ciencias de la conducta.

- Área V: Ciencias sociales.

- Área VI: Biotecnología y Ciencias agropecuarias.

- Área VII: Ingenierías. 
La búsqueda de información de los investigadores...

En el presente trabajo el grupo de sujetos a estudiar serán los investigadores de la Universidad $\mathrm{Na}$ cional Autónoma de México (UNAM), que pertenecen al SNI del área 4 de Humanidades y Ciencias de la conducta.

La cantidad de investigadores de la UNAM que pertenece al SNI vigentes en 2009 en el área 4 de Humanidades y Ciencias de la conducta son:

\begin{tabular}{|c|l|c|}
\hline Área & \multicolumn{1}{|c|}{ Nivel } & Total \\
\hline 4 & Candidatos & 38 \\
\hline 4 & Nivel 1 & 302 \\
\hline 4 & Nivel 2 & 212 \\
\hline 4 & Nivel 3 & 100 \\
\hline & & ${ }^{*} 652$ \\
\cline { 2 - 3 } 4 & *Eméritos & 22 \\
\hline
\end{tabular}

*Los investigadores Eméritos son Nivel 3 con vigencia especial.

Están incluidos dentro del conteo del Nivel 3.

La población total es de 652 investigadores de la cual se obtendrá una muestra para su estudio.

\section{Metodología}

Por la naturaleza del presente estudio los aspectos metodológicos a aplicar son los siguientes:

\section{Tipo de investigación}

La metodología ha utilizar en el presente trabajo es la investigación de campo. 
Investigaciones sobre las necesidades de información,...

\section{Método de investigación}

Cuantitativo y cualitativo.

\section{Población y muestra}

El tipo de muestra a analizar será: Muestreo probabilístico estratificado.

\section{Tamaño de la muestra}

Aplicando la tabla de Ronald Powell para la obtención de la muestra correspondiente a la población total nos da como resultado 242.

Y para los estratos de cada nivel del área 4 de Humanidades y Ciencias de la conducta con base al autor Rojas Soriano tenemos las muestras siguientes:

\begin{tabular}{|c|l|c|c|c|c|}
\hline Área & Nivel & Cantidades & Afijación & Estratos & $\begin{array}{c}\text { Tamaño de la } \\
\text { muestra }\end{array}$ \\
\hline 4 & $\begin{array}{l}\text { Candi- } \\
\text { datos }\end{array}$ & 38 & 0.0582 & 14.08 & 14 \\
\hline 4 & Nivel 1 & 302 & 0.4631 & 112.07 & 112 \\
\hline 4 & Nivel 2 & 212 & 0.3251 & 78.67 & 79 \\
\hline 4 & Nivel 3 & 100 & 0.1533 & 37.09 & 37 \\
\hline \multicolumn{2}{|c|}{ Total } & ${ }^{*} 652$ & & 242 \\
\hline
\end{tabular}

* Total de investigadores de la UNAM que pertenecen al SNI (vigentes 2009)

\section{Técnicas e instrumentos}

Se utilizará la técnica de investigación documental además de la investigación de campo aplicando como instrumento para la recolección de datos la 
La búsqueda de información de los investigadores...

cédula de entrevista estructurada, o se analizará la conveniencia del cuestionario.

\section{Procedimiento}

Para realizar la presente investigación se llevarán a acabo las siguientes actividades:

1) Búsqueda documental.

2) Análisis de la información.

3) Diseño de la cédula de entrevista estructurada.

4) Localización de los investigadores y autorización para realizarles la entrevista.

5) Aplicación de las entrevistas.

6) Análisis de los resultados arrojados por las entrevistas.

7) Conclusiones.

Los elementos señalados en la presente exposición, muestran la forma de cómo se llevará a cabo la investigación, desde su justificación hasta la secuencia de las actividades que se pretenden realizar, para alcanzar los objetivos señalados y aportar así información que ayude a fortalecer los aspectos relacionados a las bibliotecas como (servicios, sistemas, acervo, equipos, entre otros) en pro de los investigadores de la UNAM del área de Humanidades y Ciencias de la conducta que pertenecen al SNI. 
Investigaciones sobre las necesidades de información,...

\section{Bibliografía}

\section{Libros}

Calva González, Juan José. Las necesidades de información: fundamentos teóricos y métodos.

González Teruel, Aurora. Los estudios de necesidades y usos de la información: fundamentos y perspectivas actuales. Madrid: Ediciones Trea, 2005. $181 \mathrm{p}$.

Rojas Soriano, Raúl. Guía para realizar investigaciones sociales. México : Plaza y Valdés, 2005. 437 p.

Sanz Casado, Elías. Manual de estudios de usuarios. Madrid : Fundación Germán Sánchez Ruipérez, 1994. $279 \mathrm{p}$.

\section{Tesis}

García Medina, Lorena Esther. Necesidades y comportamiento informativo de los estudiantes de maestría en el área de veterinaria. México: L. García, 2007. 120 p.

Guevara Villanueva, Angélica. El fenómeno de las necesidades de información en los investigadores del área de matemáticas. México: A. Guevara, 2005.228 p. 
La búsqueda de información de los investigadores...

López Franco, Fermín. Necesidades y comportamiento en la búsqueda de información de los psicólogos dedicados a la docencia. México: F. López, 2005. $182 \mathrm{p}$.

Ortega Muñoz, Raúl. El comportamiento informativo de los alumnos de 6 años de primaria de las escuelas públicas y privadas de la delegación Coyoacán en el D.F. México: R. Ortega, 2006. 171 p.

Vasquez Velasquez, María Elvia. Las necesidades y el comportamiento informativo en adolescentes escolarizados de 12 A 15 años de edad en la Delegación Iztapalapa. México: M. Vásquez, 2006. 228 p.

\section{Página web}

CONACYT- SNI Consejo Nacional de Ciencia y Tecnología - Sistema Nacional de Investigadores. - [En línea]. - [Consultado el 27 de Enero de 2009]. - Disponible en: http://www.conacyt. $\mathrm{mx} / \mathrm{SNI} /$ Index_SNI.html

\section{Artículos de revistas}

Harris, Colín. Necesidades de los usuarios y mercados de la información: su importancia en la currícula de las escuelas de Bibliotecología. Revista Interamericana de Bibliotecología. Ene/jun 1986. Vol. 19, no. 1, p. 15-31. 
Investigaciones sobre las necesidades de información,...

Hernández Salazar, Patricia. La producción del conocimiento científico como base para determinar perfiles de usuarios. Investigación bibliotecológica. 2001. Vol. 15 no. 30, p. 29-64.

\section{Artículos de revistas electrónicas}

Bath University Of Technology, University Library. 1971. The research procedures of social scientists. Investigation Into Information Requirements Of The Social Sciences. Research Report No. 5. 1971 November. University Library, Bath University Of Technology, U.k. 23 P. 3 Illus. 8 Ref. See Isa $72-1034 / m$. Library, Information Science \& Technology Abstracts with Full Text, EBSCOhost (consultado February 18, 2009).

González, Juan José Calva. 2004. La investigación sobre las necesidades de información en comunidades de usuarios. (Spanish). Investigación Bibliotecologica 18, no. 37: 23-55. Library, Information Science E Technology Abstracts with Full Text, EBSCOhost (consultado February 18, 2009).

Haglund, Lotta. 2007. Digital Resource Use and Non-Use in the Humanities and Social Sciences Academic Settings is Multifaceted. Evidence Based Library E Information Practice 2, no. 2: 101103. Library, Information Science \& Technology 
La búsqueda de información de los investigadores...

Abstracts with Full Text, EBSCOhost (consultado February 18, 2009).

Harley, Diane. 2007. Why study users? An environmental scan of use and users of digital resources in humanities and social sciences undergraduate education. First Monday 12, no. 1: 4-4. Library, Information Science \& Technology Abstracts with Full Text, EBSCOhost (consultado February 18, 2009).

Sutton, Allison M., and JoAnn Jacoby. 2008. A Comparative Study of Book and Journal Use in Four Social Science Disciplines. Bebavioral \& Social Sciences Librarian 27, no. 2: 1-33. Library, Information Science \& Technology Abstracts with Full Text, EBSCOhost (consultado February 18, 2009).

Talja, Sanna, Pertti Vakkari, Jenny Fry, and Paul Wouters. 2007. Impact of research cultures on the use of digital library resources. Journal of the American Society for Information Science E Technology 58, no. 11: 1674-1685. Library, Information Science E Technology Abstracts with Full Text, EBSCOhost (consultado February 18, 2009). 
Investigaciones sobre las necesidades de información,...

UGWU C. I. 2008. The Effect of Personal Characteristics on the Use of Information Sources by Social Science Researchers at the University of Nigeria, Nsukka. Library Philosophy E Practice 10, no. 1: 1-6. Library, Information Science E Technology Abstracts with Full Text, EBSCOhost (consultado February 18, 2009).

Use and Users of Digital Resources. Library Hi Tech News 23, no. 5: 40-40. Library, Information Science E Technology Abstracts with Full Text, EBSCOhost (consultado February 18, 2009). 


\title{
Fuentes de información utilizadas por los estudiantes de educación media superior en el D.F.
}

\author{
KAREN MÉNDEZ RAMÓN \\ Posgrado en Bibliotecología y Estudios \\ de la Información/UNAM
}

\section{Introducción}

$\mathrm{G}^{\mathrm{n}}$ el actual contexto mundial se manifiesta un L proceso de internacionalización del capital financiero, industrial, comercial y humano, denominado globalización, que se ha potenciado con la expansión de las tecnologías de la información. Internet es un icono de la época, lo que implica la formación de personas con habilidades para adaptarse al cambio constante y la adquisición de nuevos conocimientos en torno a esas tecnologías.

La Educación Media Superior (EMS) debe preparar a los jóvenes para adquirir las habilidades y conocimientos que les permitan continuar una carrera universitaria o integrarse dignamente al trabajo y finalmente desarrollarse productivamente en el país.

Conocer cómo estos estudiantes están enfrentado los cambios tecnológicos referentes al manejo de información, si están aprovechando los nuevos recursos en su formación académica, si están adquiriendo la capacidad de discernir cuál es la información que 
Investigaciones sobre las necesidades de información,...

requieren para formar su conocimiento o si cuentan con una estrategia de búsqueda asertiva, daría a las bibliotecas la oportunidad de planear las acciones en pro de la satisfacción de los usuarios de EMS.

El propósito de esta investigación es detectar qué habilidades, hábitos y procedimientos permiten al estudiante de EMS tener éxito en la recolección de información.

En México existen tres modalidades de EMs: ${ }^{1}$

1. Bachillerato general $(58.6 \%$ de la población solicita esta opción de estudio ${ }^{2}$ )

2. Bachillerato tecnológico (ocupa el $27 \%$ de la demanda)

3. Educación Profesional Técnica (el 14\% de la demanda)

Al comparar estas tres modalidades se pueden definir las características generales y particulares de los estudiantes de EMS. Se considerarán para este estudio los alumnos de primer a tercer año o su variante en modalidad de semestres, inscritos en el ciclo 2009-2010.

1 Concurso de ingreso de la educación media superior en la zona metropolitana del a ciudad de México 2008: instructivo. México COMIPENS, 2008. 112 p.

2 La educación media superior en México. http:/www.mitecnologico.com/main/Educación Media Superior en México. 
Fuentes de información utilizadas...

Del bachillerato general se analizará el plantel número 3 de la Escuela Nacional Preparatoria (ENP) "Justo Sierra" de la UNAM. En el caso del bachillerato tecnológico se estudiará al Centro de Estudios Científicos y Tecnológicos (CECYT) número 1 "Gonzalo Vázquez Vela” del IPN; el Colegio Nacional de Educación Técnica (CONALEP) representará a la Educación Profesional Técnica, a través del plantel Iztapalapa I, clave 3.

El análisis del comportamiento informativo permitirá identificar las habilidades informativas de los estudiantes de EMS, a partir de las cuales será posible detectar áreas de oportunidad, las que permitirán plantear acciones para mejorar los servicios bibliotecarios con el objetivo de incrementar la satisfacción en la recuperación de la información por los usuarios de este nivel educativo.

Este estudio se considera viable ya que las instituciones se encuentran en el área metropolitana. Se solicitará autorización de las autoridades correspondientes para la realización de este estudio dentro de las instalaciones escolares.

La información sobre el bachillerato en México y las diferentes instituciones públicas que lo imparten se encuentra disponible en línea, en monografías, artículos de revista y publicaciones oficiales.

Con respecto al comportamiento informativo podemos decir que ha sido estudiado como parte 
Investigaciones sobre las necesidades de información,...

del fenómeno de las necesidades de información ${ }^{3}$ y existen estudios de diferentes autores, entre ellos tesis de nivel licenciatura, maestría, doctorado, artículos de revistas y monografías.

\section{Comportamiento informativo de los estudian- tes de EMS}

Existen estudiantes que tienen mayor éxito en la recuperación de la información que otros.

- ¿Qué factores determinan que algunos estudiantes tengan mayor éxito en la recuperación de información que otros?

- ¿Qué recursos utilizan con más frecuencia los estudiantes de EMS, dependiendo el tipo de bachillerato que estudian?

- ¿Cuáles son las fuentes de información que utilizan con más frecuencia los estudiantes de EMS, en los diferentes tipos de bachillerato?

- ¿Existe diferencia en el comportamiento informativo de los estudiantes de EMS dependiendo la modalidad en la cual se encuentran?

Para resolver las interrogantes que se han planteado se realizará una investigación con el objetivo

3 Juan José Calva González. Las necesidades de información: fundamentos teóricos y métodos. México: UNAM: CUIB,2004. 
Fuentes de información utilizadas...

de analizar el comportamiento informativo de los estudiantes de EMS en escuelas públicas del DF durante el ciclo 2009-2010 en sus tres modalidades: Bachillerato General, Bachillerato Tecnológico y Educación Profesional Técnica.

Para alcanzar este objetivo será necesario:

- Determinar el comportamiento informativo del estudiante de EMS en el D.F. en sus tres modalidades: Bachillerato General, Bachillerato Tecnológico y Educación Profesional Técnica.

- Identificar los recursos de información que emplea el estudiante de EMS del D.F. en sus tres modalidades para la realización de su búsqueda de información.

- Reconocer las fuentes de información que utilizan los alumnos de EMS del D.F. en sus tres modalidades.

- Examinar qué factores del medio ambiente (tipo de escuela, nivel socioeconómico, modalidad educativa. etcétera) influyen en el comportamiento informativo de los estudiantes de EMS del D.F. en sus tres modalidades.

Al visitar los diferentes planteles de EMS del D.F. para observar las conductas de los estudiantes de estos centros educativos realizamos las siguientes inferencias: 
Investigaciones sobre las necesidades de información,...

- El procedimiento en la búsqueda de información en los estudiantes es un factor que repercute en la recuperación de la misma.

- Los recursos utilizados con mayor frecuencia por los estudiantes de EMS del D.F. en la búsqueda de información son los recursos electrónicos, ya sea en el sitio o a través de Internet.

- Las fuentes de información utilizadas por el estudiante de EMS son las de la bibliografía solicitada por los profesores.

- El comportamiento informativo de los estudiantes de EMs depende del tipo de bachillerato que estudian.

Para poder comprobar la veracidad de estas suposiciones se realizará ésta investigación. Para lo cual es necesario entender el fenómeno de las necesidades de información, el que se explica a partir de la necesidad humana como esa fuerza interior que motiva al hombre a la realización de una acción, que va desde satisfacer una necesidad básica para su supervivencia hasta transformar el medio ambiente en busca de su bienestar. ${ }^{4}$

También se comprende como la necesidad de autorrealización del hombre que se da en un nivel

4 Teoría de la personalidad, José Cueli... et al. $3^{a}$ ed, México: Trillas, 1990. p.365 
Fuentes de información utilizadas...

más avanzado del mismo como resultado de su evolución, en este nivel se encuentra la necesidad de información, que deriva de una necesidad de conocimiento.

Una necesidad de información dirige al individuo hacia la resolución de sus dudas, por lo que las acciones que realiza para solucionar esa duda están determinadas por las características del sujeto (individuales, sociales, psicológicas y cognitivas). ${ }^{5}$

El fenómeno de las necesidades de información se encarga de estudiar estos comportamientos y los elementos que lo componen, de acuerdo con Calva ${ }^{6}$ son los siguientes:

1. Surgimiento de las necesidades de información.

2. Comportamiento informativo o manifestación de las necesidades de información.

3. Satisfacción de las necesidades de información.

\section{La educación media superior en México}

La EMS en México es el vínculo entre la educación básica y la educación superior, está dividida en tres modalidades las cuales surgieron para garantizar

5 Juan José Calva González, Las necesidades de información: fundamentos teóricos y métodos. México, UNAM, CUIB, p. 116.

6 Ídem p.155 
Investigaciones sobre las necesidades de información,...

una adecuada incorporación de sus egresados a instituciones de educación superior, o en su caso, al mercado laboral.

Actualmente la EMS está compuesta por tres modalidades: ${ }^{7}$

1. Bachillerato General

El bachillerato general ofrece educación de carácter general en diversas áreas, materias y disciplinas, a las cuales se da igual importancia en el plan de estudios: español, matemáticas, ciencias sociales, ciencias naturales, disciplinas filosóficas, artísticas, etcétera.

Ofrece preparación para ingresar posteriormente a la educación superior por lo cual tiene un carácter propedéutico o preparatorio, al concluir los estudios se obtiene certificado de bachillerato.

La ENP es una institución de carácter público que forma parte del sistema de bachillerato de la UNAM, actualmente está conformada por 9 planteles con 48382 alumnos inscritos. Es la institución de EMS con mayor demanda ya que hay planteles que, de acuerdo a COMIPEMS, reciben en el concurso de ingreso hasta 12 solicitudes por lugar disponible.

7 http://www.comipens.org.mx 
Fuentes de información utilizadas...

2. Bachillerato Tecnológico

Esta modalidad es bivalente ya que se puede estudiar el bachillerato al mismo tiempo que una carrera técnica, los estudiantes se preparan como técnicos de nivel medio superior en algunas de las especialidades que ofrece esta modalidad del bachillerato. Cuando se concluyen los tres años de estudio se puede ingresar a la educación superior en instituciones universitarias o tecnológicas.

Los estudios cursados en el Centro de Estudios Científicos y Tecnológicos (CECYT) del IPN, tienen el valor de bachillerato bivalente. $\mathrm{Al}$ concluir estos estudios el egresado recibe un certificado de bachillerato, y se le otorga un título y cédula profesional, esto siempre que el estudiante presente servicio social y acredite su titulación por alguna de las modalidades que el Instituto ofrece.

3. Educación Profesional Técnica

La educación profesional técnica ofrece educación de carácter especializado en un gran número de carreras o profesiones de nivel medio superior. $\mathrm{Al}$ concluir estos estudios se obtiene un certificado técnico profesional y carta de pasante, esta opción no es necesariamente terminal, el estudiante tiene la posibilidad de hacer los estudios complementarios 
Investigaciones sobre las necesidades de información,...

para realizar estudios superiores.

En el caso del Colegio Nacional de Educación Profesional Técnica (CONALEP), en el DF existen 27 planteles, con una población total de 19612 estudiantes, que son preparados para el trabajo y habilitados para acceder a la educación superior. El CONALEP incorpora en su oferta educativa los adelantos tecnológicos y científicos de la sociedad del conocimiento y atiende a los requerimientos del aparato productivo. ${ }^{8}$

Para conocer el comportamiento informativo de los estudiantes de EMS es necesario identificar las características de las instituciones que imparten cada modalidad y de los alumnos inscritos.

En la vida académica el estudiante será motivado a realizar búsquedas de información con el objetivo de responder a dudas que al ser satisfechas le llevaran a incrementar su conocimiento. El estudio de la manifestación de estas necesidades permitirá al bibliotecario tomar decisiones en pro de la satisfacción de sus usuarios.

Las manifestaciones de necesidades de información o comportamiento informativo, se da de acuerdo

8 Concurso de ingreso a la Educación Media Superior de la Zona Metropolitana de la ciudad de México 2007: instructivo. México: COMIPENS, 2007, p.90 
Fuentes de información utilizadas...

a características individuales (sexo, edad, trabajo, etcétera), y en la forma cómo el medio influye en el usuario (nivel educativo de sus padres, situación económica, tipo de bachillerato, etcétera), las cuales serán analizadas en esta investigación.

\section{Metodología}

El método que se aplicará es el descriptivo ya que expone las tendencias y las características de un grupo o población ${ }^{9}$ y el de tipo cuantitativo ${ }^{10}$ porque se usa la recolección de datos para probar hipótesis con base en la medición; también se utilizará el análisis estadístico para establecer patrones de comportamiento y probar teorías.

En la realización de una investigación lo ideal sería desarrollar un trabajo sobre una población extensa pero generalmente es muy costoso en tiempo y dinero, por lo cual los estudios se hacen a partir de una muestra de los sujetos. La muestra debe cumplir con ciertas características para que realmente sea representativa de la población y que a partir de ella se puedan hacer inferencias. El objetivo principal de una muestra es hacer uso eficiente de los recursos y obtener resultados tan precisos como sea posible. Para este estudio se utilizará la técnica de

9 Roberto Hernández Sampieri, Op Cit, pp. 102-103.

10 Roberto Hernández Sampieri, Op Cit, p. 5 
Investigaciones sobre las necesidades de información,...

muestreo simple y el cuestionario como el instrumento para la recolección de datos.

En el caso que nos ocupa la población de EMS está dividida en tres segmentos, de los cuáles se ha elegido un plantel por tipo de bachillerato:

1. Bachillerato General

Plantel No. 3 de la Escuela Nacional Preparatoria "Justo Sierra", perteneciente a la UNAM.

2. Bachillerato Tecnológico

CECYT número 1 "Gonzalo Vázquez Vela" del IPN

3. Educación Profesional Técnica

CONALEP Iztapalapa I, clave 3.

La población es de 7940 estudiantes, constituida por institución de acuerdo al cuadro siguiente:

\begin{tabular}{|l|c|}
\hline \multicolumn{1}{|c|}{ Instituciones } & Número de Alumnos \\
\hline Preparatoria No. 3 UNAM & 4210 \\
\hline CECYT No. 1 IPN & 3168 \\
\hline CONALEP Iztapalapa I & 562 \\
\hline Población & 7940 \\
\hline
\end{tabular}


Fuentes de información utilizadas...

Para determinar el tamaño de la muestra se utilizará la tabla de Krejcie-Morgan. ${ }^{11}$ En su uso ningún tipo de fórmula no es requerida, por lo que se procederá a localizar en la tabla el tamaño de la población identificando de esta manera la muestra establecida.

La tabla maneja los siguientes elementos:

$\mathrm{N}=$ Tamaño de la población

$\mathrm{S}=$ Tamaño de la muestra

Precisión $=.05$

\begin{tabular}{|c|c|}
\hline $\begin{array}{c}\text { Población } \\
\text { N }\end{array}$ & $\begin{array}{c}\text { Muestra } \\
\text { S }\end{array}$ \\
\hline 7940 & 367 \\
\hline
\end{tabular}

Dado que la muestra está integrada por los alumnos de tres diferentes instituciones se deberá realizar una distribución adecuada de la muestra, para lo cual será necesario aplicar la siguiente fórmula:

$$
\mathrm{nh}=\frac{\mathrm{Nh}}{\mathrm{N}}(\mathrm{n})
$$

$\mathrm{nh}=$ Muestra de la institución

11 Ronald R. Powell, Basic research methods for librarians, 4ht ed., pp.83-121. 
Investigaciones sobre las necesidades de información,...

Nh = subpoblación

$\mathrm{N}=$ Población $=7940$

$\mathrm{n}=$ Muestra $=367$

\begin{tabular}{|l|c|c|}
\hline \multicolumn{1}{|c|}{ Instituciones } & $\begin{array}{c}\text { Total de alumnos } \\
\text { Nh }\end{array}$ & $\begin{array}{c}\text { Muestra de los grupos } \\
\text { nh }\end{array}$ \\
\hline Preparatoria No. 3 & 4210 & 195 \\
\hline Cecyt No.1 & 3168 & 146 \\
\hline Conalep Iztapalapa I & 562 & 26 \\
\hline Totales & 7940 & 367 \\
\hline
\end{tabular}

Con base en los resultados se aplicará el número de cuestionarios a la muestra de cada institución.

Es necesario recordar que estas instituciones cuentan con más de un turno de clases, los cuestionarios serán divididos entre los turnos, y grados.

El cuestionario estará estructurado con las mínimas preguntas cerradas posibles, las primeras para datos generales y el resto de tipo likert que son afirmaciones con respuestas que van de 1 a 5 para significar el grado de uso o preferencia.

\section{Bibliografia preliminar}

Andere M. Eduardo. La educación en México: un fracaso monumental: ¿está México en riesgo. México: Planeta, 2003. 224 p. 
Fuentes de información utilizadas...

Arellano Rodríguez, J. Alberto. Guía para la formación de usuarios de la Información. México: DGES: ENBA, 1994. 102 p.

Calva González, Juan José. "Surgimiento y manifestación de las necesidades de información de los investigadores", en Investigación Bibliotecológica: archivonomia, bibliteconomía e información. No. 19, (1995) p. 9.

. "El usuario y el diseño de los servicios bibliotecarios", en Desarrollo de colecciones. México: UNAM. CUIB, 1996.

"Las necesidades de información de la comunidad académica como base en el desarrollo de las colecciones", en Seminario internacional de desarrollo de colecciones (1er. 1998).

"La investigación sobre las necesidades de información en comunidades de usuarios", en Investigación Bibliotecológica: archivonomia, biblioteconomía e información. Vol. 37, no.18 vol. 37. p. 24-55. 
Investigaciones sobre las necesidades de información,...

. "El comportamiento en la búsqueda de información de los investigadores del área de humanidades y ciencias sociales", en Investigación Bibliotecológica: archivonomía bibliteconomía e información. No. 27 (1999) p. 13.

"El fenómeno de los usuarios de la investigación: el fenómeno de las necesidades de la información", en Coloquio de investigaciones bibliotecológicias y de la información: la investigación bibliotecológica en la era de la información (XXI: 24-26 de Septiembre: 2003: México D.F.). memoria. p. $24-26,2003$.

. Las necesidades de información: fundamentos teóricos, sistema bibliotecario de información y sociedad. México: UNAM. Centro de Investigaciones Bibliotecológicas, 2004.

"Una aproximación a lo que son las necesidades de información", en Investigación Bibliotecológica: archivonomía, bibliotecología e información. Vol. 10, no.20, (ene-jun 1996) p.34.

Cariola L. y C. Cox La edución de los jóvenes: crisis de la relevancia y calidad de la enseñanza media. Santiago, Chile: M.I. Mena y S. Ritlenshaussen (eds), 1991. 
Fuentes de información utilizadas...

Carranza Palacios, José Antonio. 100 años de educación en México 1900-2000, México, Limusa, Secretaría de Educación y Cultura del Estado de Veracruz, 2003, 140p.

Ching Chin, Chen. Information seeking. New York, Neal Schuman, 1982, 205 p.

Duran Amavizca, Norma Delia. La quimera o la didáctica en México: el Bachillerato universitario y la observación compartida. México UNAM, 2005, $158 \mathrm{p}$.

Córdoba González, Sayay. "Estudiando las necesidades del usuario a partir de su práctica" en Revista AIBDA, Vol. XVII, núm.2 (jul-dic 1996) pp.149-161.

Comisión Metropolitana de Instituciones Públicas de Educación Media Superior (MÉXICO). Concurso de ingreso a la educación media superior de la zona metropolitana de la ciudad de México 2008: instructivo. México: COMIPENS, 2008, 112 p.

Directrices para los estudios relativos a los usuarios de la información. París, UNESCO, 1981, 41 p. 
Investigaciones sobre las necesidades de información,...

Ensayos sobre bistoria de educación en México. México: El Colegio de México. Centro de Estudios Históricos, 2006. 187 p.

Freund, Jhon E., Gary A. Simon. Estadística elemental, $8^{a}$ ed., México, Pearson, 1992.566 p.

Gallaway, Beth. Pain in the Braian: teen Library Behavior 101. Rowley Public Library, 2005, 205 p.

Gómez, Nancy Diana. "La conducta informativa de los físicos: un estudio cualitativo de usuraos", en Información, cultura y sociedad, No. 4 (2001) pp. 23-36.

Guerra Ramírez, María Irene. ¿Qué sentido tiene el bachillerato?: una visión desde los jóvenes. México, UPN, 2003, 433 p.

Hernández Salazar, Patricia. "El perfil del usuario de información", en Investigación bibliotecológica. Vol.7, no.15 (jul-dic 1993) pp. 13-21.

Henandez Sampieri, Roberto. Metodología de la investigación. $4^{a}$ ed., México, Mc Graw Hill, 2006. $850 \mathrm{p}$. 
Fuentes de información utilizadas...

Jones, Patrick and Joel Shoemaker. Do it right!: Best practices for serving young adults in school and public libraries. New York: Neal Schuman, 2001.

Jones, Jami. “Teens Will be Teens." (Teen Talk) School Library Journal, vol. 51, no 1 January 2005, pp. 37

López Camps, Jordi. Cómo aprender en la sociedad del conocimiento, Madrid, EPISE, 2000. pp. 17144.

Mendoza Rojas, Javier. Transición de la educación superior contemporánea en México: de la planeación al Estado evaluador. México: CESU, 2002, $374 \mathrm{p}$.

México. Secretaría de Educación Pública. Programa Nacional de Educación 2001-2006: por una educación de buena calidad para todos. Un enfoque educativo para el siglo XX. México: SEP, 2001, 241 p.

México. Secretaría de Educación Pública. La reforma integral de la Educación Media Superior. México, SEP, Subsecretaría de Educación Media Superior (2008), 9 p. 
Investigaciones sobre las necesidades de información,...

México. Secretaría de Educación Pública. Reforma integral de la educación media superior en México: la creación de un Subsistema Nacional de Bachillerato en un marco de diversidad. México, SEP, SEMS, 2008. 102 p.

Pagano, Robert R. Estadística para las ciencias del comportamiento, $5^{\text {a }}$ ed., México, Thomson, c2006. 548 p.

Rodríguez Martín, Rosa Alicia. Comportamiento informativo de los alumnos de preparatoria del gobierno del Distrito Federal "Gral. Francisco J. Mújica”, México: R. A. Rodríguez, 2004. 190p. Tesis (licenciatura en bibliotecología) Universidad Nacional Autónoma de México.

Santos, Vilma Moreira dos. Información need and uses of information channels in different phanes of projets: a literature review, en Revista da Escola de Biblioteconomía de UFMG. Vol. 17, no. 2 (sep. 1988) pp. 214-235

Solana Fernando. Educación en el siglo XXI. México, Noriega: FMIA, 1999. 295 p. 
Fuentes de información utilizadas...

. Raúl Cardiel Reyes y Raúl Bolaños. Historia de la educación pública en México. Sección de Obras de Educación y Pedagogía. México,SEP, FCE, 997.

Verdugo Sánchez, José Alfredo. Manual para evaluar la satisfacción de usuarios en bibliotecas de instituciones de enseñanza superior de la República Mexicana. México, CUIB, ANUIES, 1989. 64 p. 



\title{
Nuevas alternativas de servicios bibliotecarios con base en las necesidades de información de los estudiantes de preparatoria de ITESM. Resultados de la investigación
}

\author{
LAURA Miranda MUNGUÍA \\ Posgrado en Bibliotecología y Estudios de la Información \\ Universidad Nacional Autónoma de México
}

\section{Introducción}

T a realización de una investigación como esLta, en la cual la comunidad está integrada por sujetos de bachillerato con edades de 16 a 18 años, con la característica de pertenecer a una institución educativa privada como lo es el Instituto Tecnológico de Estudios Superiores de Monterrey. Este elemento podrá mostrar el perfil de los usuarios de la información con respecto a las bibliotecas que los atienden dentro de esta institución.

La investigación partió a partir de los siguientes aspectos:

- Los grandes cambios que se están desarrollando en el mundo actual; los que motivan al profesionista de la información para que busque mecanismos adecuados para conocer más a los usuarios, aplicados en una interacción 
Investigaciones sobre las necesidades de información,...

directa y el diseño de nuevos servicios, para atender las diversas demandas.

- Una parte estratégica para conocer a nuestros usuarios es la aplicación del Modelo NEIN, el cual está integrado por 3 aspectos: surgimiento de las necesidades de información, comportamiento informativo y satisfacción de las necesidades de información.

- Con base en la primera parte de este modelo, se realizó el presente estudio para conocer las necesidades de información en adolescentes de 15 a 18 años, con una vinculación con sus intereses, en su ámbito recreativo o de pasatiempo.

\section{Metodología:}

La metodología para llevar a cabo esta investigación fue de tipo cuantitativo ya que de una población de sujetos se obtuvo una muestra y se contabilizaron los resultados para ver poder extrapolar los resultados hacia toda la población.

El alcance de esta investigación fue en la Rectoría Zona Centro (RZC) del Instituto Tecnológico y de Estudios Superiores de Monterrey (ITESM), que comprende 3 campus: Estado de México, Querétaro y Toluca.

Así el objetivo planteado fue identificar las necesidades de información y a partir de ellas proponer 
Nuevas alternativas de servicios bibliotecarios...

nuevas alternativas de servicios bibliotecarios para los estudiantes de preparatoria de la RZC del ITESM.

Se utilizó la técnica de investigación documental, y la encuesta, con aplicación de un cuestionario a los estudiantes.

\section{Análisis de resultados}

Debido a que se presenta la conclusión de esta investigación se le dio mayor peso a presentar de forma general los resultados obtenidos.

- La información buscada en el último mes fue la relativa a la música, los deportes, las universidades, cine, libros de literatura, entre otros.

- La información específica que le gustaría tener coincide con los temas señalados anteriormente, solo cambio el orden en que fueron citados. (Universidades, música, deportes, crisis económica, arte, libros de literatura, entre otros)

- Los motivos que expresaron tener en la búsqueda de información fueron: interés, curiosidad, para aprender, el ocio, actualización.

- Dentro de los pasatiempos favoritos de esta comunidad de usuarios fueron mencionados los deportes, escuchar música, leer, salir con amigos, tocar instrumentos musicales, entre otros. 
Investigaciones sobre las necesidades de información,...

- Actividades extra-curriculares que cursa el estudiante fueron mencionados: fútbol soccer, taller de arte, natación, tenis, teatro dan$\mathrm{za}$, entre otras.

\section{Conclusiones:}

Las conclusiones generales obtenidas de esta investigación son las siguientes:

- Los temas de recreación buscados por los estudiantes fueron la música, deportes y orientación profesional principalmente, con los dos primero temas se confirma la hipótesis que su clase extra-curricular que cursan influye en sus necesidades de información.

- Se debe considerar un punto a favor y de oportunidad de la biblioteca el haber señalado a la lectura como el tercer pasatiempo favorito de los estudiantes de preparatoria.

- Se confirma la importancia de realizar estudios para la identificación de necesidades de información que nos permita conocer e integrar perfiles de los usuarios para un mejor desarrollo de nuestros procesos y servicios.

\section{Propuestas:}

- Mantener una comunicación con el departamento de División de Asuntos Estudiantiles 
Nuevas alternativas de servicios bibliotecarios...

(DAE) de quién depende las actividades extraacadémicas.

- Ofrecer servicios de alerta de acuerdo a los intereses de información para la recreación manifestados por los usuarios.

- Evaluar la factibilidad de montar exhibición de los materiales con que cuenta la biblioteca de acuerdo a los temas señalados de su interés, buscando un acercamiento en los lugares de esparcimiento que ocupan los estudiantes para dar a conocer los diversos materiales con que cuenta la biblioteca. 



\title{
Investigación del fenómeno de las necesidades de información en comunidades de vitivinicultores en México
}

\author{
JUAN José CALVA GonZÁlez \\ Coordinador del Proyecto PAPIIT IN404048 \\ Centro Universitario de Investigaciones Bibliotecológicas \\ Universidad Nacional Autónoma de México
}

\begin{abstract}
T a investigación se presenta como un ciclo: surgiLmiento de las necesidades de información, comportamiento informativo y satisfacción, ya que el fenómeno de las necesidades de información está formado básicamente por estas tres fases, las cuales pueden ser investigadas en diversas comunidades y en este caso en la compuesta por los vitivinicultores mexicanos.

La investigación conllevó a realizar un proyecto el cual fuera aprobado dentro del Programa de Apoyo a Proyectos de Investigación e innovación Tecnológica (PAPIIT) IN404408 por parte de la Dirección General de Asuntos del Personal académico de la UNAM, con lo anterior se podría dar inicio a una investigación abarcando las cinco regiones vitivinícolas del país a saber: Baja California, comarca lagunera (Aguascalientes, Durango y Zacatecas), Querétaro, Coahuila y Guanajuato.
\end{abstract}


Investigaciones sobre las necesidades de información,...

El adentrarse a investigar una comunidad no académica sino mas bien industrial era indudable que se surgieran muchos contratiempo como lo era de esperarse. Así los colaboradores de este proyecto tuvieron que enfrentarse al acercamiento con los vitivinicultores a los cuales en la mayoría de los casos les fue difícil y complicado ya que no esperaban a bibliotecólogos del área de humanidades llevando a cabo una investigación sobre los plantíos de viñedos, elaboración de vino y comercialización del mismo.

A pesar de la dificultad en el acercamiento a los vitivinicultores, ésta se logró a través de la persistencia y explicación concreta de la investigación y sus objetivos. Así es como se presentan en este libro los avances de las investigaciones que se están llevando a cabo en las cinco regiones vitivinícolas del país.

En la región de Baja California, la de mayor extensión de las cinco, ésta por concluirse la investigación a través de la información obtenido con todos los vitivinicultores en los cuales se contempla a los grandes productores como Cetto y Monte Xanic, pero también a los pequeños como ByBayoff.

Por otro lado se presenta también a la región de Parras con tres de las casas vitivinícolas, la más extensa y antigua de ellas Casa Madero, pero también se tiene dentro de la investigación a Ferriño y a la empresa Vinos Vitali. Esta investigación también 
Investigación del fenómeno de las necesidades...

está por ser terminarse, ya se tienen las visitas y entrevistas con los vitivinicultores de dichas industrias.

Asimismo también se tiene un avance en lo relacionado con la región de Querétaro donde sólo se ubican tres empresas que producen vinos, una de ellas, la más grande, Cavas Freixenet, seguida por La Redonda y una más pequeña y artesanal Vinícola San Patricio. El grado de avance de esta investigación concluirá después de llevar a cabo la última visita y entrevistas con los vitivinicultores.

De igual forma se contempló a la región de Guanajuato para verificar la existencia de dos o tres vitivinicultores, uno de ellos, el que está en marcha y evaluación, Cavas Manchón en Dolores Hidalgo, posee una amplia tradición histórica desde la época de antes de la guerra de Independencia ya que dichos viñedos estaban en esa época a cargo del Cura Hidalgo. Asimismo se tiene un acercamiento a los vestigios y lo que queda de los Viñedos San Luis Rey en la ciudad de San Luis de la Paz, los cuales se investigará si aun continúan en producción o lo que pasó con ellos, por otro lado se tiene noticia de otra empresa ubicada en San Miguel de Allende la cual se investigará en fechas próximas.

Así es como esta investigación es la primera en incursionar en comunidades de usuarios de la información industriales y que con la utilización del 
Investigaciones sobre las necesidades de información,...

Modelo NEIN ${ }^{1}$ se ha permitido casi contemplar dicha investigación la cual queda concluida en los próximos meses. Los productos de dicha investigación serán distribuidos a las diferentes vitivinícolas y en espera de obtener resultados que permitan contribuir al desarrollo de esta industria desde la bibliotecología.

Lo anterior sin perder de vista la finalidad de todo el proyecto que en general es identificar las necesidades de información y el comportamiento informativo de los vitivinicultores de las cinco regiones que se tienen identificadas en el país. Asimismo todas las investigaciones se encuentran aplicando un método directo y preguntando a los sujetos de investigación directamente con la aplicación de una cédula de una entrevista.

Por otro lado, con respecto a la planeación de este proyecto, se terminará en el año 2010 con la conclusión de la región de Parras, la de Aguascalientes, Zacatecas y Durango y la correspondiente a Querétaro y Guanajuato. Cabe señalar que se tiene terminada la investigación relativa Regulaciones nacionales e internacionales sobre la producción de Vitis vinífera: Información para los vitivinicultores.

1 Cfr. El Modelo NEIN en la obra: Juan José Calva González. Las necesidades de información. Fundamentos teóricos y métodos. México: UNAM, Centro Universitario de Investigaciones Bibliotecológicas, 2004. 


\title{
Los vitivinicultores de la región de Baja California: necesidades de información y comportamiento informativo. Avances de investigación
}

\author{
FERMÍN LÓPEZ FRANCO. \\ Colégio de Bibliotecología. \\ Universidad Nacional Autónoma de México.
}

\section{Introducción}

$\mathrm{F}^{1}$ presente trabajo se encuentra auspiciado denEtro del proyecto PAPIIT IN 404408-3 que abarca diversas comunidades vitivinícolas del país.

Los vitivinicultores manifiestan sus necesidades de información y comportamiento informativo, pero se desconocen los aspectos de este proceso, como por ejemplo, no se tiene la certeza del lugar y las fuentes de información a las que acuden para llevar a cabo sus diferentes actividades como son la selección de la uva de acuerdo a la zona, la siembra, cosecha, producción y comercialización de la vid, además del embotellamiento de sus productos.

Antes de continuar se debe reflexionar en torno a que elementos se deben identificar para determinar las características de los usuarios, es decir, los factores internos como su formación académica, los idiomas que domina, actualidad de los materiales 
Investigaciones sobre las necesidades de información,...

que consulta y los factores externos como su contratación en la compañía en que se desempeña.

Un aspecto importante para indagar el entorno de los vitivinicultores, es que al ser un sector productivo y que la bibliotecología como disciplina en un momento determinado apoye sus actividades al existir en México en sus diferentes regiones casas productoras de vino, y que

en materia de empleos, los vitivinicultores en conjunto generan 9 mil 500 fuentes de trabajo, repartidos en 4 mil 500 empleos directos (incluidas las fábricas, oficinas y laboratorios de producción) y casi 5 millones de jornales (campo vitícola, manuales y otros servicios). ${ }^{1}$

Las necesidades de información surgen de una motivación para buscar, recuperar y usar la información la cual tiene un carácter eminentemente utilitario y de producción. Aún para los investigadores que aparentemente utilizan información sin fines prácticos e inmediatos, ésta utilización está fundamentada en la necesidad de producir conocimiento, o simplemente para apoyar la toma de decisiones. ${ }^{2}$

1 "Profesionales del vino mexicano y de las vinícolas en México" http://vinosdemexico.homestead.com/vinicolas.html 1-jun-2008

2 Terminología relacionada con los estudios de usuarios". - En: Seminario Latinoamericano sobre Formación de Usuarios de la Información y Estudios de Usuarios. - México: CUIB, 1997. - p 3. 
Los vitivinicultores de la región de Baja California:...

Con la definición anterior se puede reafirmar que el concepto de "necesidades de información" es un término abstracto construido expresamente para identificar lo que un individuo a manera personal, profesional, etc, requiere para satisfacer su carencia de información y así obtener el o los documentos que demanda para satisfacer dicha necesidad.

Hasta el momento se ha tratado sobre el aspecto de las necesidades de información, pero qué sucede con el comportamiento informativo, que es la forma en que se consulta la información, las fuentes, los recursos y los formatos en que los usuarios buscan su información.

Calva González menciona que el comportamiento

está delimitado por factores individuales (fisiológicos, emocionales, cognitivos) y sociales, únicamente separables con fines descriptivos, ya que los factores se combinan y condicionan. El comportamiento puede ser comprendido en función de las necesidades que presentan las personas dentro del contexto en el cual ocurre. $^{3}$

3 Juan José Calva González. "Las necesidades de información de la comunidad académica como base en el desarrollo de las colecciones". - En: 1er. Seminario Internacional de Desarrollo de Colecciones. - México: UNAM, CUIB, 1998. - p. 52 
Investigaciones sobre las necesidades de información,...

De acuerdo a los párrafos anteriores se infiere que el comportamiento informativo surge de las necesidades que tiene el individuo y se manifiestan en las fuentes y formatos a los que acude para obtener la información que requiere.

Como se ha observado hasta el momento, el comportamiento informativo abarca los hábitos, costumbres, actitudes, procedimientos y habilidades, que se manifiestan durante la búsqueda y/o localización de la información, así como también incluye la utilización de las fuentes y recursos informativos.

Existe un modelo presentado por Kuhlthau, quien identifica seis etapas en el proceso de búsqueda de información hacia donde los buscadores de información se mueven de la senda de la incertidumbre hacia la construcción del entendimiento.

Dicho modelo comienza con los siguientes paSOS:

- Iniciación, va de los sentimientos a la incertidumbre.

- Selección, aquí se identifican las posibles fuentes de información.

- Exploración, la persona explora la información general y escoge un tópico, sentimientos de incertidumbre y confusión incrementan está etapa y al mismo tiempo la incapacidad de expresar concretamente que información 
Los vitivinicultores de la región de Baja California:...

se requiere.

- Formulación, esta es la parte más crítica del proceso donde el buscador de la información se enfoca a la solicitud.

- Recolección, este es posterior a la formulación, aquí se clarifica la incertidumbre en la cual se encontraba el solicitante de información, aquí se encuentra en una etapa de confianza y claridad respecto a lo que solicita y es aquí donde se obtiene la información.

- Presentación, en esta etapa de alivio en que la búsqueda esta completa y se expone el trabajo realizado con la información obtenida a lo largo del proceso. ${ }^{4}$

En particular, en el área vitivinícola no se han encontrado estudios sobre las necesidades y el comportamiento informativo de la comunidad de vitivinicultores en un país determinado.

Se han ubicado trabajos que tratan sobre las necesidades y el comportamiento informativo en el área de la agricultura y necesidades de información de campesinos.

Las ciencias biológicas y agrícolas son áreas muy cercanas ya que examinan aspectos fundamentales

4 Simon Attfield. "Information seeking in the context of writing: a design psychology interpretation of the problematic situation". En: Journal of Documentation. Vol. 59, No. 4, 2003. - p. 432 
Investigaciones sobre las necesidades de información,...

de los sistemas vivos y su relación con el medio ambiente, mientras que las ciencias agrícolas se enfocan a aspectos nacionales y globales de la producción y el consumo de alimentos. ${ }^{5}$

El estudio de Kuruppu tiene por objetivo examinar las necesidades de información de científicos del área de la biología y la agricultura en la Universidad estatal de Iowa, relacionados con la enseñanza, investigación y actividades de extensión.

Los cuestionamientos de los que parte Kuruppu para llevar a cabo su trabajo, son los siguientes:

- ¿Cuál es el tipo de información que utilizan los científicos de las áreas biológica y agrícola?

- ¿Qué fuentes utilizan ambas comunidades?

- ¿Qué herramientas y procedimientos utilizan para localizar su información?

- ¿Qué fuentes y servicios adicionales les gustaría tener disponibles para encontrar su información? ${ }^{6}$

En los cuestionamientos de Kuruppu se observa que incluye necesidades y comportamiento en

5 Pali U. Kuruppu. "Understanding the information needs of academic scholars in agricultural and biological sciences".-En: The Journal of Academic Librarianship. Vol. 32, No. 6, 2006. - p. 609

6 Pali U. Kuruppu. "Understanding the information needs of academic ... Op. Cit. - p. 611 
Los vitivinicultores de la región de Baja California:...

la búsqueda de información, y menciona los motivos por los cuales los investigadores requieren y las fuentes a los que acuden para localizar su información.

Lisa Nason menciona la contribución de los agricultores en la economía de los Estados Unidos, señala que

los agricultores en el desarrollo de las naciones tiene necesidades similares a las de sus colegas norteamericanos, como son el tipo de suelo de los campos de cultivo, el clima y necesitan acceder a tecnología agrícola, obtención de créditos y mercado de precios. ${ }^{7}$

Los aspectos que menciona Nason y que requieren los granjeros son los siguientes:

- Información sobre métodos de agricultura

- Legislación y políticas operaciones agrícolas

- Políticas de mercado

La información que requieren los vitivinicultores para el desarrollo de sus actividades no se expresan claramente ya que no existen trabajos que

7 Lisa Nason. "The farmers in the library: information needs of farmers and how the rural public library can fulfill them".-19-45 p. - En: Rural Library. - Vol. 27, No. 2, 2007. - p. 20 
Investigaciones sobre las necesidades de información,...

aludan a dicha comunidad, pero puede inferirse de lo que necesitan los agricultores: ${ }^{8}$

- Información sobre siembra y cosecha

- Economía y administración de la granja

- Mercadotecnia

- Direcciones de expertos

Las fuentes a las que alude Nason y en las que busca su información la comunidad citada son las siguientes:

- Fuentes electrónicas, entre las que se encuentra la base de datos PLANTS, AGRICOLA

- Radio y televisión

- Publicaciones para granjeros y agricultores.

- Bibliotecas

- Servicios Cooperativos

- Estaciones experimentales 9

En lo que respecta al comportamiento en la búsqueda de información sucede la misma situación que en el caso de las necesidades, no existe información

8 Simon K. Osei. A study of the information needs of agricultural extension agents in Ghana. - En: Quarterly Bulletin. - Vol. 51, No. 2, 2006. - p. 82

9 Lisa Nason. "The farmers in the library: information needs of... Op. Cit. - p. 24 
Los vitivinicultores de la región de Baja California:...

de este tipo de usuarios, la información encontrada se relaciona con la agricultura. ${ }^{10}$

Fuentes de información:

- Colección personal de libros

- Contacto con colegas

- Contacto con supervisores

- Contacto con investigadores

- Sesiones de entrenamiento

- Granjeros

- Bibliotecas

- Centros de Información Agrícola

- Televisión

- Radio

- Periódicos

- Revistas

También Nason menciona algunas fuentes a las que acuden los granjeros y son las siguientes: ${ }^{11}$

- Recursos electrónicos para granjeros

- Radio y televisión

- Publicaciones

10 Simon K. Osei. A study of the information needs of agricultural... Op. Cit.- p. 86

11 Lisa Nason. "The farmers in the library: information needs of... Op. Cit.- p. 24 
Investigaciones sobre las necesidades de información,...

- Servicios de cooperación

- Estaciones experimentales agrícolas

Se aprecian las distintas fuentes a las que puede acudir un agricultor, además de la variedad de recursos a los que puede acudir el usuario cuando requiere información más allá de la biblioteca.

En el ámbito latinoamericano Omar Jofré Fuentes menciona que

los campesinos requieren información para resolver cuestiones como: información sobre la actividad silvoagropecuaria y para el profesional de la actividad. ${ }^{12}$

Este autor hace una reflexión diciendo que al igual que otras actividades y profesiones se requieren los dos aspectos mencionados anteriormente, ya que la investigación es un ámbito de la actividad y obliga al desarrollo profesional y a su vez, su sistematización exige a la investigación el desarrollo de la actividad.

Para comprender a los vitivinicultores se hace necesario conocer diversas definiciones para comprender a la industria vinícola.

12 Omar Jofré Fuentes. "El campesino como usuario de la información”. -- 109-111 pp. - En: Revista de la Asociación Interamericana de Bibliotecarios, Documentalistas y Especialistas en Información Agrícola. - Vol. XIV, No. 2, 1993. - p. 110 
Los vitivinicultores de la región de Baja California:...

En las obras consultadas se menciona que no es fácil seguirle la pista al vino desde su nacimiento. La historia de esta bebida y el desarrollo de la civilización han estado ligados desde siempre, por esto determinar con precisión quién, dónde y cuándo se elaboró el vino por primera vez, sería tanto como averiguar cómo se inventó la rueda, algo que en ambos casos pudo haber sido obra de la casualidad; tal vez un hombre que comió uvas con inicios de fermentación al haber sido almacenadas por largo tiempo, experimentó un sopor desconocido que le gustó y con su ingenio innato, descubrió como repetir.

El cultivo de la vid para la producción del vino es una de las actividades más antiguas de la civilización, probablemente contemporánea al comienzo de ésta. Existe evidencia que los primeros cultivadores de viñas y productores de vino, se encontraban en la región de Egipto y Asia Menor, durante el neolítico. Al mismo tiempo que los primeros asentamientos humanos permanentes empezaron a dominar el arte del cultivo y la cría de ganado, así como el de la producción de cerámica.

Antes de continuar es conveniente mencionar la definición de uva, vitivinicultura y la enología, las cuales se presentan a continuación:

La uva es una fruta obtenida de la vid. Las uvas, granos de uva, vienen en racimos y son pequeñas 
Investigaciones sobre las necesidades de información,...

y dulces. Se comen frescas o se utilizan para producir mosto, vino y vinagre. Crecen agrupadas en racimos de entre 6 y 300 uvas. Pueden ser negras, moradas, amarillas, doradas, púrpura, rosadas, marrones, anaranjadas o blancas, aunque estas últimas son realmente verdes y evolutivamente proceden de las uvas rojas con la mutación de dos genes que hace que no desarrollen antocianos, siendo estos los que dan la pigmentación.

La uva. Fruto de la vid que es una baya más o menos redonda y jugosa la cual nace apiñada con otras, adheridas todas a un vástago común por un pezón formando racimos. ${ }^{13}$

Existen variedades de uvas a las cuales se les denomina cepas entre las que se dividen las blancas y tintas, entre las primeras se encuentran las siguientes:

- Blancas: Chardonnay, Sauvignon Blanc, Sémillon, Riesling, Chenin Blanc, Gewurztraminer, Pinot Gris/Grigio, Viognier, Moscatel.

- Tintas: Cabernet Sauvignon, Merlot, Pinot Noir, Syrah, Nebbiolo, Tempranillo, Sangiovese, Zinfandel.

13 Enciclopedia universal ilustrada: europea americana. - Madrid: Espasa-Calpe, 1996. - Tomo 66. - p. 198 
Los vitivinicultores de la región de Baja California:...

Para comprender a la industria vinícola en México se considera necesario hacer una revisión de dicha industria con algunos países de Europa y del continente americano, a continuación se presentan brevemente algunos aspectos de algunos países de los continentes mencionados:

- Francia: El clima de Francia es de los poco prometedores de las regiones vitícolas. Un aspecto que favorece la producción de vinos son sus suelos, son tan diversos que permiten casi cualquier variedad de uva de cualquier calidad, dado que la materia prima, es decir, la uva, crece en una variedad de climas lo que permite también que exista variedad en los vinos que se producen.

- Italia: El clima italiano, las ricas tierras y unas muy antiguas tradiciones en la vinicultura, hacen de Italia la nación natural del vino. Los vinos son tan personales y diferentes como los nombres y tan parte de la vida italiana.

- España: No existe una clara unanimidad sobre el lugar en el que comenzaron a realizarse los primeros cultivos de vid en España y quienes fueron los que introdujeron las técnicas de elaboración del vino. Diversas fuentes apuntan que los primeros viñedos se habrían asentado en el litoral sudoccidental andaluz 
Investigaciones sobre las necesidades de información,...

constituyendo el punto de entrada y el lugar de las viñas más antiguas de España.

- Estados Unidos: Se dice que el vikingo Leif Ericsson quien desembarcó en Terranova hacia el año 1,000, revela que la vid crecía en esa región con cierta abundancia, por esta razón se le denominó Vinland. Los primeros vinos fueron de mesa en el siglo XVII los jesuitas produjeron vino en Quebec, como hicieron las misiones franciscanas en Nuevo México, sobre el río Bravo.

- Argentina: A partir de una superficie plantada de 212000 hectáreas la Argentina es el quinto productor mundial de vinos con unos 1500 millones de litros anuales. Pero con 38 millones de habitantes que beben cada año unos 30 litros por persona, casi todo el vino de país es consumido por los sus ciudadanos, contrario a lo que ocurre con sus vecinos chilenos, de cada 10 botellas elaboradas nueve son bebidas por los argentinos y solo una se exporta

- Chile: Al igual que en el caso de México, las vides llegaron a Chile, Argentina y Perú gracias a los conquistadores españoles en el siglo XVI y prácticamente en la actualidad todos los países sudamericanos producen vino. 
Los vitivinicultores de la región de Baja California:...

Hasta el momento se ha tratado sobre la vitivinicultura en otros países para contar con un panorama general de lo que sucede en otros países, por lo que respecta a México podemos ubicarlo como el productor americano más antiguo de vino, pero su industria de vinos de calidad es relativamente reciente. Los vinos rústicos, el tequila, el mezcal, entre otros, todavía dominan la producción y el país enfrenta una fuerte competencia ante sus vecinos del norte (Estados Unidos) y del sur (Argentina y Chile).

El nombre de California fue dado por Gari Ordóñez de Montalvo a un imaginario país mencionado en su novela de caballerías "Las sergas de Esplandían" continuación de Amadís de Gaula, pero la mítica tierra de California aparece aún antes en la "Chanson de Roland". Se le llamó así a la península, por voz común, hacia 1539 al regreso de los supervivientes del viaje que hizo a ella Francisco de Ulloa. ${ }^{14}$

Los jesuitas plantaron las primeras vides en las misiones de Baja California desde 1697 y fueron reemplazados por los franciscanos cuando en 1767 se les expulsó de América. Finalmente los Dominicos continuaron con esa actividad, abriendo nuevas misiones y cultivos en los valles de Guadalupe y Santo Tomás.

14 Enciclopedia de México. - México: Enciclopedia de México, 2003. - T. 2, p. 782 
Investigaciones sobre las necesidades de información,...

Baja California es uno de los estados más importantes de México en lo que a producción agrícola y pesca se refiere. Hoy cuenta además con una creciente industria de procesamiento de alimentos.

Entre los productos alimenticios bajacalifornianos destacan: ${ }^{15}$

- Hortalizas: brócoli, espárrago, cebollín, tomate, fresas, dátiles, etc.

- Pescados y mariscos: atún, macarela, sardina, almeja, mejillón, langosta, camarón y abulón.

- Bebidas: jugos de frutas, refrescos, cerveza y vinos.

Especial mención merece la industria vitivinícola, ya que la producción de Baja California equivale a más del $90 \%$ del vino producido en el país. Muchos de estos productos, por su alta calidad, son comercializados en los exigentes y sofisticados mercados de Norteamérica, Japón y la Unión Europea.

Esta es la zona templada conocida como la franja del vino, situada entre los 30 y 50 grados de latitud norte y cuyas propiedades climáticas se conocen como las de clima mediterráneo: hay inviernos húmedos y veranos secos y templados, eso permite obtener

15 Baja California: la frontera mexicana para negocios de éxito. http:// www.investinbaja.gob.mx/industrias/alimentos.htm 27-sep-2008 
Los vitivinicultores de la región de Baja California:...

cosechas de máxima calidad, las zonas vinícolas de Baja California son las siguientes:

- Valle de San Antonio de las Minas al noroeste de Ensenada.

- Valle de Guadalupe y Valle de Calafia al noroeste de Ensenada.

- Valle de Santo Tomás, a 45 Km., al sur de Ensenada.

- Valle de San Vicente, a unos $90 \mathrm{Km}$., al sur de Ensenada.

En particular se estudia a los valles de San Antonio de las Minas y de Guadalupe:

- San Antonio de las minas es un pequeño pueblo de 494 habitantes, ubicado a 240 metros de altitud y considerado uno de los principales atractivos ya que es el corazón de la llamada ruta del vino, que se extiende también hacia el norte al Valle de las Palmas y hacia el sur a los de Santo Tomás y San Vicente Ferrer, lugares en donde se cultivan uvas Chenin Blanc, Colombard, Sauvignon Blanc y Chardonnay para los vinos blancos, al igual que Cabernet Sauvignon, Merlot, Cabernet Franc, Grenache, Carignan, Barbera, Nebbiolo y Zinfandel para los tintos. En el pueblo puede 
Investigaciones sobre las necesidades de información,...

visitar los Vestigios de las Minas de San Antonio, las cuales dieron origen a este poblado en el siglo XIX. En el museo, ubicado en la calle principal, podrá deslumbrarse con los restos de una compañía minera abandonada del siglo XIX. ${ }^{16}$

- El Valle de Guadalupe, es una región vitivinícola localizada en el estado de Baja California, México. Se le conoce equivocadamente también como Valle de Calafia, nombre que se ha intentado usar para promover los productos de esta región a nivel nacional e internacional, sin embargo, el nombre correcto es Valle de Guadalupe, establecido gracias a la misión que los franciscanos establecieran en una de sus mesetas la Misión de Nuestra Señora de Guadalupe del Norte, misma que los indígenas nativos destruyeran en el año de 1840 aproximadamente. ${ }^{17}$

Algunos de los viñedos y vinícolas que se encuentran en dichos valles son las siguientes:

16 Caminata mensual a San Antonio de las Minas en Ensenada http:// bajacalifornia.travel/caminata-mensual-a-san-antonio-de-las-minasen-ensenada/ 1-sep-2008

17 Valle de Guadalupe en Wikipedia. http://es.wikipedia.org/wiki/Valle_de_Guadalupe_(Baja_California) 30-junio-2008 
Los vitivinicultores de la región de Baja California:...

\begin{tabular}{|l|l|}
\hline \multicolumn{1}{|c|}{ San Antonio de las Minas } & \multicolumn{1}{c|}{ Valle de Guadalupe } \\
\hline - Viñas de Liceága. & - L. A. Cetto. \\
- La Casa Vieja. & - Monte Xanic. \\
- Casa de Piedra. & - La Casa de Doña Lupe. \\
- Vinisterra. & - Pedro Domecq. \\
- Bibayoff. & - Adobe Guadalupe. \\
- Viñas de Pijoan. & - Chateau Camou. \\
- Mogor Badán. & - Barón Balché. \\
- Vitivinícola Tres Valles. & - Viñedos Malagón. \\
& - Vinos Tintos del Norte 32. \\
& - Vinícola EMEVE. \\
\hline
\end{tabular}

Se ha investigado de los apoyos que proporcionan instituciones gubernamentales a la industria vinícola como las siguientes:

- Secretaría de Agricultura, Ganadería, Desarrollo Rural, Pesca y Alimentación

- Instituto Nacional de Investigaciones Forestales, Agrícolas y Pecuarias

- Nacional Financiera

- Bancomext

- Infotec

- Financiera Rural

Para la realización de este trabajo se realizará un estudio de usuarios, éste permite identificar la forma en que las personas o grupos usan los recursos y fuentes informativas, aunque en el caso de los vitivinicultores no queda de manifiesto si asisten a la biblioteca o no, quedando como interrogante a qué 
Investigaciones sobre las necesidades de información,...

recursos acuden cuando requieren de información para desarrollar sus actividades.

Según datos proporcionados por la Asociación de Vitivinicultores de Baja California, son 21 vinícolas asociadas a dicho organismo, aunque en folletos obtenidos en la región se mencionan algunas más.

Por lo que respecta a la metodología se hizo uso de:

- Investigación documental y análisis crítico.

- Investigación de campo

Las técnicas que se emplearon son las siguientes:

- Encuestar directamente a los productores de Vitis vinífera

El instrumento que se utilizó es la:

- Cédula de entrevista

La aplicación de la cédula de entrevista se llevó a cabo del día 10 al 15 de julio del año 2009, se pudo contactar con 14 vitivinicultores, en 5 casos se les entregó el instrumento no al enólogo sino al administrador comentando que se debía de revisar antes de entregar las respuestas para ver que tipo de información se solicita. 
Los vitivinicultores de la región de Baja California:...

La cédula de entrevista se estructuró en dos partes:

1) Datos personales, como nombre del entrevistado, edad, profesión, puesto en la empresa y años en la misma, relación con el viñedo y cómo nace su interés por la industria del vino

2) Información que necesitan y fuentes o recursos a los que acuden para obtenerla, actividades que realizan.

De los datos que se han obtenido son los siguientes:

1) Por lo que respecta la primera parte de la cédula se obtuvieron los siguientes datos:

- Ingeniero agrónomo, ayudante del viticultor, enólogo principal, ayudante del enólogo, agricultor, maestro normalista, bibliotecaria, biólogo.

- La edad de los entrevistados fluctúa de los 26 hasta los 56 años.

- Años en la organización, manifiestan de 4 hasta 55 años, hay quien menciona toda su vida.

- La relación que tienen con el viñedo mencionan que tiene que ver con la cosecha, 
Investigaciones sobre las necesidades de información,...

encargado del viñedo, dueño, socio, enólogo.

- De cómo nace su interés por la vitivinicultura comenta que es por herencia de sus padres y abuelos, personal.

2) En lo concerniente a la segunda parte de la cédula se pudo recabar la siguiente información:

- Las actividades que realizan en su trabajo son: la planeación, plantación, cosecha, cuidado del viñedo, vinificación, embotellado, venta, encargado de todo el rancho, selección de la uva, maquinaria, administración, cata.

- En la forma que obtienen su información mencionan que: distribuidores, catálogos de venta, páginas de Internet, personas del medio, colegas, asesores, conferencias, libros, revistas, experiencia.

- Cuando existe algún problema en las distintas fases del proceso acuden a asesores, colegas, experiencias.

- Al momento de cuestionarles hectáreas siembran, menciona que depende de la extensión de la propiedad.

- La forma en que determinan cuántas hectáreas sembrar para producir determinado tipo de vino depende de lo que 
Los vitivinicultores de la región de Baja California:...

quieren producir, el mercado, decisión propia, experimentar.

- La información que requiere es sobre el clima, suelos, plagas.

- Dan a conocer sus productos a través de ferias, promoción directa, concursos, mercado exterior, Internet, venta en restaurantes, eventos de la zona, radio.

- Tienen conocimiento del mercado en la región, en el país y en el extranjero.

- En caso de tener algún problema en el proceso que no pueden resolver acuden con el especialista, es decir, al de la maquinaria, al contador en caso de impuestos.

- Son miembros de asociaciones, llevan una bitácora para documentar sus procesos o eventos significativos.

- La forma en que se ven en el futuro es de conservar su imagen, contar con más difusión, renovarse, conservar su mercado y calidad sin perder su esencia o identidad, algunos quieren crecer como productores, otros quieren ser medianos o pequeños productores, conservar su calidad y nos sacrificarla por la cantidad. 
Investigaciones sobre las necesidades de información,...

A manera de conclusión puede observarse que en cierta medida y por los datos que se han obtenido hasta el momento, se pueden mencionar que los vitivinicultores de la región de Baja California y en particular los de los valles de san Antonio de las Minas y de Guadalupe, manifiestan sus necesidades de información de la siguiente manera:

- Requieren información sobre economía y administración de la vinícola

- Mercadotecnia

- Legislación y políticas agropecuarias.

- Políticas de mercado

Por lo que respecta a la forma en que buscan su información, es decir su comportamiento lo manifiestan de la siguiente forma:

- Cuentan con colección personal de libros

- Tienen contacto con colegas

- Acuden a expertos del área (contadores, agrónomos)

- Revistas 
Los vitivinicultores de la región de Baja California:...

\section{Bibliográfía}

Attfield, Simon. "Information seeking in the context of writing: a design psychology interpretation of the problematic situation". En : Journal of Documentation. Vol. 59, No. 4, 2003. - p. 432

Calva González, Juan José. "Las necesidades de información: la Difusión de estudios en las Jornadas Mexicanas de Biblioteconomía”. - En: Jornadas Mexicanas de Biblioteconomía (32: 2001 Jalapa, Ver.). - pp. 229-245

Jofré Fuentes, Omar. "El campesino como usuario de la información". - En: Revista de la Asociación Interamericana de Bibliotecarios, Documentalistas y Especialistas en Información Agrícola. Vol. XIV, No. 2, 1993. - 109-111 pp.

Kuruppu, Pali U. "Understanding the information needs of academic scholars in agricultural and biological sciences".-pp. 609-623 En: The Journal of Academic Librarianship. Vol. 32, No. 6, 2006.

Nason, Lisa. "The farmers in the library: information needs of farmers and how The rural public library can fulfill them".-19-45 pp. - En: Rural Library. - Vol. 27, No. 2, 2007. - p. 20 
Investigaciones sobre las necesidades de información,...

Osei Simon K. A study of the information needs of agricultural extension agents in Ghana. - p. 82-88. -- En: Quarterly Bulletin. - Vol. 51, No. 2, 2006. "Profesionales del vino mexicano y de las vinícolas en México" http://vinosdemexico.homestead.com/vinicolas.html 1-jun-2008

Terminología relacionada con los estudios de usuarios". - En: Seminario Latinoamericano sobre Formación de Usuarios de la Información y Estudios de Usuarios. - México: CUIB, 1997. - p 3. 


\title{
Aguascalientes, Zacatecas y Durango, empresas vitivinícolas del siglo $\mathrm{XX}$ y XXI: las que ya no están, sus huellas; las que están, quiénes son
}

\author{
José TOMÁs PALACIOS MEdELlíN \\ Colegio de Bibliotecología \\ Universidad Nacional Autónoma de México
}

\section{Aguascalientes, los que fueron y ya no están, sus huellas}

H renacer de la Vitis vinifera y de los vinos en tario de Agricultura Nazario Ortiz Garza fomentó el cultivo de la vid, la industrialización de la uva y la producción de vinos. Surgen las primeras empresas en los años 50, éstas fueron Compañía Vinícola de Aguascalientes que produjo los vinos Álamo y San Marcos y Vinícola Pabellón, empresa cooperativa que elaboraba aguardientes y vinos "Pabellón". En esta década, personal de Pedro Domecq de España efectúa visitas a las zonas vitícolas de Baja California, Aguascalientes, Durango, Coahuila, Sonora y Querétaro.

Casa Pedro Domecq se decide por Aguascalientes y Baja California para cultivar Vitis vinifera en 2 mil hectáreas y producir bebidas. Un 12 de octubre de 1958 se surte el primer pedido de Brandy Presidente de 750 ml.; en 1961 le sigue Brandy Don 
Investigaciones sobre las necesidades de información,...

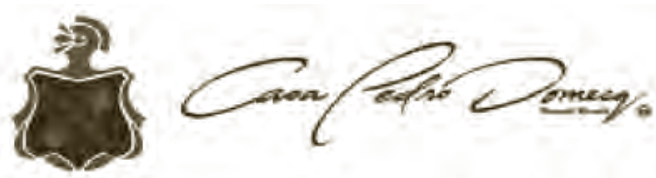

fuente: http://www.domecq.com.mx/home_flash.php 1

Pedro, Anís, crema de Lima, Vinagre y Vermouth Domecq. En 1963 en el Valle de Guadalupe, Baja California empiezan a producir el vino tinto Los Reyes, en 1971 vino blanco Los Reyes, en 1972 vino rosado Los Reyes y en 1977 vinos varietales. Al año 1980 ya tenía 28 marcas e iba por más. Para 1988 ya comercializaba los tequilas Tres Generaciones, Sauza Conmemorativo y Sauza Hornitos. ${ }^{2}$ Justo en ésta década (80's) Casa Pedro Domecq se retira de Aguascalientes, abandonando instalaciones y campos, pero siendo una empresa con instalaciones en varios estados, continua elaborando productos derivados de la Vitis vinífera. En 2004 ya cuenta con 41 marcas en México. Casa Pedro Domecq no produjo vinos en Aguascalientes, pero si miles de toneladas de Vitis vinífera en extensos campos que iban de las orillas de la ciudad de Aguascalientes hasta los límites con el Estado de Zacatecas.

1 Casa Pedro Domecq. [en línea]. Disponible en: http://www.domecq.com.mx/home_flash.php [2009, 15 de septiembre]

2 Casa Pedro Domecq, nuestra empresa. Historia. [en línea]. Disponible en: http://www.domecq.com.mx/historia/historia_50s.cfm ?CFID $=453665 \&$ CFTOKEN $=48157035$ [2009, 15 de septiembre $]$ 


\section{Aguascalientes, los que están, quiénes son}

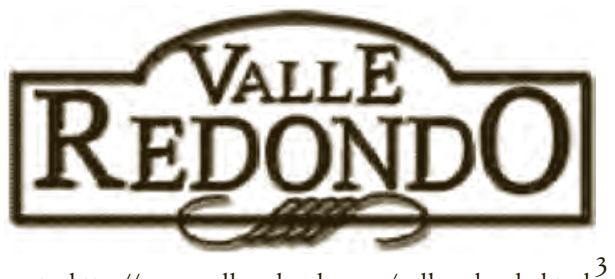

Fuente: http://www.valleredondo.com/valleredondo.html ${ }^{3}$

Año 1964 es fundada la compañía Productos de Uva de Aguascalientes, conocida hoy como Bodega y Vinícola Valle Redondo (Grupo Cetto), tiene sus viñedos en el rancho Aurora, km. 60 de la carretera \# 45 Aguascalientes-Zacatecas (al norte de Tepezalá), con 460 hectáreas cultivadas, la uva de estos viñedos se destina a jugos y concentrados, produce una pequeña parte de vinos con uva seleccionada y traída desde Baja California en la Vinícola Augurio. Bodega de productos, toneles de acero y tienda en Aguascalientes se localizan en el km. 6.5 de la carretera \# 71 Aguascalientes-Calvillo; produce 3,700.000 litros de vino cada año, del cual el 70\% es tinto elaborado con uvas Cabernet Sauvignon, Barbera y Petite Sirah; el 30\% restante es blanco con uvas Riesling, Sauvignon Blanc y Blanc de Blancs.

3 Valle Redondo. [en línea]. Disponible en: http://www.valleredondo.com/valleredondo.html [2009, 18 de septiembre] 
Investigaciones sobre las necesidades de información,...

Sus marcas de vinos son California, Don Ángel y Fratello. El responsable de la calidad de los vinos es el enólogo Francisco J. M. de Oro. ${ }^{4}$
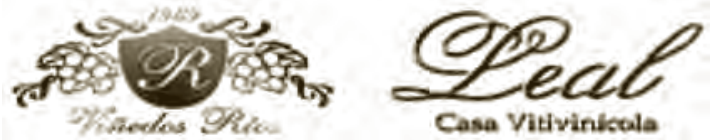

Fuente: http://megauva.com.mx $/^{5}$

El año 1969 se funda la Casa Leal y Viñedos Ríos (Viñedos La Bordaleza y Viñedos Ríos) en el municipio de Aguascalientes, en el Estado y ciudad del mismo nombre. La empresa es propietaria de los Viñedos La Bordaleza y Viñedos Ríos, que tienen una extensión de 180 hectáreas; en ellas cultiva variedades de uva Málaga Champagne, French Colombag, Chennin Blanc, Cariñan, Victoria, Ruby Cabernet y Salvador; con ellas elabora vino tinto de mesa Leal y Viñedos Ríos; vino blanco de mesa Leal y Viñedos Ríos y brandy Leal, añejados en barricas de roble blanco, con tiempo de reposo que varía de 10 a 14 meses; también elabora jugos de uva

4 Valle Redondo. Vinos y sidras. [en línea]. Disponible en: http:// www.valleredoondo.com/index.html [2009, 18 de septiembre]

5 La Bordalesa. [en línea]. Disponible en: http://megauva.com.mx/ [2009, 19 de septiembre] 
Aguascalientes, Zacatecas y Durango,...

marca Mega Uva y concentrado de uva (mosto). ${ }^{6} \mathrm{El}$ responsable es el ingeniero Jorge Ríos Pérez, hijo del fundador de esta empresa.

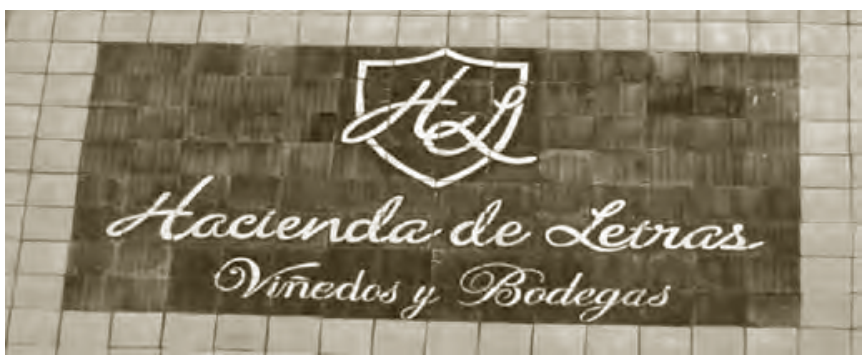

Fuente: J.T.P.M. ${ }^{7}$

El año 1978 es creada la Vitivinícola Dinastía, después denominada en 1996 Viñedos y Bodegas Hacienda de Letras, S. A. de C. V. en el poblado de San Luis de Letras que es parte del Valle de Monte Grande en el municipio Pabellón de Arteaga. Sus instalaciones son parte de una antigua hacienda de 1854. Se trata de una pequeña bodega que produce vinos de autor con viñedos cultivados en una extensión de 100 hectáreas, donde cultivan para vinos tintos variedades de uva Ruby Cabernet, Carigñan, Sangiovese, Syrah, Pinot Noir, Cabernet Sauvignon,

6 La Bordaleza. [en línea]. Disponible en: http://www.aguascalientes.gob.mx/turismo/labordaleza.aspx [2009, 20 de septiembre]

7 Foto tomada por José Tomás Palacios Medellín el 16 de junio de 2009 
Investigaciones sobre las necesidades de información,...

Malbec, Merlot, Cabernet Franc, Blending, y Nebbiolo y para vinos blancos

Riesling, Chardonnay, Sylvaner, Sauvignon Blanc, Semillón, Muscat Blanc; sus vinos son 100\% monovarietales y fechados, reposados en barricas de roble francés y americano. Las marcas de esta empresa son: vinos blancos Rosa y Oro, Riesling 2005, Chardonay 2005, Christine, Capilla de Fátima; vinos tintos: Merlot 1998, Cabernet 2001, 425 Aniversario, Vendimia 32, Hacienda de Letras, Tempo; vino dulce Karol; línea superiores Montgrand Malbec, Montgrand 2005 y Tempranillo 2001. Los responsables son los enólogos Carlos Salas Luján y Luis Carlos Hernández Chacón. ${ }^{8}$

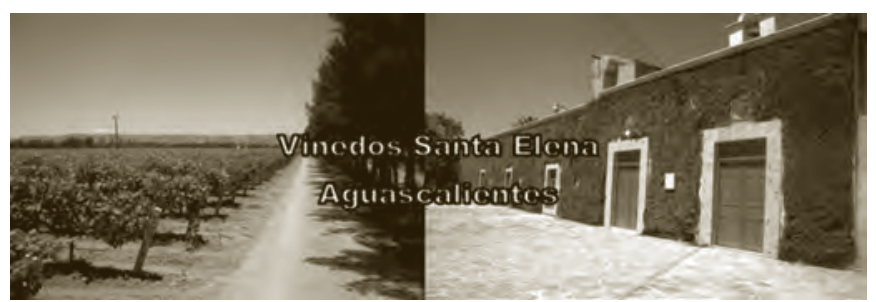

Fuente: Imagen donada por el Ing. J, Trinidad Jiménez D. a José T. Palacios M.

Año 2005, J. Trinidad Jiménez D. y Ricardo Álvarez Jiménez establecen la empresa Viñedos Santa

8 Entrevista al ing. Carlos Hernández Chacón en la Hacienda de Letras, poblado de San Luis de Letras el 16 de junio de 2009 
Aguascalientes, Zacatecas y Durango,...

Elena (Aborigen, S.A. de C.V.), con base en el Rancho Santa Elena, ubicado a $20 \mathrm{~km}$. al norte de la capital Aguascalientes, entre el poblado Emiliano Zapata y el Rancho San Isidro en el municipio de San Francisco de los Romo. Cuentan con 13 hectáreas de viñedos propios en los municipios de San Francisco de los Romo y Cosío, donde han sembrado las variedades de uva Malbec, Tempranillo, Sirah, Cinsault, Nebbiolo y Carignane. Empezaron produciendo sus primeros vinos asesorados por el enólogo Hugo D’Acosta (años 2006-2008) con uva comprada en Ojocaliente, Zacatecas. Las marcas con que cuentan hoy son: Tabla No. 1, elaborado 100\% con uvas Malbec 2006, Tabla No. 1, con uva Malbec 2007; Entretanto, con uva Carignane 2007; Entretanto, uvas varias 2007 (mezcla bordaleza); Tabla no. 1, uva Malbec 2008 (en barricas) y Entretanto, uva Carignane 2009.'

\section{Bodegas Garza Pimentel (Vinícola Augurio) Año 2007}

J. Trinidad Jiménez Domínguez, gerente del Consejo del Sistema Producto Uva dijo... acaba de darse cima

9 Información facilitada por el ing. J. Trinidad Jiménez D. en visita a Aguascalientes, acudiendo a cita en Av. de la Convención Norte, No. 1204-C, Fraccionamiento Circunvalación Norte en el mes de junio de 2009 
Investigaciones sobre las necesidades de información,...

al proyecto de una nueva vitivinícola en Aguascalientes, denominada Augurio y que está abocada a elaborar tintos con uvas adecuadas compradas a microproductores de esta Comarca, aunque en el mediano plazo la firma mencionada, donde están ligados en el negocio un inversionista local y dos regiomontanos, contará con su propio viñedo. ${ }^{10}$

Se trata de Bodegas Garza Pimentel (Vinícola Augurio), fundada en 2007 por Jorge Pimentel y G. Rafael Garza García domiciliada en la carretera Aguascalientes-Calvillo, km. 6.5. Han empezado a producir el vino Garza y Pimentel con uva Merlot cosecha 2007 comprada en Luis Moya, Zacatecas, los responsables ya contarán con uvas de su propio viñedo en 2010 o 2011.

\section{Zacatecas, los que fueron y ya no están, sus huellas}

En el siglo XX, la primera empresa vinícola que se funda en este Estado es Bodegas del Altiplano por Francisco Javier González en 1970. Todavía en 1990 se menciona a la Casa Pinzón Hermanos produciendo las

10 J. Trinidad Jiménez Domínguez. (2008). Refundación de vitivinicultura. Formaron en Aguascalientes un viñedo madre para la producción de uva de variedades para elaboración de tintos. [en línea]. Disponible en: http://www.hidrocalidodigital.com/ [2009, 2 de junio] 
Aguascalientes, Zacatecas y Durango,...

marcas Foylenmilch, Don Eugenio, Alcalde, Grenache, Chardonnay y Cabernet; Antonio Fernández y Cía. con las marcas Etiqueta de Oro, Semillón, Riesling, Chenin Blanc, Rubi Cabernet, Sauvignon Blanc y Sylvaner; la Unión Vinícola Zacatecana con la marca Pioneros y por último Puerta de Hierro con vinos del mismo nombre.

\section{Zacatecas, los que están, quiénes son Vinícola del Saucito (Vinos Carrera)}

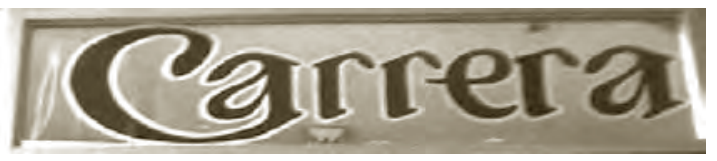

Fundada en 1972 por Jorge y Daniel Carrera S., la Vinícola del Saucito (Vinos Carrera), ubicada en la Carretera Panamericana, km. 680, un poco adelante del poblado General Enrique Estrada. Cultiva viñedos en 120 hectáreas ubicadas en los municipios de El Saucito, Santa Claudia, Tapias, Buenaventura, Ex Hacienda de Baños y Santa Cruz las variedades de uva Traminer, Cabernet Sauvignon, Chenin Blanc y Ruby Cabernet, con las que produce 1,200.000 botellas o 100,000 cajas. Sus vinos son tintos, blancos, de frutas y cogñac con la marca Carrera. Hace su vendimia en los meses de julio y agosto. 
Investigaciones sobre las necesidades de información,...

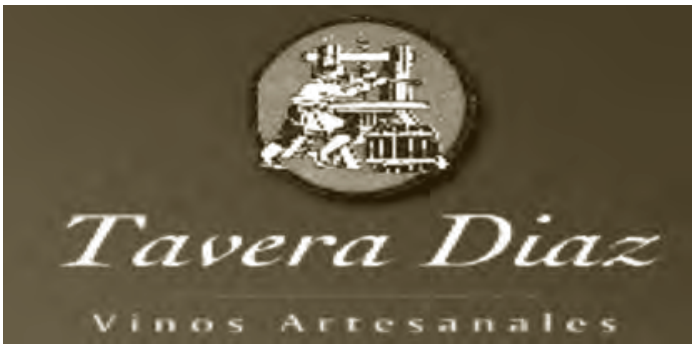

Fuente: http://www.taveradiaz.com ${ }^{11}$

Casa Tavera Díaz es fundada en 1981 por Guillermo Tavera y Yolanda A. Díaz Cervantes, en ella producen vinos artesanales tintos y blancos con uva comprada de las variedades Cabernet Sauvignon, Malbec, Merlot, Ruby Cabernet, Beirut Blanca, Chenin Blanc y Moscatel de Alejandría. Su domicilio está en el Rancho Las Nubes, poblado de Tacoaleche (antes de llegar a Zacatecas, viniendo de Las Arcinas, entre los pueblos de Bermejo y Zoquite, carretera federal 175). Han plantado 7 hectáreas de viñedos propios en 2008, los cuales se encuentran en crecimiento para que en años posteriores puedan producir vino con uva propia. Actualmente producen las marcas Tavera Díaz, Moscatel y Don Lupe en cantidad de 500 a 800 botellas que se pueden adquirir en Zacatecas, en el Callejón Lancaster no. 121, colonia Centro.

11 Casa Tavera Díaz. [en línea]. Disponible en: http://www.taveradiaz.com [2009, 2 de junio] 


\section{Compañía Vinícola del Valle de las Arcinas}

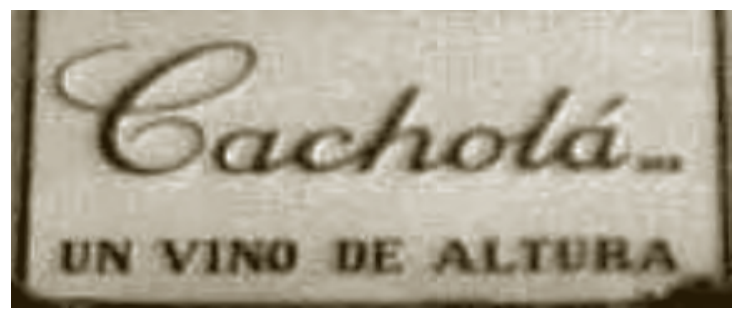

Fuente: fotografía tomada por J.T.P.M. en la ciudad de Zacatecas en julio de 2008

1984 es el año en que la Compañía Vinícola del Valle de las Arcinas (Grupo Mier) es fundada por Jesús López López, con viñedos en 50 hectáreas ubicadas en la Carretera Panamericana, km 634, entronque con la Carretera a San Luis Potosí, km 161, Las Arcinas, municipio Guadalupe. Ahí se cultivan las variedades de uva Ruby Carbernet, Chenin Blanc y French Colombard y produce dos vinos blancos y uno tinto marca Cacholá, el que en su mayor parte exporta, pero que también vende en el centro de Zacatecas en el mercado Jesús González Ortega. Vinos Cacholá enfrenta un reto muy grande, pues por diversos problemas (cierre de pozos, supuestas deudas de impuestos) de 2008 a 2009 se han secado sus viñedos. La alternativa para seguir produciendo vinos es comprar uva, y continuar aprovechando las instalaciones de Las Arcinas. 
Investigaciones sobre las necesidades de información,...

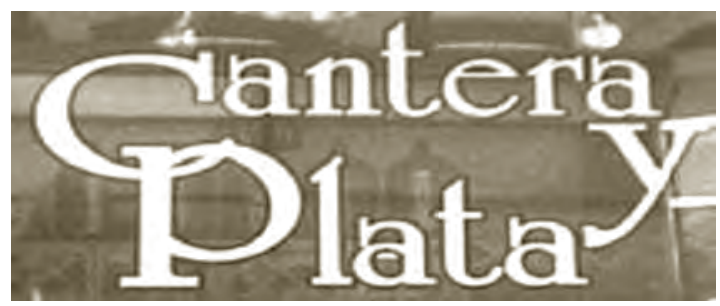

Fuente: fotografía tomada en Zacatecas en Julio 2008 por J.T.P.M.

En 1990 es registrada la marca Cantera y Plata, se trata de una vinícola especial y Manuel Ignacio Díaz, ingeniero químico y enólogo, es su fundador. Díaz menciona:

Compramos uva de regiones como Fresnillo, de Ojo caliente, Luis Moya, Villa de Cos — cuando producía- y de Calera. La planta está ubicada en Morelos, Zacatecas, a $15 \mathrm{~km}$ del centro de la ciudad y sólo producimos los fines de semana. ${ }^{12}$

Es una empresa que no cuenta con viñedos propios y compra las uvas que necesita, como Chenin Blanc, Moscatel, Chardonay, Sauvignon Blanc, Ruby Cabernet Cabernet Sauvignon, Malbec, Petite Sirah, Merlot y Silvaner; produce quince vinos de

12 Rocío Fonseca. Secretos sabor uva. (2008). [en línea]. Disponible en: http://vinomex.homestead.com/zacatecas01.html (2008, 30 de julio) 
Aguascalientes, Zacatecas y Durango,...

tipo semiartesanal, blancos, tintos, rosados, varietales, dulces y mezclas con las marcas Cantera y Plata, Igneus, Fray Margil y Vinos Personalizados que se pueden adquirir en el Mercado Jesús González en la ciudad de Zacatecas.

\section{Durango, los que fueron y ya no están, sus huellas}

Año 1880, Santiago Lavín Cuadra y Gómez de origen español, adquirió una enorme extensión de tierras en Durango, que iba desde la margen izquierda del Río Nazas a la altura de la antigua hacienda de Santa Rosa de Lima, hasta la Hacienda de Santa Rosa de Mapimí, que llegó a tener 54 mil hectáreas, 18 mil de ellas regadas por el Río Nazas; la cabecera de este latifundio fue la Hacienda de Noé.

En esta zona el 15 de septiembre de 1885 se funda la ciudad de Gómez Palacio. Al morir Santiago Lavín en 1896, el latifundio fue llamado "Perímetro Lavín" por sus herederos; es aquí donde en 1905 ya estaba produciendo vinos la Compañía Productora de Vinos y Aguardientes Lavín y Paparelli, Compañía Vinícola de Noé (nombre con apellidos de la familia Lavín y del químico y especialista vitivinícola Luis Paparelli más el de la Hacienda de Noé). Para este negocio, los Lavín habían sembrado más de un millón de parras en sus viñedos y esperaban que en cuatro años más (por 1909) llegaran a los tres millones; para producir 
Investigaciones sobre las necesidades de información,...

el vino, adquirieron y pusieron en funcionamiento instalaciones modernas para esa época donde utilizaban procedimientos europeos; además contaban con distribuidores de vinos en Durango, Chihuahua, Guadalajara y Zacatecas. Varias fueron las causas que propiciaron la desaparición de la empresa vitivinícola: los Lavín habían pedido un préstamo de 5 millones de francos a la Societé Francaise pour l'Industrie de Mexique, pero al estallar la Revolución en 1910, los peones abandonaron los campos y la empresa se declaró en quiebra, siendo embargada para cubrir el préstamo. Otro factor fue que el químico y especialista vitivinícola Luis $\mathrm{Pa}$ parelli hizo amistad con los hermanos Madero, y se fue a trabajar la producción de vinos con ellos a Parras, Coahuila. 


\begin{tabular}{|c|c|c|}
\hline $\begin{array}{l}\text { Compania Vinicola de Noe } \\
\text { Lista de productos y precios } \\
\qquad \text { en } 1907\end{array}$ & Litro & $\begin{array}{c}\text { Caja con } \\
12 \\
\text { botellas } \\
\text { dellito }\end{array}$ \\
\hline $\begin{array}{l}\text { Cogñac Angostura } \\
\text { (ligeramente amargo) }\end{array}$ & $\begin{array}{l}5 \\
1.50\end{array}$ & $\begin{array}{c}5 \\
15.00\end{array}$ \\
\hline Cognac Monte Cristo & 1.25 & 13,00 \\
\hline Aguardiente "Lägrimas de $\mathrm{Noe}^{-}$ & 1.00 & 12.00 \\
\hline Aguardiente Lagunero & 0.50 & 6.50 \\
\hline Aguardiente Supremo & 0.50 & 6.50 \\
\hline Aguardiente de Orujos de Lva & 0,48 & 6.35 \\
\hline Aguardiente Popular & 0.40 & 5.65 \\
\hline Vina Evaporado Ipara consagrar & 0.30 & 5.50 \\
\hline Angellica Mexicana & 0.30 & 5.50 \\
\hline Recuerdos de Rioja. Blanco & 0.30 & 5.50 \\
\hline Vino Tonico de Quiria & 0.60 & 7.50 \\
\hline Vermouth Toring & 0.50 & 7,00 \\
\hline Vermouth Quinado & 0.55 & 8.00 \\
\hline $\begin{array}{l}\text { Barricas de } 100-110 \text { litros } \\
\text { de capacidad, siu }\end{array}$ & $\begin{array}{l}5 \\
3.50\end{array}$ & \\
\hline Earriles de $60-65$ iltros & 2.50 & \\
\hline Castañas de $28-30$ & 2.00 & \\
\hline \multicolumn{3}{|c|}{$\begin{array}{l}\text { Estos precios son por mercancia puesta en la } \\
\text { Estacion de Noe det F,C.C.M. Lavin y Paparelli. } \\
\text { [Gomez Palacio, Durango] }\end{array}$} \\
\hline
\end{tabular}

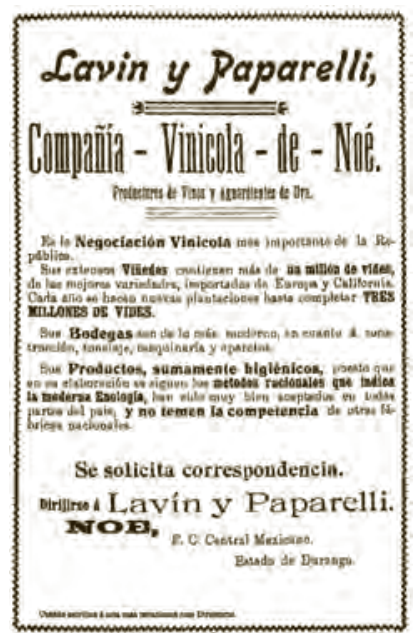

Fuente: Baca, A. C. de y Agustín Aguirre Hermosillo. 13

Fuente: La Gaceta Regional, 29 de agosto de $1907{ }^{14}$

En el año 1941 los empresarios Luis J. Garza y Tomás Villarreal Martínez viajaron a la ciudad de California en Estados Unidos para traer las mejores cepas de Vitis vinífera, pues ya se habían puesto de acuerdo

13 Sergio Antonio Corona Páez. La vid en La Laguna. (2007). [en línea]. Disponible en: http://cronicadetorreon.blogspot. com/2007_08_01_archive.html [2009, 6 de julio]

14 Baca, A. C. de y Agustín Aguirre Hermosillo. (1906). Directorio Comercial e Industrial de La Laguna 1905-1906, Torreón, Gómez Palacio, Lerdo, San Pedro, Viesca, Matamoros. [en línea]. Disponible en: http://www.torreon.gob.mx/imdt/libros/libroshistoria. php [2009, 25 de septiembre] 
Investigaciones sobre las necesidades de información,...

para establecer una vitivinícola en el municipio de Gómez Palacio. Logrado su objetivo, en 1943 fundaron La Compañía Vinícola del Vergel, S. A., y ubicaron las instalaciones donde anteriormente estuvieran las bodegas de la Compañía Productora de Vinos y Aguardientes Lavín y Paparelli y las instalaciones del Ferrocarril Central, en las cercanías de Gómez Palacio, donde ya contaban con viñedos en 241 hectáreas. La Compañía es legal y formalmente registrada como sociedad el 23 de febrero de 1946 con capital inicial de $600 \mathrm{mil}$ pesos, sus fundadores: Luis J. Garza, Tomás Villarreal Martínez y José de la Mora. Sus primeros químicos fueron franceses e italianos de la empresa Corvousier de Francia. Un año después se inauguraron sus bodegas a cargo de Antonio Paelle Minetti; para la dirección técnica contrataron al Sr. Gerardo Colliere de la Maliere. La Compañía prosperó y, en 1957, su capital social había pasado de 600 mil a 10 millones de pesos, también los viñedos habían aumentado, pues ya contaban en ese mismo año con 517 hectáreas repartidas en 4 ranchos en Gómez Pala-cio: El Quemado, La Loma, El Vergel y Ensenada, y 1 en Torreón: Rancho La Paz; La Compañía tuvo cavas subterráneas de mármol sin pulir cerca de la planta, en la que fue la casa del Sr. Luis J. Garza. Hasta 1985 la Compañía elaboró vino rosado, blanco, tinto, dulce o de postre, oporto, aguardiente, coñac, vermouth y 
Aguascalientes, Zacatecas y Durango,...

brandy. Su primer producto fue el brandy Grandier, después el coñac Mogavi Extra y coñac Vergel Supremo, vino tinto Viña Santiago, tinto seco Superior, Verdizo, Corina, Malvasia Port y Mesón de la Hacienda; vino blanco seco Verdizo, Noblejo; vino rosado Salvador; moscatel Tokay Selecto, oporto Moscatel; vino seco para consagrar autorizado Excelencia y dulce para consagrar autorizado Eminencia; brandy Viejo Vergel, Marc Añejo y Marc Blanco; aguardiente de orujo Noblejo; Vermouth tipo francés Lugano Seco; Lugano RoJo y dulce tipo Torino. Tanto en México como en el extranjero, tuvieron gran demanda, especialmente entre chicanos de Los Ángeles y Chicago. Actualmente las instalaciones donde no hay actividad alguna, están en el km. 11 de la carretera Gómez Palacio DurangoChihuahua, también conocida como Torreón-Ciudad Juárez.

¿Instalaciones sin actividad en 2009? Sí, veamos por qué. Esta inactividad comenzó a gestarse en el año 1985. Se cuenta con el testimonio de Luis Garza Suárez, director de Casa Arias, distribuidores de bebidas alcohólicas en Gómez Palacio:

Desde que nací me he dedicado a éste negocio. Mi padre era uno de los propietarios de la Vinícola El Vergel. En 1985 se realiza la venta de la compañía a 
Investigaciones sobre las necesidades de información,...

\section{Bacardí. ${ }^{15}$}

Sí, se trata de la empresa Grupo Bacardí de México, que poco a poco trasladó la producción de vinos de Gómez Palacio hacia Baja California, proceso que finalizó en 1995. De acuerdo con la reseña histórica de los municipios elaborada por el gobierno de Durango, tenemos que:

1995. En los primeros meses de este año concluyó sus actividades la Cía. Vinícola "El Vergel”, por más de 40 años representó una importante fuente de trabajo y un centro de procesamiento de la producción vinícola de la Región. ${ }^{16}$

Hoy donde se cultivaba Vitis vinifera hay colonias, empresas, comercios o dependencias del gobierno.

Esta es la causa por la que hoy las instalaciones de la Compañía Vinícola el Vergel se encuentran abandonadas y sus puertas de acceso sólo están custodiadas

15 Virginia Hernández. (2005). Distribuir vino, un negocio complicado. En: El Siglo de Torreón. [en línea]. Disponible en: http:// www.elsiglodetorreon.com.mx/noticia/140947.entrevista-distribuir-vino-un-negocio-complic.html [2008, 4 de marzo]

16 Enciclopedia de los Municipios de México. Durango, Gómez Palacio. Cronología de hechos históricos. [en línea]. Disponible en: http://www.sesa-dg.gob.mx/diagnostico\%20municipal/ municipios/10007a.htm [2008, 21 de agosto] 
Aguascalientes, Zacatecas y Durango,...

por dos vigilantes; la casa donde vivieron los dueños de la Compañía (Familia Garza Suárez) en la actualidad es alquilada (incluyendo sus cavas subterráneas) para todo tipo de eventos con la razón social "La Casa Grande del Vergel". El vino que se consume en Durango se trae de otros estados o se importa del extranjero.

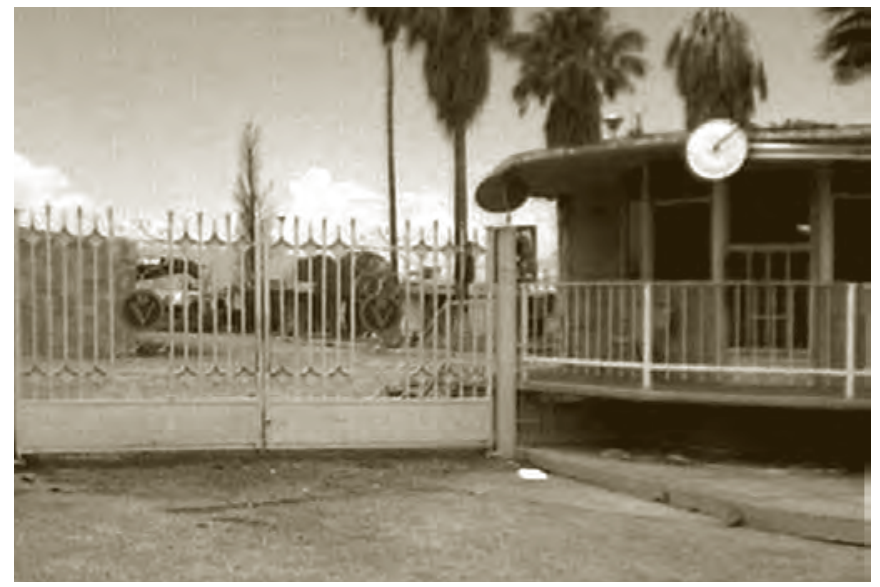

Puerta de entrada y caseta de vigilancia de la vinícola Viejo Verjel, que dejó de producir vinos en 1995.

Fuente: fotografía tomada por J.T.P.M. en julio de 2008 en visita a Gómez Palacio, Durango 
Investigaciones sobre las necesidades de información,...

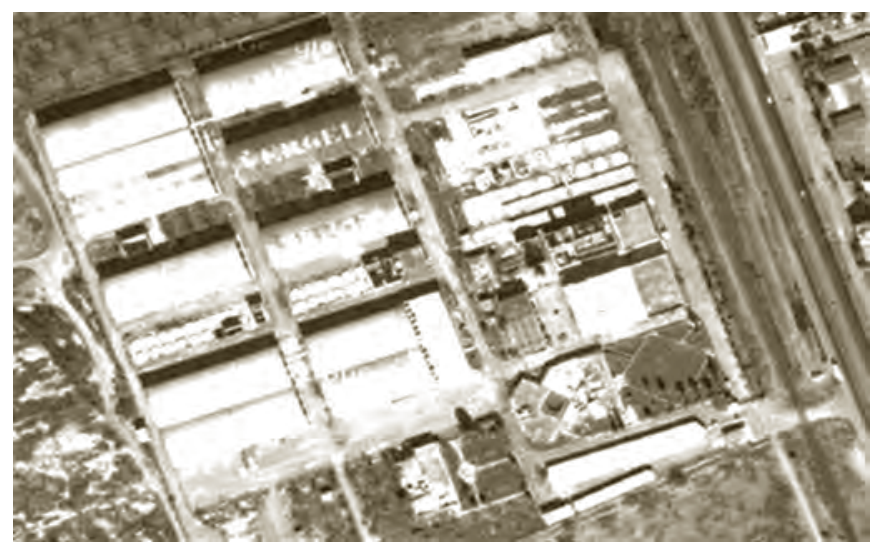

Vista aérea de las instalaciones de lo que fue la Compañia Vinícola Vergel, septiembre de 2009 Fuente: Google Earth ${ }^{17}$

\section{Bibliografía}

Corona Páez, Sergio Antonio. La Compañia Vinícola del Vergel. (2009). [en línea]. Disponible en: http://cronicadetorreon.blogspot.com/2009/08/ la-compania-vinicola-del vergel.html [2009, 3 de septiembre]

17 Google Earth. (2009). [en línea]. Disponible en: http:// es.geocities.com/amigosalvaro25/Googleearthonline.htm [2009, 28 de septiembre] 
Aguascalientes, Zacatecas y Durango,...

El Valle de Parras y el desastre de la filoxera, 1870-1910. Génesis y consolidación de una empresa vitivinícola en tiempos de crisis. En: Revis80/mundo_agrario/numeros/no-18-1er-sem2009/el-valle-de-parras-y-el-desastre-de-la-filoxera-1870-1910-genesis-y-consolidacion-de-una-empresa-vitivinicola-en-tiempos-de-crisis [2009, 25 de septiembre]

Manchuca Macías, Pablo. (1977). Ensayo sobre la fundación y desarrollo de la ciudad de Gómez Palacio. México [en línea. Archivo pdf]. Disponible en: http://www.estaciongomezpalacio.galeon.com/ [2009, 10 de julio]

Michaud, Julio. (1990). El libro del vino mexicano. México: Casa Pedro Domecq. 188 p.

La ruta del vino: Zacatecas. SDP Noticias. (16 abril 2009). [ en línea]. Disponible en: http://sdpnoticias.com/sdp/columna/wendy-marin/2009/04/15/ 376358 [2009, 20 de septiembre] 



\title{
El perfil de información de los vitivinicultores de Vitis vinífera en la región de Coahuila. Avances
}

\author{
ENEDINA SALAZAR MÉNDEZ
}

Posgrado en Bibliotecología y Estudios de la Información Universidad Nacional Autónoma de México

\section{Introducción}

耳 ste trabajo tiene como objetivo identificar los

_requerimientos de información que presentan los vitivinicultores de la región de Coahuila para la producción de sus vinos. Como parte esencial de dicho trabajo es importante conocer primero de donde proviene y como se ha ido desarrollando esta actividad a través de los años.

El Nuevo Mundo, el primer lugar que tuvo el cultivo de la vid y, por consiguiente, donde se produjo por primera vez vino fue en la Nueva España en el año de 1524 cuando Hernán Cortés ordenó la importación de la variedad Vitis vinífera para sembrarse en suelo colonizado pues, aunque existían uvas silvestres, éstas no eran aptas para la producción de vino; de este modo los introductores del vino en nuestro país, y posteriormente el resto de lo que sería el continente hispanohablante, fueron los conquistadores, aunque sus grandes propagadores 
Investigaciones sobre las necesidades de información,...

de la viticultura como tal, les correspondió a los misioneros que llegaron tras la Conquista.

Los cultivos se extendieron por grandes regiones, no sólo en tierras mexicanas sino mucho más allá, pues en poco tiempo abarcó lugares tan lejanos como Perú, Argentina y Chile. En el México virreinal las principales zonas vinícolas fueron Querétaro, Guanajuato, Puebla, San Luis Potosí, en el centro; y en el norte el Valle de Parras, Baja California y Sonora.

Desde sus orígenes, el pueblo de las Parras o Santa María de las Parras, como también se le conoció, fue un centro de civilización, prosperidad y riqueza. Bajo la dirección de los jesuitas y con el apoyo de los tlaxcaltecas se fundaron numerosos pueblos. Sus habitantes se dedicaron con preferencia al cultivo de la vid y a la fabricación de vinos. ${ }^{1}$ Aquí se produjo la primera barrica de vino con uva cimarrona, acontecimiento que le dio nombre al sitio y marcó su destino productivo. Las uvas cimarronas pronto fueron remplazadas por cepas de uva europea. Uvas blancas, rojas y moscateles se transformaron en vinos, aguardientes y vinagres. La villa tuvo su bonanza vitivinícola en los siglos XVII y XVIII. Posteriormente en el siglo XIX se le rebautizó

1 Breve historia de Coabuila. María Elena Santoscoy... [et al.] México: El Colegio de México: Fondo de Cultura Económica, c2000 p. 56 
El perfil de información de los vitivinicultores...

como Parras de la Fuente, en honor a Juan Antonio de la Fuente notable liberal coahuilense.

El caso de Parras fue tal la excepción de la Nueva España que en el siglo XVIII, en 1760 era ya una de las zonas más prósperas de toda la región de la Nueva Vizcaya, e incluso de todo el reinado, pues su economía había crecido tanto a raíz de las cepas, que daba pie a otras cosechas como trigo, maíz, fríjol y una variedad de frutas. La sociedad parrense se diversificó enormemente al convertirse en un polo de crecimiento durante el resto del siglo, aunque con profundas contradicciones entre pequeños y grandes productores agrícolas derivadas de la tierra y la mano de obra; no obstante puede concluirse que Parras tuvo un régimen atípico durante todo el periodo colonial, sólo y gracias a su pujante desarrollo vinícola.

En la actualidad en Parras existen dos empresas que cuentan con viñedos, producen vino y comercializan el mismo, ellas son: "Casa Madero" y "Finca y Viñedos Buena Fe".

Es importante mencionar que existen dos viñedos más de Vitis vinífera en la región: el "Tunal" y "Rancho González", los cuales esperan producir vino dentro de poco tiempo.

Asimismo se encuentran las bodegas: "El Vesubio" y "El Perote" que, aunque procesan y venden vino no se consideraron en este trabajo ya que ninguno 
Investigaciones sobre las necesidades de información,...

cuenta con viñedos propios y compran la uva a personas de la región.

\section{Casa Madero}

Don Lorenzo García fundó las Bodegas de San Lorenzo en 1597, después de recibir la "Merced" que el Rey Felipe II le concedió con la condición de plantar viñas. A su muerte, la hacienda fue adquirida por diferentes propietarios en el orden que se mencionan: Don Luis Hernández Escudero, Doña María de Cárdenas, Don Francisco Gutiérrez Barrientos, el capitán Juan de Oliden, Don Juan Lucas de Lazaga, Don Manuel Ybarra, Don Leonardo Zuloaga, Doña Luisa Ybarra Goribar de Zuloaga, Don Juan Martínez Zorrilla.

Más tarde, en 1883 Evaristo Madero Elizondo compró la Hacienda de San Lorenzo en París, ya que ésta pertenecía a una compañía de franceses, que durante la intervención francesa la habían adquirido y quienes la nombraron Lorenzo-Mexique, a esta compra se sumó también la adquisición de nuevas variedades de uva, equipo y maquinaria, así como la contratación de expertos en la materia traídos de España, Italia y Francia.

En 1896 constituyó la razón social Ernesto Madero y Hermanos, para administrar San Lorenzo. El 15 de mayo de 1946 la firma administradora de San Lorenzo cumplió sus bodas de oro, y ese 
El perfil de información de los vitivinicultores...

mismo día fue suplantada por la firma Casa Madero, S.A. ${ }^{2}$

Desde hace cinco décadas al frente de Casa Madero se encuentra el ingeniero José Milmo Garza quien ha dedicado su mayor esfuerzo y experiencia a mejorar la calidad de sus productos y estar al día en cuanto a tecnología se refiere, además de establecer convenios de asesoría técnica con universidades de Francia y California, con la finalidad de que el personal mexicano de esta empresa cuente con los más sólidos conocimientos.

\section{Viñedos}

Comprenden 400 hectáreas de los cuales: El 70 a $75 \%$ es de uva tinta: Cabernet Sauvignon, Merlot, Tempranillo, Shiraz y Cabernet Franc. El 20 a 25 \% es de uva blanca: Chardonnay, Cheninc Blanc, Semillon.

A nivel experimental tienen las siguientes variedades: Para tintos: Pinot Noir, Malbec, Zinfandel, Montelpuciano. Para blancos: Sauvignon Blanc, Pinot Grigio.

\section{Marcas}

- Casa Grande Gran Reserva

2 Gildardo Contreras Palacios. Parras 400: noticias de su fundación y otras cuestiones históricas. Torreón, Coah.: Editorial del Norte Mexicano, 1999. p.74 
Investigaciones sobre las necesidades de información,...

- Casa Madero

- San Lorenzo

- Monteviña

\section{Finca y viñedos Buena Fe}

Su propietario, el Lic. José Antonio Rivero junto con su familia comparten el interés por el viñedo, el proceso y la comercialización del vino, con un propósito común que el vino Rivero González sea reconocido por su calidad y llegar a competir con los mejores vinos, iniciaron el primer sembrado en 1998, la primer cosecha fue en el 2002 y aparecen en el mercado en el 2003.

\section{Viñedos}

En la Finca Buena Fe se tienen 2 hectáreas y 7 más en otro lote llamado La Lagunilla, las variedades que se maneja en Buena Fe son: Merlot $60 \%$, Cabernet Sauvignon $20 \%$ y Cabernet Franc 20\%; en La Lagunilla: Cabernet Sauvignon y Shiraz, esta última en proyecto.

\section{Marcas}

Vino tinto Rivero González

En Cuatrociénegas las primeras exploraciones se realizaron en 1567 por Rodrigo Río de la Loza que construyó algunas edificaciones que en poco tiempo abandonaría por los continuos ataques de los 
El perfil de información de los vitivinicultores...

naturales, este suceso se presentó en repetidas ocasiones por la resistencia de los indígenas, los cuales atacaban a las poblaciones recién fundadas. La fundación decisiva ocurrió el 24 de mayo de 1800 por el gobernador de Coahuila Antonio Cordero y Bustamante, que nombró como jefe de la villa a Don Julián de la Riva, el cual junto a otras diez personas se consideran los verdaderos fundadores de esta población que ha sido llamada Nuestra Señora de los Dolores, Cuatro Ciénegas, Villa Venustiano Carranza y finalmente Cuatrociénegas de Carranza ${ }^{3}$

Debido a los continuos ataques de los indios nómadas, la estabilidad y desarrollo en esta región fueron frenados; no obstante al contar con varios manantiales que abastecían permanentemente al Río San Marcos, les permitía tener propiedades agrícolas aunque relativamente modestas comparadas con tierras ganaderas que ahí mismo existía y que floreció a tal grado que en muchos lugares acabó los pastizales, dejando sólo barrizales.

Los terrenos agrícolas, irrigados por el Río San Marcos, se agrupaban en un área relativamente pequeña en torno a la villa de Cuatrociénegas. Esas tierras se sembraban con trigo y cebada en el invierno; y con maíz y fríjol en verano.

3 Cuatrociénegas: Enciclopedia de los municipios de México: Estado de Coahuila [en línea] www.inafed.gob.mx/work/templates/... /05007a.htm Consultado el 10 de junio 2009 
Investigaciones sobre las necesidades de información,...

En cuanto al cultivo de uva, había una producción nada desdeñable. En el año de 1896 la producción de uva alcanzó las 167 toneladas y la industria vinícola local producía a su vez alrededor de 130 mil litros de vino y casi cien mil de aguardiente.

Actualmente en Cuatrociénegas se encuentran las empresas: "Bodegas Ferriño" y "Vinos Vitali"

\section{Bodegas Ferriño}

Originarios del Sur de Italia, de la provincia de Campania llegaron a México Don Miguel Ferriño Lander junto con tres de sus hermanos. Miguel, atraído por las parras que había, decide establecerse en Cuatrociénegas y edificar la vinícola "La Fronteriza" en el año de 1860 iniciándose con la destilación de aguardiente de uva y brandy, con el tiempo adquiere algunas otras propiedades incluyendo el predio que hasta la fecha continua y se enfoca hacia la elaboración de vinos generosos; destacando la marca "Sangre de Cristo", nombre que tomó en recuerdo a un vino de su tierra natal llamado "Lacrima Cristi". A su muerte, ocurrida en 1921, sus hijos deciden llamarla "Testamentaria Miguel Ferriño".

En 1955 se forma una sociedad con la participación de 8 de los 11 hijos que tuvo don Miguel, con el nombre de "Bodegas Ferriño", en la actualidad son 15 los miembros de la familia que integran la asociación. 
El perfil de información de los vitivinicultores...

\section{Viñedos}

Constituido por 15 hectáreas dentro de las cuales se encuentran las variedades de: Lenoir, Rosa del Perú y Ruby Red con un $80 \%$. Además de Moscatel de Alejandría, Carignane, Tokay, Cabernet y Granada. En San Pedro y Fresnillo tienen algunas hectáreas destinadas a Carignane, Tokay, Cabernet, Palomino y Málaga.

\section{Marcas}

Dentro de su catálogo de productos se encuentran:

- Sangre de Cristo

- Moscatel

- Vino Generoso Ferriño

- Vino Tinto Ferriño

- Vino Generoso Tipo Jerez Ferriño

- Vino Generoso Seco Ferriño

- También producen brandy, licor de granada y aguardiente.

\section{Vinos Vitali}

Empresa cuyo origen surge de la separación de uno de los socios de Bodegas Ferriño, Nicolás Ferriño Ramos a quien le cedieron la octava parte de tierras y barricas para que iniciara su propia empresa, a su muerte su hijo Nicolás Ferriño Charles se hace cargo de la misma, la que cierra más tarde por motivos 
Investigaciones sobre las necesidades de información,...

de salud; después de veinte años su hijo el ingeniero Sergio Ferriño Vitali en sociedad con su esposa han tenido el interés por conservar la tradición familiar reabriendo el negocio desde hace 8 años.

\section{Viñedos}

En 1 hectárea se encuentran las variedades siguientes: Ruby Red, Lenoir, Carignana y Moscatel.

\section{Marcas}

- Generoso moscatel

- Tinto Dulce ARFI

- Tipo Oporto

- Tinto Semi Seco

- Produce también: Crema de aguardiente, Crema de aguardiente anisada, Licor de uva Lenoir y Licor de manzana

\section{Bibliografía}

Breve historia de Coabuila. María Elena Santoscoy... [et al.] México: El Colegio de México: Fondo de Cultura Económica, c2000. 372 p.

Coabuila : la llave del Norte. México: Grupo Imperial, 2004. $271 \mathrm{p}$. 
El perfil de información de los vitivinicultores...

Contreras Palacios, Gildardo. Parras 400: noticias de su fundación y otras cuestiones históricas. Torreón, Coah. : Editorial del Norte Mexicano, 1999. $217 \mathrm{p}$.

Corona Páez, Sergio Antonio. La viticultura en el Pueblo de Santa María de las Parras: producción de vinos, vinagres y aguardiente bajo el paradigma andaluz (Siglos XVII-XVIII). Coahuila: Ayuntamiento de Torreón/IMDT, 2004.302 p.

Cuatrociénegas: enciclopedia de los municipios de México: Estado de Coahuila [en línea] www. inafed.gob.mx/work/templates/.../05007a.htm Consultado el 10 de junio 2009 



\title{
Recursos de información para el uso de los productores de la vid en el estado de Guanajuato. Avances
}

\author{
Ana laura Peña Aguilar \\ Posgrado en Bibliotecología y Estudios de la Información \\ Universidad Nacional Autónoma de México
}

\section{Introducción}

E sta investigación tiene como propósito aportar a la Bibliotecología un estudio sobre el comportamiento informativo de un grupo muy específico de la población, y al mismo tiempo contribuir a que la sociedad conozca cuales son los obstáculos y necesidades a los que se enfrentan los productores de la vid del estado de Guanajuato.

En el caso de los productores de vid en el estado de Guanajuato, específicamente en los municipios de Dolores Hidalgo y San Luis de la Paz, se ha detectado que las empresas son familiares y se han transmitido a través de generaciones, esto hace que la producción artesanal de vino sea un elemento importante a considerar en la detección de necesidades específicas de información.

El objetivo general de la investigación es detectar las necesidades específicas de información e identificar las fuentes y/o recursos de información que utilizan los productores de la vid del estado de 
Investigaciones sobre las necesidades de información,...

Guanajuato para determinar su influencia en las etapas de su producción.

El desarrollo del cultivo de la vid en el estado de Guanajuato se inicia desde los comienzos de la Nueva España ya que el viñedo comenzó a extenderse a partir de la ciudad de México hacia las regiones septentrionales de Querétaro, Guanajuato y San Luis Potosí. ${ }^{1}$

Para el año de 1810 Miguel Hidalgo hizo crecer uvas, y enseñó a algunos indígenas el proceso del vino dentro de la Villa de Dolores. ${ }^{2}$ De hecho fue promotor de la vitivinicultura en la Intendencia de Guanajuato. Durante su gestión como párroco del poblado de Dolores, de 1803 a 1810, fomentó el cultivo de la vid y la consecuente producción de vino.

De acuerdo con datos históricos recabados, desde 1673 se tienen registros de plantaciones de vid en el municipio de San Luis de la Paz que eran entregados como parte del diezmo de la región. En el período de 1673 a 1695 el cultivo de la uva con el de frijol, trigo, cebada y chile llegaba apenas al 2,5\% de la producción agrícola de la zona. Para el período de 1696 a 1731 la producción de uva se incrementa drásticamente conformando ella sola el $2 \%$

1 Vinomex. http://www.vinomex.homestead.com/historia.html (Consultada 22/02/08)

2 Juan Meneses Quezada. Recopilación documental sobre vitivinicultura. Estado de México, FES Cuautitlán, 2001. p.71 
Recursos de información para el uso de los productores...

de la producción; finalmente en el período de 1732 a 1777 llega al 12\% de la producción. ${ }^{3}$

Gráfica 1. Producción Histórica de vid en San Luis de la Paz

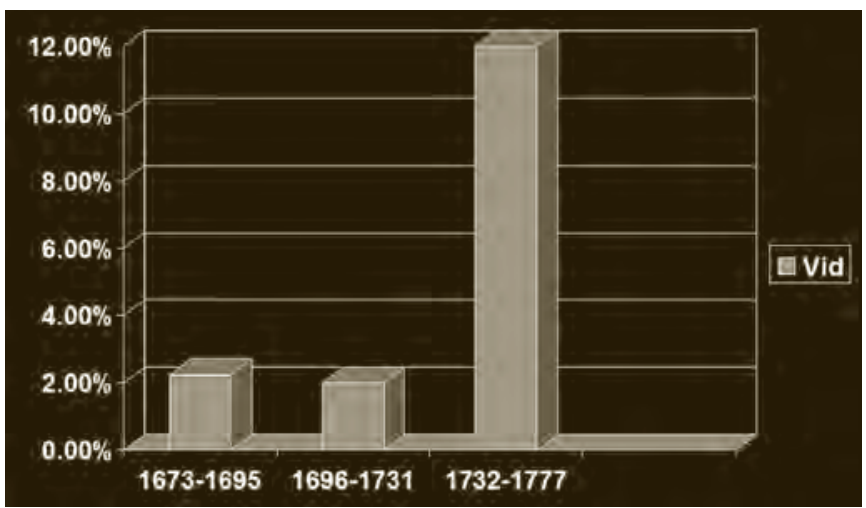

Por otro lado en el municipio de Dolores Hidalgo durante el período de 1740 a 1757 la uva representa el 5,25\% de la producción agrícola, mientras que en el período de 1758 a 1789 llega a representar el $8,93 \%{ }^{4}$

3 Cecilia Rabell. Los diezmos de San Luis de la Paz.

4 Flor de María Hurtado López. Dolores Hidalgo: estudio económico: 1740-1790. México, INAH, SEP, 1974. p.83 
Investigaciones sobre las necesidades de información,...

Gráfica 2. Producción histórica de vid en Dolores Hidalgo

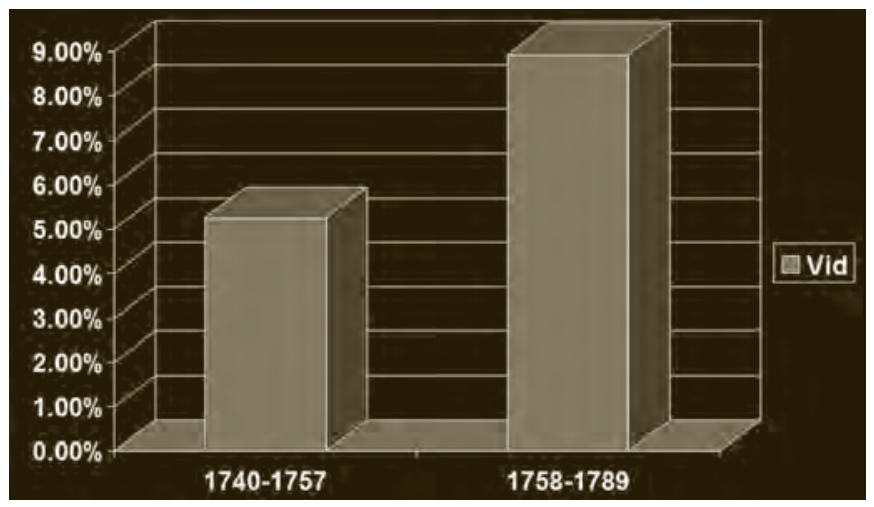

Actualmente de acuerdo con registros oficiales de la SAGARPA se tienen únicamente sembradas 2 hectáreas en el municipio de Dolores Hidalgo en la localidad de Allende, al visitar las Cavas Manchón se detectó que tienen sembradas 20 hectáreas y continúan en proceso de expansión. 
Recursos de información para el uso de los productores...

Tabla 1. Registro histórico de hectáreas de vid en Guanajuato

\begin{tabular}{|c|c|c|c|c|c|}
\hline Años & $\begin{array}{c}\text { Sembrada } \\
\text { (Ha) }\end{array}$ & Cosechada ( $\mathrm{Ha}$ ) & $\begin{array}{l}\text { Producción } \\
\text { (Ton) }\end{array}$ & $\begin{array}{l}\text { Rendimiento } \\
(\text { (Ton/Ha) }\end{array}$ & $\begin{array}{c}\text { Precio Medio } \\
\text { Rural } \\
\text { (S/Ton) }\end{array}$ \\
\hline 1999 & 60 & 60 & 616 & 10.267 & 3,697 \\
\hline 2000 & 62 & 40 & 320 & 8.000 & 3,800 \\
\hline 20001 & 42 & 6 & 48 & 8.000 & 4,000 \\
\hline 2002 & 44 & 0 & 0 & 0.000 & 0 \\
\hline 2003 & 4 & 0 & 0 & 0.000 & 0 \\
\hline 2004 & 3 & 3 & 11 & 3.860 & 5,000 \\
\hline 2005 & 3 & 0 & 0 & 0.000 & 0 \\
\hline 2007 & 2 & 0 & 0 & 0.000 & 0 \\
\hline 2008 & 2 & 2 & 1 & 0.500 & 4,000 \\
\hline
\end{tabular}

Asimismo se está desarrollando un proyecto con los productores de la región para que dediquen de 1 hectárea de sus tierras para la siembra de vid teniendo a las Cavas Manchón como cliente cautivo de su producción para fomentar nuevamente la producción de vid en el estado de Guanajuato.

Durante la visita de campo realizada a Dolores Hidalgo se detectó que han existido otros esfuerzos por fomentar la vitivinicultura en el estado a lo largo del tiempo, un ejemplo de esto es el Viñedo Padre Hidalgo fundado en 1960 y localizado a la entrada de la ciudad y que depende de la Secundaria Técnica número 16 en la que los alumnos acudían a realizar prácticas, entre las cuales se encontraba la siembra, cuidado y recolección de la vid para la fabricación de vino. 
Investigaciones sobre las necesidades de información,...

Asimismo encontró información relativa a que para las festividades del bicentenario se planea crear la Cava Bicentenaria en una hacienda que data aproximadamente del año 1800 en la que se contará con la presencia de 15 a 18 mil etiquetas o marcas solamente de vino mexicano a fin de iniciar una cultura del vino en toda la zona del Bajío.

\section{Instrumento}

Dadas las condiciones de los productores del estado de Guanajuato es necesario diseñar dos instrumentos o cédulas de entrevista que se adapten a las características de ellos.

Básicamente son 50 preguntas divididas en los apartados de datos generales, procedimiento, cultivo, recolección, empresa, necesidades de información y región.

\section{San Luis de La Paz}

\section{Bodega y Cavas San Luis Rey}

Actualmente la fábrica sólo se utiliza como bodega de vinos ya que se estableció como museo del vino en la región, a través de la Secretaría de Turismo del estado de Guanajuato, se organizan visitas guiadas a las instalaciones. En entrevista con el Sr. Hugo Gamba, propietario de la fábrica, éste nos manifiesta el interés por retomar la producción de vino, por lo que resalta identificar sus necesidades de información 
Recursos de información para el uso de los productores...

que le permitan reactivar la producción de la empresa.

\section{Dolores Hidalgo}

\section{Cavas Manchón S. A. de C. V.}

La empresa se localiza en el Rancho el Rosillo ubicado en el kilómetro 14.5 de la carretera de San Luis de la Paz a Dolores Hidalgo en el municipio de Dolores Hidalgo, Guanajuato.

Cavas Manchón cuenta con una capacidad productiva de $10000 \mathrm{~L}$ de vino al año, entre los que destaca con una mayor producción el vino generoso. En sus cavas tienen actualmente 12500 litros de mistela, moscatel y brandy que se están reservando para el festejo del Bicentenario de la Independencia.

\section{Necesidades de Información}

Durante el contacto con los productores de vid del Estado de Guanajuato se han detectado las primeras necesidades de información, con el diseño y aplicación del instrumento se pretende conocer de manera más precisa y detallada las necesidades de información.

Las primeras necesidades de información identificadas fueron:

- Costos de producción en México y otros países. 
Investigaciones sobre las necesidades de información,...

- Normatividad existente y trámites

- Información referenciada sobre: clima, temperatura, lluvia y humedad.

- Procedimientos experimentales (por ejemplo criomaceración)

- Procesos de producción

- Injertos

- Plagas y enfermedades de la vid.

\section{Bibliografía}

Calva González, Juan José. Satisfacción de usuarios: la investigación sobre las necesidades de información. México, UNAM, CUIB, 2009. 41p.

La investigación sobre las necesidades de información en diferentes comunidades: Memoria del III Seminario de Usuarios de la Información. México, UnAM, CUIB, 2009. 308 p.

Hurtado López, Flor de María. Dolores Hidalgo: estudio económico: 1740-1790. México, INAH, SEP, 1974.

Rabell, Cecilia. Los diezmos de San Luis de la Paz: economía en una región del bají en el siglo XVIII. México, UNAM, IIS, 1986.

SAGARPA Sistemas Producto http://www.uva.gob. $\mathrm{mx} /$ index.php?portal $=\mathrm{uva}$ 


\title{
El perfil informativo de los vitivinicultores en el estado de Querétaro: el cultivo de la vid. Avances
}

\author{
JosÉ Mejía RuIZ \\ Posgrado en Bibliotecología y Estudios de la Información \\ Universidad Nacional Autónoma de México
}

\section{Introducción}

耳 ste trabajo de investigación pretende dar a coEnocer la infraestructura de las compañías vitivinícolas en el Estado de Querétaro, con la intención de mostrar cómo el vitivinicultor ha plasmado sus conocimientos en la producción de la vid. Por lo que se ha planteado el siguiente cuestionamiento: ¿El encargado del viñedo cuenta con información acerca de la climatología, la cantidad de agua, el viento, las distancias entre plantas, el terreno, el tipo de suelo, el talud, los tipos de uva apropiados, los injertos, y la fauna nociva?

El interés por responder a estas cuestiones se debe a los escasos datos sobre la vitivinicultura en el estado de Querétaro, y a la falta de información sobre este aspecto en sus bibliotecas públicas, se presupone que existe la carencia de información para cubrir las necesidades del encargado de los cultivos de la vid en este estado. 
Investigaciones sobre las necesidades de información,...

Retomando los objetivos del estudio tenemos que:

- Objetivo general:

- Elaborar el perfil informativo de los vitivinicultores en el Estado de Querétaro

- Objetivos específicos:

- Identificar las zonas vitivinícolas del Estado de Querétaro

- Determinar la necesidad de información en relación a: climatológica, al riego, la plantación de la vid y del tipo de suelo, a la temperatura, las precipitaciones, el sol y el viento en el Estado de Querétaro

- Especificar las necesidades de información, sobre de los tipos de uvas que son aptos para el Estado y el tipo de maquinaria adecuada

- Determinar la información necesaria acerca de la fauna nociva que afecta el cultivo en el Estado de Querétaro

Con la información y las observaciones obtenidas en las visitas a cada compañía vinícolas, se presenta la infraestructura de las mismas.

\section{Viñedos en Querétaro}

El estado en la década de los 70 contaba con 8000 
El perfil informativo de los vitivinicultores...

hectáreas, ahora en 2009 se cuentan con menos de 300 hectáreas para el cultivo.

El estado tiene a tres vitivinicultores que han logrado subsistir y son: Freixenet de México, Viñedos La Redonda y Compañía Vinícola San Patricio productor de Jerez Uva de Oro.

\section{Freixenet de México}

Es la compañía más grande de las tres. A mediados de la década de los ochenta, durante el siglo XX, Grupo Freixenet realizó un programa para la implantación de otros centros de elaboración de espumosos según el método tradicional champenoise con cavas propias en Penedés (Cataluña, España), Champagne (Francia), Sonoma (California USA) y Querétaro (México). En pleno corazón de la zona vinícola de San Juan del Río, en Ezequiel Montes, Querétaro, se funda Cavas FREIXENET.

Las líneas de productos Freixenet de México, cuenta con dos líneas de producto: Vino Espumoso, que es el $80 \%$ de la producción total y el $20 \%$ restante son vinos de mesa.

La compañía brinda el servicio de visitas guiadas. ${ }^{1}$ Posteriormente se realiza un recorrido por la planta vinícolas para observar la maquinaría y el

1 Las visitas están impartidas por personal capacitado no profesional, que brinda la información en general. 
Investigaciones sobre las necesidades de información,...

equipo con el que se elaboran los diferentes tipos de vinos.

Los tipos de uva que utiliza Freixenet de México en la elaboración de sus vinos son los siguientes:

- Vinos blancos: Sant Emilion, Macabeu, Chenin, Pinot Noire y Sauvignon Blanc

- Vinos blancos espumosos: Chardonnay

- Vinos rosados: Malbec, Carbernet Sauvignon y Merlot

- Vinos rosados espumosos: Pinot Noire y Macabeu

- Vinos tintos: Malbec, Cabernet Sauvignon, Cabernet Franc, Tempranillo, Merlot y Syrah

En los viñedos se observa el gran cuidado con el que protegen sus cultivos, una barda rodea todo el viñedo, así como una maya ciclónica por encima de la barda. ${ }^{2}$

También se observa el uso de la tecnología en la vid, con aparatos que miden la velocidad del viento así como la temperatura, el aprovechamiento de esta tecnología ayuda a obtener productos de calidad.

2 La observación sobre este aspecto la realice desde las afueras del viñedo, debido a que no hay acceso al mismo. Tampoco se da ninguna información respecto a la vid que se tiene al momento. Al respecto de la protección al viñedo se puede optar también por una franja de árboles frutales con el fin de alejar a la fauna nociva. 
El perfil informativo de los vitivinicultores...

Esta compañía cuenta con la maquinaria y el equipo necesarios para la producción de sus vinos, como lo es el laboratorio para la realización de pruebas, la despalilladora, la filtradora, los grandes tanques con capacidades de veinticinco mil litros, las líneas llenadoras, las encorchadoras, los tipos de botellas y las barricas para los vinos añejados. ${ }^{3}$

Todas las operaciones a las que se somete la uva para transformarla en vino, se denominan vinificación, según el tratamiento que reciban las uvas blancas o tintas, siempre constará de las siguientes etapas:

- Estrujado o prensado

- Corrección de los mostos

- Encubado y Maceración en la vinificación en tinto (fermentación alcohólica)

- Descubado o Separación del vino

- Fermentación Maloláctica en la vinificación en tinto y en blancos muy particulares

- Clarificación, Filtración, Estabilización

- Crianza

- Embotellado

- Se revisa cada proceso, atendiendo a las necesidades de las 3 principales variedades de vinos: blancos, rosados y tintos

3 Esta información en particular fue proporcionada por el Ing. Javier Nieto Flores que tiene a su cargo la dirección de producción. 
Investigaciones sobre las necesidades de información,...

La compañía cuenta con el personal profesional así como también con el personal que recibe la capacitación para la realización de las diferentes actividades. ${ }^{4}$

En cuanto a la cava, es una obra de ingeniería pensada en la conservación de los diferentes vinos. Esta se encuentra baja las instalaciones a una profundidad de veinticinco metros y una temperatura constante de 14 a 15 grados centígrados.

El acomodo de las botellas en las rejillas que se localizan de pared a pared, refleja la experiencia en el manejo de los diferentes estadios del vino. Las barricas acomodadas en otro sitio demuestra la organización por parte del encargado del viñedo.

En la elaboración de los diversos vinos se utilizan diferentes tipos de uvas como se aprecia a continuación.

Entre los vinos espumosos se encuentran:

- Petillant Brut, es un vino blanco espumoso natural elaborado bajo el método champenoise ( $2^{a}$ fermentación en botella). Los tipos y porcentajes de uvas con el que es elaborado consta de un 70\% de Sant Emilion, y un 30\%

4 En esta compañía se cuenta con dos profesionales en ingeniería química, con seis elementos capacitados en diversas áreas como en supervisión, y veintitrés entre otros (mecánicos, electricistas, encargados de línea). 
El perfil informativo de los vitivinicultores...

de Macabeu, Chenin, Pinot Noire y Sauvignon Blanc. Este vino tiene un añejamiento de 9 meses.

- Petillant Fruite Blancoes un vino blanco espumoso natural elaborado bajo el método champenoise ( $2^{\mathrm{a}}$ fermentación en botella). Los tipos y porcentajes de uvas con el que es elaborado consta de un 70\% de Sant Emilion, y un 30\% de Macabeu, Chenin, Pinot Noire y Sauvignon Blanc. Este vino tiene un añejamiento de 9 meses.

- Petillant Fruite Rosé, en un vino rosado espumoso natural elaborado bajo el método champenoise ( $2^{\mathrm{a}}$ fermentación en botella). Los tipos y porcentajes de uvas con el que es elaborado consta de un 33\% de Malbec, un $33 \%$ de Carbernet Sauvignon y un 33\% de Merlot en porcentajes aproximadamente iguales. Este vino tiene un añejamiento de 9 meses.

- Sala Vivé Brut, en un vino blanco espumoso natural elaborado bajo el método champenoise ( $2^{a}$ fermentación en botella). Los tipos y porcentajes de uvas con el que es elaborado consta de un $70 \%$ de Chenin, Sauvignon Blanc y Pinot Noire y Macabeu, y un $30 \%$ de Sant Emilion (Ugni Blanc) este vino tiene un añejamiento de 18 meses. 
Investigaciones sobre las necesidades de información,...

- Sala Vivé Semi Seco, es un vino blanco espumoso natural elaborado bajo el método champenoise ( $2^{\mathrm{a}}$ fermentación en botella). Los tipos y porcentajes de uvas con el que es elaborado consta de un 70\% de Chenin, Sauvignon Blanc, Pinot Noire y Macabeu, y un 30\% de Sant Emilion (Ugni Blanc). Este vino tiene un añejamiento de 18 meses.

- Viña Doña Dolores Brut Nature Gran Reserva, es un vino blanco espumoso natural elaborado bajo el método champenoise ( $2^{a}$ fermentación en botella). Los tipos y porcentajes de uvas con el que es elaborado consta de un $40 \%$ de Sant Emilion, un 15\% de Chenin, un 40\% de Macabeu y un $5 \%$ de Pinot Noire. Este vino tiene un añejamiento de 24 meses.

- Viña Doña Dolores Semi Seco, es un vino blanco espumoso natural elaborado bajo el método champenoise $\left(2^{\mathrm{a}}\right.$ fermentación en botella). Los tipos y porcentajes de uvas con el que es elaborado consta de un $40 \%$ de Sant Emilion, un 15\% de Chenin, un 40\% de Macabeu y un 5\% de Pinot Noire. Este vino tiene un añejamiento de 12 meses.

- Viña Doña Dolores Rosé, es un vino rosado espumoso natural elaborado bajo el método champenoise ( $2^{a}$ fermentación en botella). Los tipos y porcentajes de uvas con el que es 
El perfil informativo de los vitivinicultores...

elaborado consta de un $90 \%$ de Pinot Noire y un $10 \%$ de Macabeu. Este vino tiene un añejamiento de 18 meses.

- Viña Doña Dolores Chardonnay Brut Nature, es un vino blanco espumoso natural elaborado bajo el método champenoise ( $2^{a}$ fermentación en botella). El tipo de uva con el que es elaborado consta de un 100\% de Chardonnay. Este vino tiene un añejamiento de 12 meses.

Entre los vinos tranquilos se encuentran:

- Vivante Blanco Seco, en un vino Tranquilo Blanco. Los tipos y porcentajes de uvas con el que es elaborado consta de un 70\% de Macabeu, Chenin y Pinot Noire, y un 30\% de Sant Emilion. Este vino, sale de las cavas, listo para ser consumido.

- Vivante Blanco Dulce, es un vino Tranquilo Blanco. Los tipos y porcentajes de uvas con el que es elaborado consta de un 70\% de Macabeu, Chenin y Pinot Noire, y un 30\% de Sant Emilion. Este vino, sale de las cavas, listo para ser consumido.

- Vivante Rosado, es un vino Tranquilo Rosado. Los tipos de uva con el que es elaborado consta de 50\% de Cabernet Sauvignon y 50\% 
Investigaciones sobre las necesidades de información,...

de Malbec. Es un vino joven afrutado y aromático donde no se aconseja el añejamiento, sino el consumo temprano.

- Vivante Tinto, es un vino Tranquilo Tinto. El tipo y porcentaje de uva con el que es elaborado consta de un100\% de Malbec. Este vino, sale de las cavas, listo para ser consumido.

- Viña Doña Dolores Chardonnay, es un vino Tranquilo Blanco. El tipo y porcentaje de uva con el que es elaborado consta de un $100 \%$ de Chardonnay. Este vino tiene de 1 a 3 meses en barrica.

- Viña Doña Dolores Sauvignon Blanc, es un vino Tranquilo Blanco. El tipo y porcentaje de uva con el que es elaborado consta de un $100 \%$ de Sauvignon Blanc. Este vino tiene de 2 a 4 meses en barrica.

- Viña Doña Dolores Merlot, es un vino Tranquilo Rosado. El tipo y porcentaje de uva con el que es elaborado consta de un 100\% de Merlot. Es un vino joven afrutado y aromático donde no se aconseja el añejamiento, sino el consumo temprano.

- Viña Doña Dolores Crianza, es un vino Tinto Tranquilo. Los tipos y porcentaje de uvas con el que es elaborado consta de un $60 \%$ Cabernet Sauvignon y 40\% de Malbec. Este vino tiene 8 meses en barrica de roble blanco americano y 8 meses en botella. 
El perfil informativo de los vitivinicultores...

- Viña Doña Dolores Gran Reserva, es un vino Tinto Tranquilo. Los tipos y porcentaje de uvas con los que es elaborado consta de un $60 \%$ de Cabernet Sauvignon Blanc y un 40\% de Malbec. Este vino tiene 14 meses en barrica de roble blanco americano y 10 meses en botella.

- Viña Doña Dolores 4 Regiones, es un vino Tinto Tranquilo. Los tipos de uvas con los que es elaborado consta de Cabernet Sauvignon, Cabernet Franc, Malbec, Tempranillo, Merlot y Syrah. Este vino tiene 4 meses en barrica nueva de roble francés y americano. ${ }^{5}$

La venta de los vinos la realizan en la tienda que se encuentra en las instalaciones. No cuentan con el servicio de distribuidor, ya que se enfocan primeramente en atender las necesidades de su comunidad y estados circunvecinos. La publicidad la manejan por medio de folletos y actividades como festivales o eventos particulares. La compañía cuenta con una página en Internet donde brinda la información básica de la empresa y sobre sus actividades. ${ }^{6}$

5 Esta información fue recopilada en la página de Internet de la compañía.

6 Freixenet de México. Disponible en [http://www.freixenetmexico.com.mx/Freixenet/Index.html] 
Investigaciones sobre las necesidades de información,...

Con esto damos paso al siguiente productor que es Viñedos La Redonda.

\section{La Redonda}

El enólogo italiano Vittorio Bortoluz, originario de Treviso en 1972 desarrollo del rancho "La Redonda", ubicado en el Municipio de Ezequiel Montes y que en aquel entonces no formaba parte de ningún corredor vitivinícola, pero quedo convencido del microclima de esas tierras.

Hoy en día, el cultivo de varios tipos de uva Merlot, Cabernet Sauvignon, Tempranillo, Malbec, Chenin Blanc, Trebbiano y Sauvignon Blanc entre otras menos conocidas pero complementarias.

La compañía brinda el servicio de visitas guiadas $^{7}$ donde se puede apreciar el viñedo y sus diversas etapas en la que se encuentra: $1^{a}$. Etapa. Definido el producto que se necesita, se procede a seleccionar el sarmiento adecuado, así como el pie que se unirán para formar la nueva planta. $2^{a}$. Etapa. La vid injertada y enraizada en vivero, se planta en el terreno escogido para que brote y forme la futura planta. Esta tarda un año para su desarrollo e inicio de su etapa de formación. $3^{a}$. Etapa. La vid está lista para su formación y estará de acuerdo a la

7 Las visitas están impartidas por personal capacitado no profesional, que brinda la información en general. 
El perfil informativo de los vitivinicultores...

producción al sol deseada, con el fin de obtener uva de calidad. $4^{a}$. Etapa. La vid se forma en espaldera, a la altura del primer alambre, pudiendo ser de uno o dos cordones. $5^{\text {a }}$. Etapa. Al tercer año la vid empieza a producir, y se puede apreciar finalmente el fruto. La producción es del $20 \%$ de lo que debe producir al sexto año. $6^{a}$. Etapa. La vid se poda anualmente para determinar su formación, y balancear adecuadamente la producción, de acuerdo a su desarrollo vegetativo. $7^{\text {a }}$. Etapa. La vid normaliza su producción entre el quinto y sexto año de ser plantada. Se poda, fertiliza y cuida; en particular contra enfermedades como: Botrytis, Oidio, Mildiu, Nematodos, etc. $8^{a}$. Etapa. Al final de su vida productiva (25 años), la vid se caracteriza por perder parte de su corteza, los brazos se deforman, la madera muere parcialmente, y su producción declina significativamente.

Posteriormente se realiza un recorrido por la planta vinícolas para observar la maquinaría y el equipo con el que se elaboran los diferentes tipos de vinos.

En los viñedos se observa el gran cuidado con el que protegen sus cultivos, una cerca de árboles frutales que rodea todo el viñedo, con esto se impide que aves, roedores o insectos afecten el producto de 
Investigaciones sobre las necesidades de información,...

la vid. ${ }^{8}$

Los tipos de uva que utiliza La Redonda en la elaboración de sus vinos son los siguientes:

- "La Redonda" (blanco y tinto) y "Orlandi" (blanco, tinto y espumoso)

- Vino Blanco: Viura, Chenin Blanc, Trebbiano, Verdona y Sauvignon Blanc.

- Vino Rosado: Malbec y Cabernet Sauvignon.

- Vino Tinto: Malbec, Ruby Cabernet, Cabernet Sauvignon y Merlot.

- Vino Espumoso: Chenin, Verdona y Trebbiano.

Todas las operaciones a las que se somete la uva para transformarla en vino, se denominan vinificación, según el tratamiento que reciban las uvas blancas o tintas, siempre constará de las siguientes etapas:

- Estrujado o prensado

- Corrección de los mostos

- Encubado y Maceración en la vinificación en tinto (fermentación alcohólica)

8 La observación sobre este aspecto la realice en el viñedo, debido a que hay acceso al mismo. Se da información respecto a la vid que se tiene al momento. 
El perfil informativo de los vitivinicultores...

- Descubado o Separación del vino

- Fermentación Maloláctica en la vinificación en tinto y en blancos muy particulares

- Clarificación, Filtración, Estabilización

- Crianza

- Embotellado

- Se revisa cada proceso, atendiendo a las necesidades de las 3 principales variedades de vinos: blancos, rosados y tintos.

\section{Maquinaria y equipo:}

La compañía cuenta con la maquinaria y el equipo para la producción del vino, como lo es el laboratorio para la realización de pruebas, la despalilladora, la filtradora, los tanques, las líneas llenadoras, las encorchadoras, los toneles y las diferentes botellas de acuerdo al tipo de vino.

La compañía cuenta con el personal profesional así como también con el personal que recibe la capacitación para la realización de las diferentes actividades.

La Redonda elabora una gran variedad de vinos.

A continuación, se menciona el nombre del vino, el tipo de vino y el porcentaje de los tipos de uvas que los componen.

9 Esta información en particular, fue proporcionada por una edecán, que tiene conocimientos de la producción. 
Investigaciones sobre las necesidades de información,...

- La redonda Vinos de mesa:

- La Redonda vino blanco seco, es un Vino joven de alta calidad. Los tipos y porcentajes de uvas con el que es elaborado consta de un $70 \%$ de Viura y Chenin Blanc y un 30\% de Trebbiano.

- La Redonda vino blanco semiseco. Los tipos y porcentajes de uvas con el que es elaborado consta de un 70\% de Trebbiano y un 30\% de Verdona.

- La Redonda vino rosado semiseco. Los tipos y porcentajes de uvas con el que es elaborado consta de un $85 \%$ de Malbec y un $15 \%$ de Cabernet Sauvignon.

- La Redonda vino tinto joven de alta calidad. El tipo de uva con el que es elaborado consta de un 100\% de Malbec.

- La Redonda tinto dulce Ruby Cabernet. El tipo de uva con el que es elaborado consta de un 100\% de Ruby Cabernet. Este vino es fermentado a baja temperatura para guardar las características propias del fruto.

- La Redonda vino espumoso dulce. Los tipos de uvas con el que es elaborado consta de Chenin, Verdona y Trebbiano. Este vino esta añejado por 12 meses. 
El perfil informativo de los vitivinicultores...

- Orlandi vinos varietales:

- Orlandi Blanco Seco Sauvignon Blanc. El tipo y porcentaje de uva con el que es elaborado consta de un $100 \%$ de Sauvignon Blanc.

- Orlandi Rosado Seco Cabertnet Sauvignon. El tipo y porcentaje de uva con el que es elaborado consta de un 100\% de Cabertnet Sauvignon.

- Orlandi Tinto Cabernet Malbec. Los tipos y porcentajes de uvas con el que es elaborado, consta de un 50\% de Cabernet Sauvignon y un 50\% de Malbec. Este vino tiene 8 meses de crianza en roble.

- Orlandi tinto Merlot Cabernet vino de amplio sabor, de taninos bien integrados, es equilibrado. Los tipos y porcentajes de uvas con el que es elaborado, consta de un 75\% de Merlot y un 25\% de Cabernet Sauvignon. Este vino tiene 15 meses de barrica de roble americano.

- Orlandi Vino Espumoso Semiseco. Este vino tiene un añejamiento en botella de 18 meses en las cavas.

- Orlandi Espumoso Brut Nature Gran Reserva. Este vino tiene un añejamiento mínimo de 24 meses en las cavas. 
Investigaciones sobre las necesidades de información,...

- Orlandi Espumoso Rosado Semiseco. Los tipos y porcentajes de uvas con el que es elaborado, consta de un 50\% de Cabernet y un 50\% de Malbec. Este vino tiene 12 meses de crianza en bote1la. ${ }^{10}$

La venta de los vinos la realizan en la tienda que se encuentra en la entrada del rancho. No cuentan con el servicio de distribuidor, ya que se enfocan primeramente en atender las necesidades de su comunidad y estados circunvecinos. La publicidad la manejan por medio de folletos y actividades como festivales o eventos particulares. La compañía cuenta con una página en Internet, en donde brinda la información básica de la empresa y sobre sus actividades. ${ }^{11}$

Con esto damos paso al siguiente productor que es Compañía Vinícola San Patricio.

\section{Compañia Vinícola San Patricio}

Inicia sus funciones en noviembre de 1999, su propietario el Ing. Químico Alberto Rodríguez González de origen mexicano.

10 Esta información fue recopilada en la página de Internet de la compañía.

11 La redonda. Disponible en [http://www.laredonda.com.mx/] 
El perfil informativo de los vitivinicultores...

Finca sin cava, viñedo aparte en Ejido Santillán entre Tequisquiapan y Ezequiel Montes, cuenta con 11 hectáreas (julio de 2008).

La compañía brinda el servicio de visitas guiadas. ${ }^{12}$ Posteriormente se realiza un recorrido por la planta vinícolas para observar la maquinaría y el equipo con el que se elaboran los diferentes tipos de vinos

Los tipos de uvas que utiliza la compañía para la elaboración de sus vinos son los siguientes:

- Vinos tintos: Malbec y Cabernet

- Vinos blancos: Chenin blanc y Uniblanc

- Jerez: Globo, Cabinai y Revier

Tipos de vinos y uvas

- Vino blanco Santiago apóstol. Los tipos de uva con el que es elaborado consta de 50\% de Chenin blanc y 50\% de Uniblanc.

- Vino tinto Santiago apóstol. Los tipos de uva con el que es elaborado consta de $50 \%$ de Cabernet y $50 \%$ de Malbec.

- Jerez uva de oro. Los tipos de uva con el que es elaborado consta de Globo, Cabinai y Revier.

12 Las visitas están impartidas por personal capacitado no profesional, que brinda la información en general. 
Investigaciones sobre las necesidades de información,...

Para su producción de vinos, adquieren uvas de los productores de los alrededores y de otros estados como Zacatecas y Aguascalientes.

Las 11 hectáreas se encuentran en proceso de preparación para la implantación de los viñedos.

Maquinaria y equipos

La compañía cuenta con la maquinaria y el equipo para la producción del vino, como lo es el laboratorio para la realización de pruebas, la despalilladora, la filtradora, los tanques, las líneas llenadoras, las encorchadoras y las diferentes botellas de acuerdo al tipo de vino.

Todas las operaciones a las que se somete la uva para transformarla en vino, se denominan vinificación, según el tratamiento que reciban las uvas blancas o tintas, siempre constará de las siguientes etapas:

- Estrujado o prensado

- Corrección de los mostos

- Encubado y Maceración en la vinificación en tinto (fermentación alcohólica)

- Descubado o Separación del vino

- Fermentación Maloláctica en la vinificación en tinto y en blancos muy particulares

- Clarificación, Filtración, Estabilización

- Embotellado 
El perfil informativo de los vitivinicultores...

- Se revisa cada proceso, atendiendo a las necesidades de las 3 principales variedades de vinos: blancos, tintos y el jerez

La compañía cuenta con el personal profesional así como también el personal que recibe la capacitación para la realización de las diferentes actividades.

La venta de los vinos la realizan en la tienda que se encuentra en la parte baja de las oficinas. No cuentan con el servicio de distribuidor, ya que se enfocan primeramente en atender las necesidades de su comunidad y estados circunvecinos. La publicidad la manejan por medio de sus propios clientes quienes recomiendan sus productos. 



\title{
Regulaciones nacionales e internacionales sobre la producción de Vitis vinífera. Información para los vitivinicultores: resultados de la investigación
}

\author{
Miguel Ángel de la RosA HeRnÁNdeZ \\ COFEPRIS \\ Secretaría de Salud
}

$\mathbf{Z}_{\text {más interesantes que se han dado a nivel interna- }}^{\mathrm{n} \text { é }}$ cional en donde los gobiernos han regulado en torno a la industria vitivinícola, y como la información está al alcance de los vitivinicultores. Con estos ejemplos podemos tener un panorama, en general, de los esfuerzos que se han dado en cuestión de acceso a la información de regulación para los vitivinicultores.

Los vitivinicultores en México no tienen acceso a la información, lo que afecta su producción y su introducción al mercado interno y por supuesto, no les permite competir con los vinos europeos y sudamericanos.

Argentina y Chile son los países americanos con mayor índice de producción y exportación de vinos, así como España y Francia lo son de Europa, por ello se eligieron como referente de confrontación con México. 
Investigaciones sobre las necesidades de información,...

El problema de ésta investigación consistió en determinar:

a) ¿Cuáles son las regulaciones o normas para la producción de Vitis vinifera en México, Argentina, Chile, España y Francia?

b) ¿Dónde se ubican y quién produce las normas o regulaciones de la producción de Vitis vinífera en México?

El objetivo principal del trabajo fue analizar las regulaciones o normas mexicanas para la producción de Vitis vinífera contra las establecidas en Argentina, Chile, España y Francia.

El trabajo plantea las siguientes hipótesis:

a) El acceso a información sobre las Normas o Regulaciones para la producción de Vitis vinife$r a$ en México es una variable que afecta la producción de los derivados de la Vitis vinifera.

b) Las Normas o Regulaciones Mexicanas sobre producción de Vitis vinífera no cuentan con la misma difusión y acceso a los usuarios de la información finales como lo tienen otros países como España, Francia, Chile y Argentina.

Se realizó un estudio retrospectivo de la regulación mexicana mediante una revisión bibliográfica 
Regulaciones nacionales e internacionales...

de las regulaciones mexicanas para determinar los orígenes de la regulación actual, un estudio de la historia de la producción de la Vitis vinifera y sus derivados en México, un estudio de la industria vinícola mexicana, las Asociaciones, y Órganos reguladores nacionales, así como las regulaciones vigentes de la producción de Vitis vinífera en México.

La historia nos demuestra que se han implementado múltiples y variadas regulaciones de la Vitis vinifera y que cumplir con ellas no ha sido fácil. México tuvo la vitivinicultura más antigua de América en la época colonial, y a la vez la más reciente en todo el continente, ya que realmente los vinos mexicanos que ahora conocemos, solo existen desde hace poco más de cincuenta años.

En 1943 fue promulgada la Ley Vitivinícola que procuraba regular toda la industria, procesos, métodos, comercio, entre otros aspectos, y que actualmente no esta vigente. Habiendo existido esta Ley que pretendía dar certeza y prestigio a la vitivinicultura mexicana, hoy prácticamente la regulación más importante es la NOM-142- de la Secretaría de Salud, apoyándose solo en algunos otros ordenamientos.

En México existen cuatro órganos reguladores que emiten diversas disposiciones que integran el marco jurídico de la Vitis vinifera, el cual se encuentra disperso y poco o casi nada difundido. 
Investigaciones sobre las necesidades de información,...

El problema de acceso a las regulaciones radica en que no hay una entidad que recopile todo el marco jurídico aplicable a la Vitis vinífera, aunado a que no existen mecanismos establecidos para el acceso a la información. Otro aspecto que afecta el acceso es el hecho de que cada uno de los cuatro organismos regula una etapa o parte de la producción de Vitis y aplican un número amplio de regulaciones.

Se realizó un estudio de la historia de la producción de la Vitis vinífera y sus derivados, de las asociaciones, consejos y órganos reguladores, así como las regulaciones vigentes de la producción de Vitis vinifera en Argentina, Chile, España y Francia. Asimismo se revisaron los organismos y regulaciones regionales e internacionales más importantes a los que pertenecen los países objeto de estudio.

Los vinos europeos están apegados a reglas muy estrictas y leyes muy claras sobre la producción y el cultivo de la vid establecida por ley y la elaboración del vino, lo permitido y lo no permitido. Son países con tradiciones ancestrales en el tema y sus legislaciones son sumamente restrictivas al respecto.

Los vinos americanos por el contrario son mucho más experimentales, las reglas no son tan claras ni tan definidas y su proceso de elaboración es más moderno.

El prestigio de la vitivinicultura chilena se debe a la creación de un reglamento de 1969. La legislación 
Regulaciones nacionales e internacionales...

en Chile regula las formas de cultivo, procedimientos de elaboración y tipos de vino, dando certeza a toda la cadena de producción.

$\mathrm{La}$ vitivinicultura argentina va por los tres siglos de existencia, en un principio fue una industria artesanal que ha ido evolucionando a una industrialización completa con vinos muy variados y poderosas sociedades productoras. La actividad vitivinícola en Argentina esta regulada por el Instituto Nacional de Vitivinicultura, que garantiza la legitimidad y calidad de los vinos.

Los vinos de España y Francia tienen sin lugar a duda una tradición y una calidad a prueba de todo sustentada en una sólida regulación, cada uno con sistema de regiones reglamentadas por denominación de origen y bajo la reglamentación de la Unión Europea.

El análisis comparativo de la información entre México, Argentina, Chile, España y Francia confrontando los datos encontrados durante la investigación.

Argentina y Chile han sabido aprovechar la experiencia europea creando Organismos únicos, con personalidad jurídica propia, que regulan el sector vitivinícola.

Los vitivinicultores españoles y franceses tienen el soporte de sus Instituciones Oficiales con sistemas de información accesibles, incentivos gubernamentales, 
Investigaciones sobre las necesidades de información,...

subsidios, se respaldan en sus Consejos Reguladores, encargados de fomentar y controlar la calidad de los vinos, promocionar su imagen, defender los intereses del sector y de aplicar las normativas de su respectiva zona vitivinícola.

La siguiente tabla presenta el número de organismos reguladores de México, Argentina, Chile, España y Francia. En el caso de México son varios los Organismos Federativos en los que recae la responsabilidad de legislar la Vitis vinífera y sus derivados, está diversidad presenta inconvenientes para el sector vitivinícola porque no existe coordinación entre ellos para regular el sector vitivinícola.

\begin{tabular}{|l|l|l|l|l|}
\hline \multicolumn{5}{|c|}{ Comparativo de los Órganos reguladores y Asociaciones } \\
\hline \multicolumn{1}{|c|}{ México } & Argentina & \multicolumn{1}{c|}{ Chile } & \multicolumn{1}{c|}{ España } & \multicolumn{1}{c|}{ Francia } \\
\hline $\begin{array}{l}\text { 4 Órganos } \\
\text { Reguladores }\end{array}$ & $\begin{array}{l}\text { Ó́rgano } \\
\text { Regulador }\end{array}$ & $\begin{array}{l}1 \text { Órgano } \\
\text { regulador }\end{array}$ & $\begin{array}{l}\text { 2 Órganos } \\
\text { Reguladores }\end{array}$ & $\begin{array}{l}\text { 2 Órganos } \\
\text { Reguladores }\end{array}$ \\
\hline 9 Asociaciones & $\begin{array}{l}\text { No se } \\
\text { encontraron } \\
\text { asociaciones }\end{array}$ & 3 Asociaciones & 9 Asociaciones & 14 Asociaciones \\
\hline & & & $\begin{array}{l}\text { 68 Consejos } \\
\text { reguladores }\end{array}$ & $\begin{array}{l}\text { 57 Consejos } \\
\text { reguladores }\end{array}$ \\
\hline
\end{tabular}

La siguiente tabla muestra el contraste entre el número de zonas, regiones o áreas vitivinícolas de México, Argentina, Chile, España y Francia. La diferencia entre el número de zonas de los países no es significativa por la cantidad, sino porque la reglamentación sirve de base, en el en el caso de los otros 
Regulaciones nacionales e internacionales...

países, para la certificación de la calidad de los vinos mediante las indicaciones geográficas y las denominaciones de origen.

\begin{tabular}{|c|c|c|c|c|}
\hline \multicolumn{5}{|c|}{ Comparativo de las Zonas Vitivinícolas } \\
\hline México & Argentina & Chile & España & Francia \\
\hline 8 estados & 6 zonas & 5 regiones & 15 zonas & 12 zonas \\
\hline 24 regiones & $\begin{array}{l}\text { 184 departamentos, } \\
\text { provincias y regio- } \\
\text { nes. }\end{array}$ & 14 subregiones & $\begin{array}{l}\text { De estás principales zonas de } \\
\text { existen un sinnúmero de } \\
\text { regiones }\end{array}$ \\
\hline
\end{tabular}

En el caso de Francia y España la información se encuentra fácilmente y su acceso esta disponible para todos los vitivinicultores a través de los consejos reguladores en cada región. Las Denominaciones de Origen dan seguridad en toda la cadena productiva, los vitivinicultores conocen y aplican su regulación.

Para el caso de México se han compilado 73 regulaciones sobre la producción de Vitis vinífera y sus derivados.

Tabla comparativa de las Regulaciones vigentes de Vitis vinifera y sus derivados.

El que México integre un gran número de disposiciones jurídicas no es sinónimo de que la industria esté debidamente regulada, por el contrario se torna complicado porque se deben aplicar una o varias regulaciones en las distintas etapas de la cadena de 
Investigaciones sobre las necesidades de información,...

producción, porque no existe una ley que regule toda la actividad vitivinícola y su comercio

\begin{tabular}{|c|c|c|c|c|}
\hline \multicolumn{5}{|c|}{ Comparativo de las Regulaciones vigentes de Vitis vinífera y sus derivados } \\
\hline México & Argentina & Chile & España & Francia \\
\hline 1 Constitución & 4 Leyes & 2 Leyes & 2 Estatutos & 1 Ley \\
\hline 3 Leyes & 1 Decreto & 1 Reglamento & 6 Leyes & \begin{tabular}{|l}
400 \\
Denominacio- \\
nes de Origen
\end{tabular} \\
\hline $\begin{array}{l}3 \text { Tratados } \\
\text { Internacionales }\end{array}$ & \begin{tabular}{|l}
87 \\
Indicaciones \\
Geográficas
\end{tabular} & 2 Decretos & $\begin{array}{l}9 \text { Reales } \\
\text { Decretos }\end{array}$ & \\
\hline $\begin{array}{l}6 \text { Normas } \\
\text { Oficiales } \\
\text { Mexicanas }\end{array}$ & \begin{tabular}{|l}
2 \\
Denominacio- \\
nes de Origen \\
Controlada \\
\end{tabular} & \begin{tabular}{|l} 
\\
Denominacio- \\
nes de Origen
\end{tabular} & 1 Decreto & \\
\hline $\begin{array}{l}17 \text { Normas } \\
\text { Mexicanas } \\
(\mathrm{NMX})\end{array}$ & \begin{tabular}{|l|}
96 \\
Denominacio- \\
nes sin Área \\
Geográfica \\
Reconocida \\
\end{tabular} & \begin{tabular}{|l}
14 \\
Indicaciones \\
Geográficas
\end{tabular} & 18 Ordenes & \\
\hline 3 Reglamentos & & & 6 Resoluciones & \\
\hline 2 Acuerdos & & & \begin{tabular}{|l|}
71 \\
Denominacio- \\
nes de Origen \\
\end{tabular} & \\
\hline \multicolumn{5}{|l|}{34 Trámites } \\
\hline \multicolumn{5}{|l|}{\begin{tabular}{|l|}
2 Iniciativas del \\
Ejecutivo
\end{tabular}} \\
\hline \multicolumn{5}{|l|}{$\begin{array}{l}1 \text { Convenio de } \\
\text { Autorregula- } \\
\text { ción }\end{array}$} \\
\hline $\begin{array}{l}0 \\
\text { Denominacio- } \\
\text { nes de Origen }\end{array}$ & & & & \\
\hline
\end{tabular}


Regulaciones nacionales e internacionales...

España tiene 41 regulaciones y 71 denominaciones de origen. Francia tiene cerca de 400 denominaciones de origen y comparte con España las 137 regulaciones de la Comunidad Económica Europea.

La problemática de dicha regulación es la confusión del productor desorientado por las regulaciones procedentes de un sistema jurídico complejo y distinto de las clasificaciones internacionales y por la superposición de las normativas nacionales y regionales, que añade complejidad a todo el sistema.

México cuenta con 10 denominaciones de origen y 3 marcas colectivas, ninguna es relativa a Vitis vinifera y sus derivados.

El material recopilado en México, teniendo en cuenta que en su conjunto se ha obtenido de las cuatro instituciones reguladoras, puede decirse que es abundante, pero poco difundido, y el acceso a la información se torna en su mayoría complicado.

La falta de información, promoción, financiamiento y políticas regulatorias en México para la industria vitivinícola provocan que la producción nacional sea incapaz de satisfacer el mercado interno.

Actualmente se ha incrementado la información que los órganos reguladores emiten sobre Vitis vinifera, lo que dificultan su difusión y acceso. Esta situación requiere una nueva estrategia para el establecimiento de servicios de información. 
Investigaciones sobre las necesidades de información,...

\section{Conclusiones}

En México la experiencia en regulación de Vitis vinífera y sus derivados es bastante amplia pero los antecedentes no han sido debidamente aprovechados, la información no ha sido difundida y prácticamente no se tiene acceso a ella.

En años recientes los principales países productores han implementado nuevas leyes para regular sus procesos, producción y comercialización. Desgraciadamente, en México aún no existe, como en otros países una regulación que permita desarrollar la industria vitivinícola.

La regulación más completa es la de España, seguida por la francesa, argentina y la chilena. La regulación más accesible es la de Argentina, seguida de España, Chile, México y al final Francia.

La poca difusión y acceso a la regulación de $V i$ tis vinifera y sus derivados, entre otras variables, son algunas de razones que explican la poca productividad vinícola de México, pese a ello el mercado mexicano es cada día más atractivo, no todo el panorama es desolador, hay productores que desde hace algún tiempo han empezado a hacer de los vinos mexicanos un buen producto apto para abastecer sin demérito al creciente mercado interno, de ahí su necesidad de información para poder competir con los vinos sudamericanos y europeos. 
Regulaciones nacionales e internacionales...

\section{Propuesta}

Ante la falta de políticas de regulación y de acceso a la información para la industria vitivinícola mexicana se debe considerar la creación de la figura de un Consejo Regulador que supervise el proceso de elaboración de vinos para establecer regulaciones claras, lineamientos de calidad, y de acceso a la información, entre otros. Asimismo es necesario crear leyes que establezcan parámetros para poder regular a la industria y mediante el Órgano Regulador se faciliten servicios de información a los productores.

\section{Bibliografía}

Aleixandre Benavent, José Luis. Enología. Valencia: Universidad Politécnica de Valencia, 1996.

Álvarez Áspero, José. La viña, la vid y el vino. México: Trillas, 1991.

El vino en México. Oficina Económica y Comercial de la Embajada de España en México: la oficina, 2006.

Guzmán Peredo, Miguel. "El vino en México". En: México Desconocido No. 340, junio de 2005.

Introducción a la vitivinicultura. Mundo Gourmet Especialista en vino. México. Curso, enero de 2008. 
Investigaciones sobre las necesidades de información,...

Larrea Redondo, A. Enología básica. Barcelona: Aedos, 1983.

Macias Hernández, Humberto I. Manual práctico de viticultura. México: Trillas: UNAM, 1993.

Michaud, Julio. El libro del vino mexicano. México: Casa Pedro Domecq, 1990.

Reynoso Ron, Javier. Viticultura, enología y algo más. México: McGraw Hill, 1996.

Spence, Godfrey. Vino blanco, Manual para sibaritas. Koln: Evergreen, 1999.

Vázquez Montalbán, Manuel. El gran libro del vino: beber o no beber, del vino y las costumbres bebedoras de los españoles. España: Ediciones B, 2002. 


\section{Conclusiones}

D

espués de la discusión de los diversos proyectos de investigación en el Seminario permanente de Investigación sobre Usuarios de la Información, tanto en una modalidad cerrada como en una modalidad abierta, se llegaron, de manera general, a las siguientes conclusiones y acuerdos:

1. La investigación sobre el fenómeno de las necesidades de información en diversas comunidades es necesaria ya que poco se tiene investigado a nivel mundial.

2. Es preciso continuar obteniendo resultados de investigaciones en diversas comunidades sociales para poder enriquecer el Modelo NEIN (Modelo sobre las necesidades de información) en sus fases, variables, elementos y métodos.

3. La incursión en comunidades industriales como lo es la vitivinícola marca el inicio de adentrarse no solo en las académicas, sino en otro tipo de usuarios de la información. 
Investigaciones sobre las necesidades de información,...

4. Las comunidades indígenas presentes no solo en México, sino en toda América Latina abren toda una beta de investigaciones que se pueden llevar a cabo no solo de forma individual, como se hace ahora en el CUIB por uno de sus investigadores, mas bien iniciar un seminario permanente de investigación propio de este tipo de comunidades.

5. Debido a la detección de escasa bibliografía en español, y poca en inglés o en otros idiomas y países, se acordó iniciar un proyecto conjunto entre España y México sobre las investigaciones que se hayan llevado a cabo en ambos países. Por tal razón, como un inicio de este acuerdo, se estableció elaborar un proyecto en donde queden involucrados, en primera instancia, un investigador del CUIB y uno de la Universidad Complutense de Madrid para iniciarlo para 2010.

6. De igual forma, a iniciativa del investigador del CUIB responsable del proyecto de investigación en comunidades indígenas, se analiza la idea de establecer un seminario permanente de investigación sobre comunidades indígenas desde la perspectiva de que son usuarios de la información y por lo tanto investigados con el punto de vista de la ciencia bibliotecológica y de la información. 
Asimismo se consideró adecuado iniciar la búsqueda de otros colegas que se encuentren investigando sobre el fenómeno de las necesidades de información en otros países para acordar trabajos comunes y que realmente aporten elementos teóricos del desarrollo de una teoría bibliotecológica.

Juan José Calva González 

Investigaciones sobre las necesidades de información, el comportamiento informativo y la satisfacción en diferentes comunidades: proyectos, avances y resultados. La edición consta de 150 ejemplares. Cuidado de la edición, Zindy Elizabeth Rodríguez Tamayo. Formación editorial, Mario Ocampo Chávez. Centro Universitario de Investigaciones Bibliotecológicas. Fue impreso en papel cultural de 90 grs. en Producciones Editoriales Nueva Visión, ubicados en Juan A. Mateos No. 20, Planta alta, Col. Obrera, Mexico D.F. Se terminó de imprimir en el mes de Junio de 2011. 
